UNIVERSIDADE DE BRASÍLIA

FACULDADE DE EDUCAÇÃO FÍSICA

PROGRAMA DE PÓS-GRADUAÇÃO STRICTO-SENSU EM EDUCAÇÃO FÍSICA

\title{
AVALIAÇÃO DA FUNÇÃO AUTONÔMICA CARDÍACA E DA SOBRECARGA CARDIOVASCULAR DE BOMBEIROS \\ MILITARES DURANTE TURNO DE SERVIÇO OPERACIONAL
}

Rosenkranz Maciel Nogueira

BRASÍLIA 


\section{AVALIAÇÃO DA FUNÇÃO AUTONÔMICA CARDÍACA E DA SOBRECARGA CARDIOVASCULAR DE BOMBEIROS MILITARES DURANTE TURNO DE SERVIÇO OPERACIONAL}

ROSENKRANZ MACIEL NOGUEIRA

Dissertação apresentada ao Programa de Pós-Graduação em Educação Física, da Universidade de Brasília, como requisito para obtenção do título de Mestre em Educação Física.

ORIENTADOR: PROF. DR. LUIZ GUILHERME GROSSI PORTO

Projeto apoiado pelo CNPq, Edital Universal 14/2013, n. 480092/2013-3 


\section{DEDICATÓRIA}

Dedico esse trabalho aos Bombeiros Militares do Brasil, que têm por missão precípua proteger vidas, patrimônio e meio ambiente. Essa missão é traduzida no lema: "Vidas alheias e riquezas salvar". 


\section{AGRADECIMENTOS}

Agradeço a Deus pelo dom da vida e que permitiu a minha participação no mestrado e a oportunidade de conhecer pessoas que são verdadeiros exemplos éticos e acadêmicos. Eu, na realidade, me separei das pessoas mais próximas para me encontrar na Universidade; e agora me separo do ambiente acadêmico para me reencontrar. Assim é a nossa jornada terrena, é sempre um reencontro.

Agradeço também a esta belíssima Universidade, que tanto contribui para o bem da humanidade na construção de um mundo melhor, aos professores, direção e administração. Agradeço especialmente ao Professor Doutor Luiz Guilherme Grossi, meu orientador, pelo empenho e dedicação, um verdadeiro mestre nos ensinamentos, pela sua lisura, respeito, probidade, empenho e seriedade em todos os momentos do desenvolvimento da pesquisa.

Agradeço ao Professor Dr. Luiz Fernando Junqueira, pela disponibilidade em ceder o laboratório de Cardiologia da Universidade de Brasília, pelas orientações e contribuições dadas durante o desenvolvimento da pesquisa.

Agradeço de coração à minha mãe Letícia Ferreira Pires, heroína, amiga que sempre me deu apoio, incentivo nas horas mais difíceis, sempre com palavras sábias que alimentavam a minha alma. É verdade quando se diz que carinho de mãe é alimento espiritual.

Agradeço aos meus filhos por toda parceria e ensinamentos que proporcionam na minha vida, Brunna, Natália e Daniel, tornando-a mais leve e com mais pureza. Se alguém me perguntar como eu gostaria de ser chamado, porque meu nome é complicado para se pronunciar, ROSENKRANZ, eu responderia que gostaria de ser chamado da forma mais simples, eis aí o avô da LAURA. 
"Há a alegria de ser puro e de ser justo, mas há, sobretudo, a maravilhosa, a imensa alegria de servir.

Que triste seria o mundo se tudo estivesse feito, se não existisse uma roseira a plantar, uma obra a iniciar.

Que não chamem somente os trabalhos fáceis. É tão bonito fazer o que os outros se recusam. Mas não caia no erro de que só há mérito nos grandes trabalhos; há pequenos serviços que são bons serviços: arrumar a mesa, organizar os livros, pentear uma criança. Aquele que critica, este é o que destrói; seja você o que serve.

O servir não é trabalho de seres inferiores. Deus, que dá o fruto e a luz, serve. Poderia chamar-se assim: 'Aquele que serve'. E tem seus olhos fixos em nossas mãos e nos pergunta a cada dia: A quem servistes hoje?" 


\section{RESUMO}

Introdução: As rotinas de trabalho dos bombeiros incluem extinção de incêndios, salvamentos e atendimento a emergências médicas. Tais atividades expõem esses profissionais a riscos ocupacionais e a intensa sobrecarga física e emocional. Objetivos: Avaliar a função autonômica cardíaca (FAC), em um dia de rotina profissional habitual em comparação com uma condição basal, a sobrecarga cardiovascular durante um turno de trabalho e a aptidão cardiorrespiratória (ACR) de bombeiros. Indivíduos: Foram selecionados, por conveniência, 30 bombeiros do sexo masculino (35-47 anos), sem restrições médicas e/ou doenças cardiometabólicas. Métodos: Foram avaliados índices temporais e espectrais da variabilidade da frequência cardíaca (VFC) na condição basal em laboratório (AVA1), no início de um turno diurno de trabalho (AVA2) e ao seu término (AVA3). A sobrecarga cardiovascular foi avaliada por meio do comportamento da frequência cardíaca, registrada ao longo do plantão. A ACR foi estimada em repouso por questionário validado. Foram comparados os valores da VFC nos 3 momentos, calculados os tempos absolutos e relativos de permanência em cada zona de intensidade de esforço ao longo do turno e avaliada a correlação entre os índices da VFC com a ACR . Resultados: Observou-se diminuição da modulação vagal em AVA3, expressa pela redução significativa do PNN50\% na postura ortostática ao final do turno: $0,35(0,0$ - 60,3), comparativamente aAVA1: 2,6 (0,0 - 31,5). $97,3 \pm 4,2 \%$ do tempo de trabalho foi de atividades leves e cerca de $2 \%$ de intensidades vigorosas/muito vigorosas. Houve correlação positiva $(\mathrm{p}<0,05)$ entre PNN50\%, RMSSD; AABF e AAAF em AVA1 e AVA3 com a ACR $\left(0,37<r_{s}<0,46 ; 0,35<r_{s}<0,49\right)$. Conclusões: A atividade desses bombeiros ocorreu majoritariamente em zona de intensidade cardiovascular leve, intercalada com curtos períodos de elevadíssima sobrecarga cardiovascular. Observou-se redução da modulação vagal ao término de um turno diurno de trabalho e associação da VFC com a ACR.

Palavras-Chaves: Variabilidade da frequência cardíaca; Atividade laboral; Aptidão cardiorrespiratória; Risco cardiovascular; Frequência cardíaca. 


\begin{abstract}
Introduction: Firefighters' work routines include firefighting, rescue, and medical emergencies. Such activities expose these professionals to occupational hazards and intense physical and emotional overload. Objectives: To evaluate the cardiac autonomic function (CAF) in a professional routine day compared to a baseline condition, the cardiovascular overload during a work shift and the cardiorespiratory fitness (CRF) of firefighters. Group: A convenient sample of 30 male firefighters (35-47 yrs old) without medical restrictions and / or cardiometabolic diseases was selected. Methods: We evaluated temporal and spectral indexes of heart rate variability (HRV) at the baseline laboratory condition (EVA1), at the beginning of a work shift (EVA2) and at the end of it (EVA3). Cardiovascular overload was assessed by heart rate profile, recorded throughout the shift. CRF was estimated at rest by validated questionnaire. HRV values were compared at 3 moments, absolute and relative times were calculated in each zone of effort intensity throughout the shift, and the correlations between HRV and CRF indexes were also evaluated. Results: A decrease in vagal modulation in EVA3 was observed, expressed by a significant reduction of the PNN50\% in the orthostatic posture at the end of the shift: 0.35 (0.0-60.3), as compared to EVA1: 2.6 (0.0 - 31.5). $97.3 \pm 4.2 \%$ of working time was of light activities and about $2 \%$ of vigorous/very vigorous intensities. There was a positive correlation $(\mathrm{p}<0.05)$ between PNN50\%, RMSSD; AABF and AAAF in EVA1 and EVA3 with CRF $(0.37<$ rs <0.46; $0.35<$ rs <0.49). Conclusions: The activity of these firefighters occurred mainly in a zone of light cardiovascular intensity, interspersed with short periods of very high cardiovascular overload. A reduction of vagal modulation was observed at the end of a day shift of work as well as an association between HRV and CRF.
\end{abstract}

Keywords: Heart rate variability; Work activity; Cardiorespiratory fitness; Cardiovascular risk; Heart rate. 


\section{LISTA DE FIGURAS E QUADROS}

Figura 1 Primeiro modelo de carro do Corpo de Bombeiros no Brasil..

Figura 2 Risco de morte em serviço por faixa etária, por doença coronariana, em bombeiros norte americanos.

Figura 3 Modelo teórico de eventos cardíacos súbitos em bombeiros

Figura 4 Sobrecarga cardiovascular em bombeiros.

Figura 5 Esquema da modulação autonômica sobre o coração e as possibilidades de análise da variabilidade da frequência cardíaca, tanto no domínio do tempo quanto da frequência espectral.

Figura 6 Protocolo experimental.

Figura 7 Assinatura do TCLE por bombeiro militar participante da pesquisa..

Figura 8 Modelo de pedômetro usado no estudo.

Figura 9 Registro da série temporal dos intervalos R-R para avaliação da VFC na posição supino.

Figura 10 Registro da série temporal dos intervalos R-R para avaliação da VFC na posição ortostática..

Figura 11 Correia fixa que capta e transmite os intervalos R-R do ECG para o receptor, acoplada a uma correia elástica para colocação do aparelho em volta do tórax.

Figura 12 Exemplo de atividade operacional desenvolvida durante o turno de trabalho em monitoração.

Figura 13 Valores amostrais dos escores de qualidade de vida avaliada em bombeiros militares em escala de prontidão, por meio do WHOQOL

Figura 14 Ilustração de registro efetuado com frequêncímetro Polar V800 em voluntário de 42 anos, IMC: 25,1 km/m2; que acumulou 9319 passos e atuou em incêndio florestal. Registra o deslocamento do voluntário $(93,19 \mathrm{~km})$, a duração do registro (11h08min), bem como valores mínimo (60 bpm), médio (87 bpm) e máximo (162bpm) do voluntário.

Figura 15 Ilustração de registro da $\mathrm{FC}$ e da temperatura ambiente durante turno rotineiro de trabalho em atividades operacionais de prontidão de voluntário de 42 anos, IMC: 25,1 km/m2; que acumulou 9319 passos e atuou em incêndio florestal

Figura 16 Ilustração de registro da FC, da temperatura ambiente e a velocidade dos deslocamentos durante turno rotineiro de trabalho em atividades operacionais de prontidão de voluntário de 42 anos, IMC: $25,1 \mathrm{~km} / \mathrm{m} 2$; que acumulou 9319 passos e atuou em incêndio florestal. Destaca-se o deslocamento em automóvel (aumento da velocidade) antecedendo períodos de incremento da FC ocorrido durante a atuação do bombeiro no combate a incêndio florestal......... 
Figura 17 Ilustração de registro da FC durante turno rotineiro de trabalho em atividades operacionais de prontidão de voluntário de 39 anos, IMC: 27,4 km/m2; que acumulou 16416 passos e atuou em dois atendimentos a acidentes automobilísticos. Evidenciam-se aqui vários períodos de elevação importante da $\mathrm{FC}$, sendo que alguns chegaram a durar entre 10 e 15 min.....

Figura 18 Ilustração de registro da FC durante turno rotineiro de trabalho em atividades operacionais de prontidão de voluntário de 41 anos, IMC: $26,7 \mathrm{~km} / \mathrm{m} 2$; que acumulou 12190 passos e atuou em atendimento de salvamento. Evidencia-se aqui longo período de baixa intensidade de esforço, mas atingiu intensidade muito vigorosa no final do turno ( $\mathrm{FC}=190 \mathrm{bpm} ; 106,1 \% \mathrm{FC}$ máxima prevista para a idade).

Figura 19 Valores medianos (intervalo interquartial) do PNN50\% na postura ortostática nas 3 avaliações instituídas

Figura 20 Espectrograma de um voluntário de 41 anos na condição de repouso supino em AVA1, onde se registrou a razão BF/AF igual a $0,79 \ldots \ldots$.

Figura 21 Espectrograma de um voluntário de 41 anos na condição de repouso ortostático em AVA1, onde se registrou a razão BF/AF igual a 1,8...

Figura 22 Espectrograma de um voluntário de 41 anos na condição de repouso supino em AVA2, onde se registrou a razão BF/AF igual a 1,3.........

Figura 23 Espectrograma de um voluntário de 41 anos na condição de repouso ortostático em AVA2, onde se registrou a razão BF/AF igual a 5,8...

Figura 24 Espectrograma de voluntário de 41 anos na condição de repouso supino em AVA3, onde se registrou a razão BF/AF igual a $6,8 \ldots \ldots \ldots$.

Figura 25 Espectrograma de um voluntário de 41 anos na condição de repouso ortostático em AVA3, onde se registrou a razão BF/AF igual a 4,4...

Quadro 1 Riscos cardiovasculares crônicos e agudos associados à atividade e profissional de bombeiros.

Quadro 2 Critérios de inclusão dos voluntários na amostra............................... 40

Quadro 3 Critérios de exclusão e motivo da exclusão dos voluntários da amostra. 


\section{LISTA DE ABREVIATURAS}

AF - Área espectral de alta frequência

ACR - Aptidão Cardiorrespiratória

BF - Área espectral de baixa frequência

CV - Coeficiente de variação

DP - Desvio padrão

FAC - Função autonômica cardíaca

FC - Frequência cardíaca

FCsup - Frequência cardíaca na posição supina

FCort - Frequência cardíaca na posição ortostática

FR - Frequência respiratória

IMC - Índice de massa corporal

iRR - Intervalo R-R

PAS - Pressão arterial sistólica

PAD - Pressão arterial diastólica

pNN50 - Percentual de intervalos R-R adjacentes com diferença superior a $50 \mathrm{~ms}$

Razão BF/AF - Razão entre a área absoluta de baixa frequência pela área espectral absoluta de alta frequência

Razão SD1/SD2 - Razão entre o índice SD1 pelo índice SD2

r-MSSD - Raiz quadrada da média do quadrado das diferenças sucessivas dos intervalos R-R

SNA - Sistema nervoso

VFC - Variabilidade da frequência cardíaca 


\section{LISTA DE TABELAS}

Tabela 1 Valores amostrais medianos (min - max) de variáveis de caracterização da amostra..

Tabela 2 Valores medianos (extremos) da PA no repouso supino (SUP) e ortostático (ORT) nas 3 avaliações (AVA1-3) $(\mathrm{n}=30)$

Tabela 3 Valores medianos (extremos) da FC no repouso supino (SUP) e ortostático (ORT) nas 3 avaliações (AVA1-3) $(\mathrm{n}=30)$

Tabela 4 Valores amostrais do tempo de permanência nas 4 zonas de intensidade

Tabela 5 Comparação dos valores de FC máx e do \% da FC max prevista para a idade atingidos durante um turno de atividade operacional de bombeiros militares segundo o tipo e a quantidade de ocorrências.....

Tabela 6 Caracterização da análise temporal da VFC nas postura de repouso supino (SUP) e ortostático (ORT), na condição de registro basal (AVA1), no início (AVA2) e após (AVA3) o término do turno de trabalho, de bombeiros militares do Distrito Federal do sexo masculino $(\mathrm{n}=30)$

Tabela 7 Caracterização da análise espectral da VFC nas postura de repouso supino (SUP) e ortostático (ORT), na condição de registro basal (AVA1), no início (AVA2) e após (AVA3) o término do turno de trabalho, de bombeiros militares do Distrito Federal do sexo masculino $(n=30)$.

Tabela 8 Valores medianos (min - max) da variáveis amostrais de caracterização amostral segundo o estado autonômico basal.

Tabela 9 Coeficiente de correlação de Spearman entre a capacidade cardiorrespiratória (VO2max estimado) e os índices temporais e espectrais da VFC nas posições supina (SUP) e ortostática (ORT) nas 3 avaliações instituídas (AVA1-3), de bombeiros militares do sexo masculino. 


\section{SUMÁRIO}

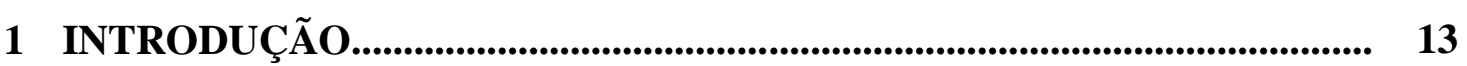

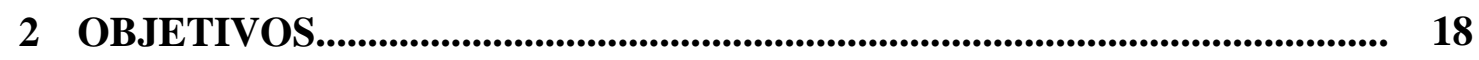

3 HIPÓTESES.................................................................................................. 19

4 REVISÃO DA LITERATURA ............................................................. 20

4.1 Breve Histórico sobre o Corpo de Bombeiros no Brasil: Aspectos Históricos e Operacionais Relevantes.................................................................... 20

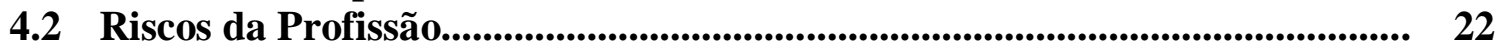

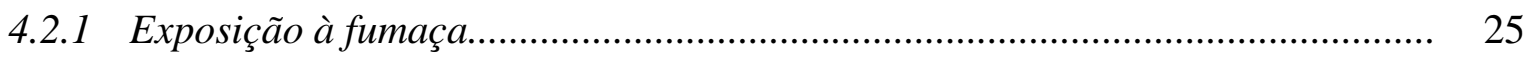

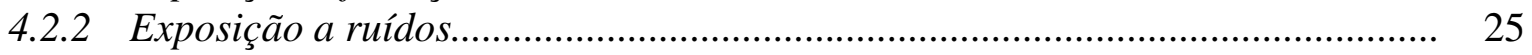

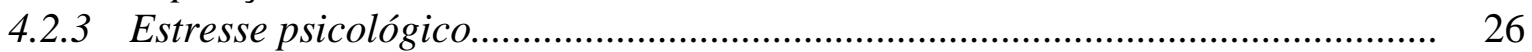

4.2.4 Exigência Física para Combater Incêndios com Efetividade............................. 26

4.3 Regulação Cardiovascular e Função Autonômica Cardíaca............................ 29

4.4 Estresse Cardiovascular........................................................................................ 32

4.5 Prevalência de Doenças Crônicas Não-Transmissíveis em Bombeiros: Impactos no Risco Cardiovascular Global....................................................... 35

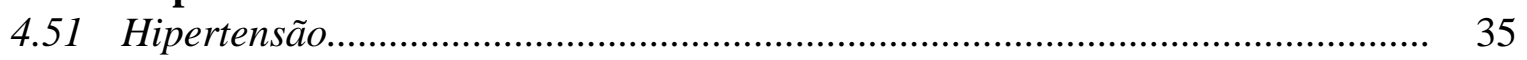

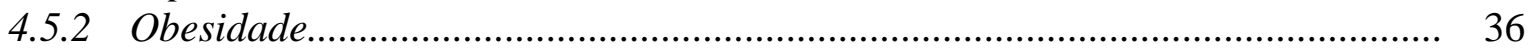

4.5.3 Diabetes mellitus.................................................................................. 36

5 MATERIAIS E MÉTODOS........................................................................... 38

5.1 Aspectos Metodológicos Gerais........................................................................ 38

5.2 Indivíduos Avaliados............................................................................... 38

5.3 Critérios de Inclusão e/ou Exclusão de Indivíduos e/ou Registros................ 39

5.4 Procedimentos de Coleta de Dados......................................................................... 41

5.5 Instrumentos de Medida e Avaliação....................................................................... 44

5.5.1 Avaliação da atividade física e do tempo sentado.............................................. 44

5.5.2 Avaliação da qualidade vida.......................................................................... 45

5.5.3 Avaliação da Função Autonômica Cardíaca..................................................... 46

5.6 Análise Estatística dos Dados................................................................... 50

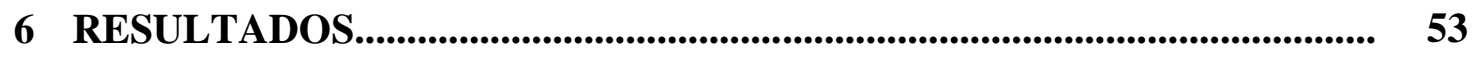

6.1 Caracterização do Nível de Atividade Física, do Tempo Sentado e da 53 Qualidade de Vida.

6.2 Caracterização Funcional de Repouso............................................................. 54

6.3 Sobrecarga Cardiovascular Durante o Turno de Trabalho Operacional..... 55

6.4 Avaliação da Função Autonômica Cardíaca por Meio da Variabilidade da Frequência Cardíaca.

6.4.1 Índices temporais resultantes das séries de 5 minutos de intervalos $R-R$ do $E C G$, obtidos por meio do frequencímetro Polar........................................... 59

6.4.2 Índices espectrais resultantes das séries de 5 minutos de intervalos $R-R d o$ ECG, obtidos por meio do frequencímetro Polar........................................... 61

6.4.3 Comparação dos índices da VFC nas três avaliações, segundo o padrão autonômico basal no repouso supino na condição controle (medida no laboratório)...... 
6.4.4 Correlações entre índices temporais e espectrais da VFC com a aptidão cardiorrespiratória.

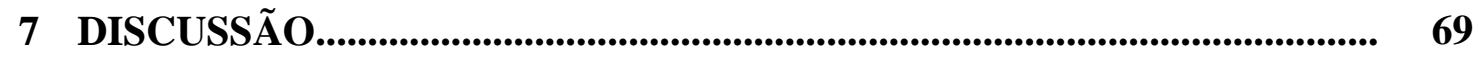

7.1 Considerações Preliminares........................................................................ 69

7.2 Caracterização Funcional de Repouso............................................................. 71

7.3 Sobrecarga Cardiovascular Durante o Turno de Trabalho............................. 73

7.4 Avaliação da FAC por Meio da VFC......................................................... 76

7.5 Limitações do Estudo..................................................................................................... 79

CONCLUSÕES......................................................................................... 81

REFERÊNCIAS …............................................................................................. 84 


\section{INTRODUÇÃO}

As rotinas de trabalho dos bombeiros variam em todo o mundo, mas geralmente incluem tarefas como extinção de incêndios, salvamentos e atendimento às emergências médicas. Tais atividades expõem esses profissionais a diversos fatores de riscos ocupacionais e a intensos fatores estressores físicos e psicológicos, caracterizando esta profissão como de elevado risco à saúde (KALES et al., 2007; SOTERIADES et al., 2011; SMITH; BARR; KALES, 2013).

Nas diferentes tarefas operacionais desempenhadas por bombeiros, identificam-se facilmente fatores estressores ao sistema cardiovascular, tanto de ordem física, quanto emocional. A combinação única de demandas psicofísicas às condições de riscos ambientais, que bem caracterizam esta profissão, levam a uma ativação robusta do sistema nervoso simpático, bem como depressão do grau de modulação parassimpática sobre o coração, o que pode resultar em desfechos cardiovasculares negativos como arritmias e morte súbita (KARASON et al., 1999; AL-ZAITI; CAREY, 2015 ).

Sabe-se que a regulação cardiovascular de curto prazo é dependente das modulações nervosas sobre o aparelho cardiovascular, implicando os componentes autonômicos simpático e parassimpático, que englobam a Função Autonômica Cardíaca (FAC) (DONCHEVA; NIKOLOVA; DANEV, 2003; JUNQUEIRA JÚNIOR, 2008; ROBINSON et al., 1966).

A integridade da FAC possibilita ajustes imediatos da frequência cardíaca e da pressão arterial em situações de modificação das demandas cardiovasculares nas diferentes circunstâncias funcionais do cotidiano, como a mudança de decúbito, exercício físico e estresse emocional (PUMPRLA et al., 2002).

Assim, uma disfunção neste importante mecanismo de regulação cardiovascular (Disfunção Autonômica Cardíaca) pode se manifestar em variados graus e acarreta, potencialmente, diversos problemas funcionais ou sintomas limitantes das atividades da vida diária. As implicações para a saúde humana podem ser de diferentes magnitudes, desde uma simples tontura ao levantar, até casos extremos de morte súbita (JUNQUEIRA JÚNIOR, 2012; PUMPRLA et. al., 2002; FUKUDA et al., 2015; SHEN; ZIPES, 2014). Estudos apontam para a possibilidade de prejuízos na FAC configurarem marcadores iniciais de aumento do risco cardiovascular e/ou para o desenvolvimento de condições como a hipertensão arterial sistêmica, sem olvidar que a aptidão física, a obesidade, a hipertensão 
arterial e o diabetes mellitus estão associados a alterações, positivas ou negativas, na FAC (KARASON et al., 1999; DONCHEVA; NIKOLOVA; DANEV, 2003).

A relação entre o risco de eventos cardiovasculares graves a atividade profissional de bombeiros ficou muito evidente em um estudo publicado em 2007 ao indicar que $45 \%$ das mortes de bombeiros americanos em serviço eram causadas por doenças cardíacas. Diante do estresse da atividade a que são submetidos esses profissionais, envolvendo elevadas demandas físicas e emocionais, compreende-se que o resultado possa ser uma importante sobrecarga cardiovascular associada à atividade laboral e ao esforço físico exigido em muitos casos (KALES et al., 2007).

Entre bombeiros americanos, a principal causa de mortalidade em serviço, correspondendo a quase metade das ocorrências, é a doença cardiovascular, em grande parte associada à doença cardíaca coronária (KALES et al., 2007; SINGH et al., 1998; SOTERIADES et al., 2011). Portanto, atividades relacionadas com o trabalho dos bombeiros exigem ajustes constantes do sistema cardiovascular, em que a função autonômica cardíaca (FAC) desempenha papel de destaque (KARASON et al., 1999; PUMPRLA et al., 2002; GUYTON; HALL, 2011; JUNQUEIRA JÚNIOR. 2008, ROBINSON et al., 1966). Sabe-se que a hiperatividade simpática e a atividade parassimpática diminuída são arritmogênicas e consideradas condições associadas à morte súbita cardíaca (MSC) (HURTADO, 2004; JUNQUEIRA JÚNIOR, 2012; FUKUDA et al., 2015; SHEN; ZIPES, 2014). A despeito do papel da FAC nos ajustes cardiovasculares necessários a atividades rotineiras de bombeiros, bem como do potencial mecanismo da disfunção autonômica cardíaca na morte súbita cardíaca entre bombeiros, pouco se sabe sobre a condição basal da FAC de bombeiros, assim como suas modificações ao longo da jornada de trabalho.

O Corpo de Bombeiros Militar do Distrito Federal (CBMDF) desenvolve diversas atividades, como as já mencionadas. Considerando-se, portanto, o perfil de demandas ocupacionais desses trabalhadores, há uma preocupação específica com a saúde dos bombeiros, os quais necessitam de resistência e vigor físico, para atender às demandas da profissão (SMITH; BARR; KALES, 2013; SOTERIADES et al., 2011).

Além de uma possível característica específica do grau de modulação autonômica cardíaca desses profissionais, associada às exigências singulares da profissão, estudos demonstram alta prevalência de obesidade, hipertensão arterial, sedentarismo e baixos níveis de aptidão cardiorrespiratória entre os mesmos, que são condições associadas a prejuízos na 
modulação autonômica cardíaca (POSTON et al., 2011; NOGUEIRA et al., 2016; MALLIANI et al., 1991; MEHTA, 2015).

Vários estudos têm apresentado dados que levantam preocupações com a aptidão física de bombeiros e sua composição corporal, apesar das características inerentes à função. Trabalho publicado em 2011 demonstra existir elevada prevalência de sobrepeso (79,5\%) e obesidade $(33,5 \%)$ entre bombeiros de carreira americanos. Esta elevada percentagem de bombeiros obesos é semelhante à população em geral (POSTON et al. 2011), o que também é motivo de preocupação, tendo em vista que as exigências profissionais demandam perfil diferenciado em comparação com os demais componentes populacionais. Em estudo conduzido por nosso grupo (NOGUEIRA et al., 2016), observou-se prevalências de sobrepeso e obesidade bem menores que aquelas observadas entre bombeiros americanos, mas com a preocupante similaridade, com o fato de que, também entre bombeiros brasileiros, as prevalências de sobrepeso e obesidade se assemelham àquelas da população em geral. Considerando-se, portanto, as relações entre obesidade, baixa aptidão cardiorrespiratória e depressão da modulação autonômica (NOGUEIRA et al., 2016; MEHTA, 2015), reforça-se a importância da caracterização da FAC entre bombeiros.

Neste contexto, há que se avaliar, também, possíveis efeitos do comportamento sedentário, uma vez que a própria atividade laboral pode contribuir para esse comportamento. Uma hipótese é a de que o tempo de permanência sentado seja elevado entre esses profissionais, em virtude do desenvolvimento de atividades com baixa demanda física nos períodos de prontidão. Identifica-se, assim, potencial soma de riscos cardiovasculares, agregando-se aqueles inerentes à atividade profissional com fatores atrelados ao estilo de vida, como o elevado comportamento sedentário, a baixa aptidão física e a inadequada composição corporal, entre outros, e seus riscos à saúde (KATZMARZYK et al., 2009; EKELUND et al., 2016; NOGUEIRA et al., 2016).

A aptidão cardiorrespiratória (ACR) tem demonstrado ser inversamente relacionada com a prevalência da síndrome metabólica $(\mathrm{SM})$ em bombeiros. A prevalência de SM foi quase 10 vezes maior entre os bombeiros com menor ACR da categoria ( $\leq 10 \mathrm{METs}$ ), em comparação com aqueles da mais alta categoria de ACR (> 14 METs) (BAUR et al., 2012).

A associação entre a atividade física regular e a saúde tem sido bem estabelecida, particularmente na prevenção de doenças do aparelho circulatório, com redução de várias condições de risco cardiometabólico, (KUEHL et al., 2012; HASKEL et al., 2007). A melhora da aptidão cardiorrespiratória pode ter um impacto positivo na saúde cardiovascular e redução 
da mortalidade total. Também se evidencia que pequenas mudanças no IMC podem estar associada à redução de risco cardiometabólico (MILESKI et al., 2015).

No Brasil, conforme análise desenvolvida no Curso de Altos Estudos para Oficiais do Corpo de Bombeiros Militar do Distrito Federal (CBMDF), constatou-se que os bombeiros militares da localidade tiveram uma expectativa de sobrevida média de 5,9 anos a menos do que a população masculina da mesma região. Evidencia-se, também, que o vínculo entre a atividade profissional de bombeiros, a presença de doenças e/ou fatores de risco cardiovasculares e a saúde, têm sido alvo de investigação científica (SANTOS, 2011).

Assim, no cenário acima descrito, das elevadas exigências profissionais a que bombeiros são expostos (SMITH et al., 1996; VON HEIMBURG; RASMUSSEN; MEDBO, 2006) e dos riscos cardiovasculares associados (SMITH et al., 2016a), um foco importante da pesquisa deve ser a identificação precoce de indivíduos mais suscetíveis, uma vez que o aumento de risco cardiovascular não ocorre de forma aleatória, nem quanto aos sujeitos, ao tipo de atividade desempenhada, à hora do dia ou à estação do ano (KALES et al., 2003; MBANU et al., 2007, SOTERIADES et al., 2011). Sabe-se que a maior suscetibilidade tem sido associada a atividades de efetivo combate a incêndios, a sujeitos portadores de condições clínicas diversas como obesidade, hipertensão arterial, cardiomegalia e baixa aptidão cardiorrespiratória (SOTERIADES et al., 2001; SMITH et al., 2016a; KORRE et al., 2016a; DURAND et al., 2011; BAUR et al., 2011; BAUR et al., 2012). Portanto, a identificação precoce de sujeitos mais suscetíveis pode subsidiar adaptações laborais, como mudança de atribuições, o que pode, em última instância, salvar vidas. No cenário desta atividade laboral que exige, muitas vezes, elevado predomínio absoluto e/ou relativo da porção simpática do SNA, para fazer frente às sobrecargas físicas e emocionais, buscou-se avaliar prioritariamente o comportamento da regulação cardiovascular mediada pelo SNA durante um turno diurno rotineiro de trabalho, sob a hipótese de que após algumas horas de atividade profissional os bombeiros apresentem aumento absoluto e/ou relativo da modulação simpática, o que é compatível com baixa variabilidade da FC e, portanto, poderia representar um aumento do risco de eventos cardiovasculares súbitos em serviço (DEKKER et al., 2000), especialmente entre aqueles bombeiros com conhecidos fatores de risco cardiovasculares e/ou doença cardiometabólica previamente identificada.

Diante das características ocupacionais da profissão, a presente pesquisa foi proposta, haja vista a relevância do tema, a exiguidade de dados relativos à FAC entre bombeiros e o 
possível papel da modificação autonômica cardíaca na morbimortalidade cardiovascular de bombeiros. 


\section{OBJETIVOS}

No contexto da análise da variabilidade da frequência cardíaca para avaliação clínica da função autonômica cardíaca durante a jornada de trabalho de bombeiros, a presente pesquisa teve os seguintes objetivos principais:

1) Avaliar a função autonômica cardíaca (FAC) de bombeiros do sexo masculino, em um dia de rotina profissional habitual, por meio da análise da variabilidade da frequência cardíaca (VFC) nos domínios do tempo e da frequência espectral, em comparação com uma condição basal controle;

2) Avaliar a sobrecarga cardiovascular a que estão sujeitos bombeiros do sexo masculino, durante um turno diurno de atividade operacional de rotina;

Como desdobramento das análises efetuadas, são apresentados ainda os seguintes objetivos específicos:

1) Avaliar a aptidão cardiorrespiratória, o nível de atividade física (NAFT) e o comportamento sedentário (CS) de bombeiros do sexo masculino;

2) Avaliar a associação da FAC com a aptidão cardiorrespiratória;

3) Analisar o impacto das circunstâncias de trabalho, como o número e o tipo de atividade operacional realizada em um turno de trabalho na sobrecarga cardiovascular associada à atividade operacional de bombeiros militares. 


\section{HIPÓTESES}

Tendo por base os objetivos formulados, apresentam-se as hipóteses de trabalho consideradas no presente estudo:

1) No repouso basal em ambiente controlado existe maior modulação autonômica cardíaca e predomínio da atividade vagal em bombeiros, comparativamente à situação de início da jornada de trabalho;

2) A modulação autonômica cardíaca em bombeiros está deprimida ao final de um turno diurno de desempenho profissional de rotina e é caracterizada por predomínio simpático, comparativamente ao início da jornada de trabalho e à avaliação em repouso em ambiente controlado;

3) Existem períodos curtos de elevada sobrecarga cardiovascular durante um turno de atividade operacional de bombeiros militares;

4) Existe associação entre a modulação autonômica cardíaca e seu comportamento pré e pós-jornada de trabalho com a aptidão cardiorrespiratória;

5) A magnitude da sobrecarga cardiovascular durante um turno de trabalho está na dependência do tipo e da quantidade de atendimentos prestados pelo bombeiros militares. 


\section{REVISÃO DA LITERATURA}

\subsection{Breve Histórico sobre o Corpo de Bombeiros no Brasil: Aspectos Históricos e Operacionais Relevantes}

Até 1856 não existia uma corporação voltada exclusivamente para o combate a incêndios no Brasil. Essa tarefa era feita pelo Serviço de Extinção de Incêndios, com seções nos Arsenais de Marinha e Guerra, Repartição de Obras Públicas e Casa de Correção, no Rio de Janeiro. A primeira solicitação para a criação desse tipo de corporação foi feita em 1851 ao Imperador D. Pedro II, pelo então Inspetor do Arsenal de Marinha das Cortes, o Capitão de Mar e Guerra (CMG) Joaquim José Inácio. Após a recusa inicial, o atendimento deste pleito veio a ocorrer em julho de 1856 (SOUZA, 2014).

A primeira corporação específica, criada em 1856 pelo Decreto n. 1775, foi efetivada a 30 de abril de 1860, conforme o Decreto n. 2.587, sob o nome de Corpo Provisório de Bombeiros da Corte, com chefia do então Major João Batista de Castro Moraes Antas. Em 1865 a corporação recebeu a primeira bomba a vapor, com a finalidade de combater os incêndios que ocorressem no litoral ou nos navios ancorados no porto, havia a necessidade de vinte homens para transportá-la. Na época não havia sirene e, sim, um apito para alertar a população sobre o trabalho dos soldados bombeiros (MENEZES, 2007). Nesse mesmo ano, voluntários do Corpo de Bombeiros, mais de uma centena, juntaram-se às tropas do Império e atuaram bravamente na Guerra do Paraguai (ASTE, 1991).

Durante o período de escravidão, muitos escravos viam no recém-criado Corpo de Bombeiros o local de abrigo e liberdade (ASTE, 1991). O autor ressalta que os escravos fugidos acolhidos pela Corporação, após conquistar a confiança de seus superiores, acabavam sendo comprados de seus proprietários. Nesse período, também foram publicadas as posturas municipais, determinado que cada vizinho de quarteirão ao incêndio deveria mandar um escravo com um barril de água para extinguir o incêndio.

Para manusear e transportar esses equipamentos pesados de combate a incêndio, a seleção para ingresso dos bombeiros na Corporação já exigia boa qualidade física, sendo selecionados os mais ágeis, mais robustos, e "moralizados", sendo preferidos os mais amestrados em qualquer dos ofícios de maquinismo ou construção (ASTE, 1991). Entre 1870 e 1875 o apito foi substituído pela corneta militar e foram introduzidos muares para puxar as viaturas da corporação, como se observa na Figura 1. Percebe-se assim, desde cedo, a exposição desses profissionais a condições estressantes, como a sobrecarga física e o ruído, 
que são hoje em dia bem caracterizados como fatores de risco cardiovascular (SMITH et al., 2016a).

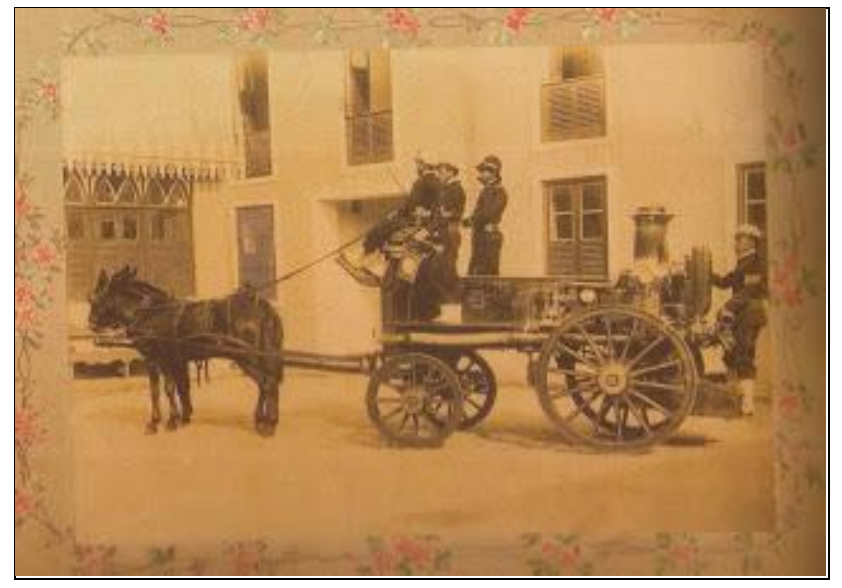

Figura 1 - Primeiro modelo de carro do Corpo de Bombeiros no Brasil Fonte: (FIREFIGHTERS BRASIL, 2011)

Ao longo dos anos a instituição foi sendo ampliada em seus recursos, tanto humanos como físicos. A título de curiosidade e talvez sinal de destaque da corporação, registra-se que o quartel do Corpo de Bombeiros foi o primeiro prédio militar do Rio de Janeiro a ter telefone, ligando-se à loja de Antônio Ribeiro Chaves, que comercializava aparelhos elétricos e mecânicos. Porém, somente em 1880 a corporação foi agraciada com graduações militares e insígnias, pelo Decreto n. 7.776, de 19 de julho. O Diretor Geral foi transformado em Tenente Coronel, o Ajudante em Major, os Comandantes de Seções em Capitães e os Instrutores em Tenentes, o que foi efetivado pelo Regulamento de 1881 (CBMGO, 2016).

Por esse regulamento, expresso pelo Decreto n. 8.837, de 17 de dezembro de 1881, o Corpo de Bombeiros foi efetivado como instituição militar, com efetivo de trezentos homens. Em caso de guerra a corporação poderia ser chamada, atuando como Corpo de Sapadores ou Pontoneiros, com a mesma organização do Batalhão de Engenheiros (MELO, 2015). Foi em 1 de junho de 1913 que o Corpo de Bombeiros começou a usar automóvel, movido a motor de explosão, em suas atividades, porém as viaturas puxadas por muares ainda foram usadas durante algum tempo (AMARAL, 2014).

Atualmente, o Corpo de Bombeiros Militar do Distrito Federal (CBMDF) desenvolve diferentes atividades inerentes à profissão que são claramente definidas em sua Lei de Organização Básica (Lei n. 8.255, de 20 de novembro de 1991), de onde se extraem as seguintes competências: "realizar serviços de prevenção e extinção de incêndios, serviços de busca e salvamento, perícias de incêndio relacionadas com sua competência, prestar socorros 
nos casos de sinistros, sempre que houver ameaça de destruição de haveres, vítimas ou pessoas em iminente perigo de vida, atividades de segurança contra incêndio e pânico, com vistas à proteção das pessoas e dos bens públicos e privados, atividades de prevenção aos incêndios florestais, com vistas à proteção ambiental” (BRASIL, 1991, p. 1). Nessas atribuições são evidentes algumas condições que podem implicar sobrecarga cardiovascular e demandar elevado preparo físico e emocional para o adequado desempenho da função. Nesse contexto, passar-se-á ao detalhamento dos fatores estressores à saúde associados à atividade profissional de bombeiros.

\subsection{Riscos da Profissão}

Nas atividades operacionais, os bombeiros configuram um grupo mais propenso a sofrer eventos cardiovasculares, durante períodos de alto estresse físico ou psicológico, tais como resposta a alarme ou extinção de incêndios. O exercício físico regular de duração suficiente é amplamente aceito para promover cardioproteção. No entanto, quantidades pouco frequentes e insuficientes de atividade física são comuns no serviço de combate a incêndio. Bombeiros rotineiramente experimentam longos períodos de prontidão nos quartéis com menor exigência física, além do fato de que na maioria dos quartéis do Brasil, não há a prática de exercício físico regular (DONCHEVA; NIKOLOVA; DANEV, 2003).

Há várias explicações biologicamente plausíveis para a alta mortalidade por eventos cardiovasculares entre os bombeiros. Essas explicações incluem exposição química e à fumaça, esforço físico irregular, manuseio de equipamentos e materiais pesados, estresse térmico, o trabalho por turnos, alta prevalência de fatores de risco cardiovascular e estressores psicológicos (MELIUS, 2001).

As mortes por doença coronariana entre os bombeiros são verdadeiramente precipitadas pelo seu trabalho. Os bombeiros em serviço forneceram evidências preliminares de que os eventos coronarianos podem ser desencadeados por serviços específicos de combate a incêndios. Uma importante, da associação do risco cardiovascular com o desempenho profissional, é o fato do ritmo circadiano de mortes por doença coronariana acompanhar os horários de exigência profissional, diferentemente da população em geral (KALES et al., 2003). Para confirmar essas pesquisas e explorar mais detalhadamente os fatores de riscos específicos para a morte por doença cardíaca coronariana, foram realizadas pesquisas de todos os óbitos ocorridos em bombeiros nos Estados Unidos entre 1994 e 2004, onde se evidenciou que quase $50 \%$ são de origem cardiovascular. (KALES et al., 2007) 
Conforme relatórios de óbitos por morte súbita de bombeiros americanos, de acordo com as rotinas de trabalho durante o turno de serviço, o início dos sintomas ocorreram antes ou após atividades de combate a incêndios, resposta ao alarme, retorno do socorro, treinamento físico, emergência de serviços médicos, resgates e outras emergências nãoviolentas e atividades de não-emergência (FRIEL; STONES, 1992; KALES et al., 2007). Nesta pesquisa, as mortes foram classificadas como estando associadas ao combate a incêndio, a resposta ao alarme, bem como, respostas a incidentes de emergência, incluindo falsos alarmes. O retorno do alarme incluiu todos os eventos que ocorreram durante o retorno de incidentes e aqueles que ocorreram dentro de várias horas após uma chamada de emergência. O treinamento físico incluiu todas as atividades físicas de trabalho, testes de habilidades físicas e exercícios simulados ou atividade real de resgate, emergência e pesquisa. (KALES et al., 2007). Segue abaixo o gráfico representativo (Figura 2), extraído do mesmo artigo, no qual detalha as ocorrências com maior incidência de mortes nas atividades realizadas pelos bombeiros e correlacionadas com a faixa etária.

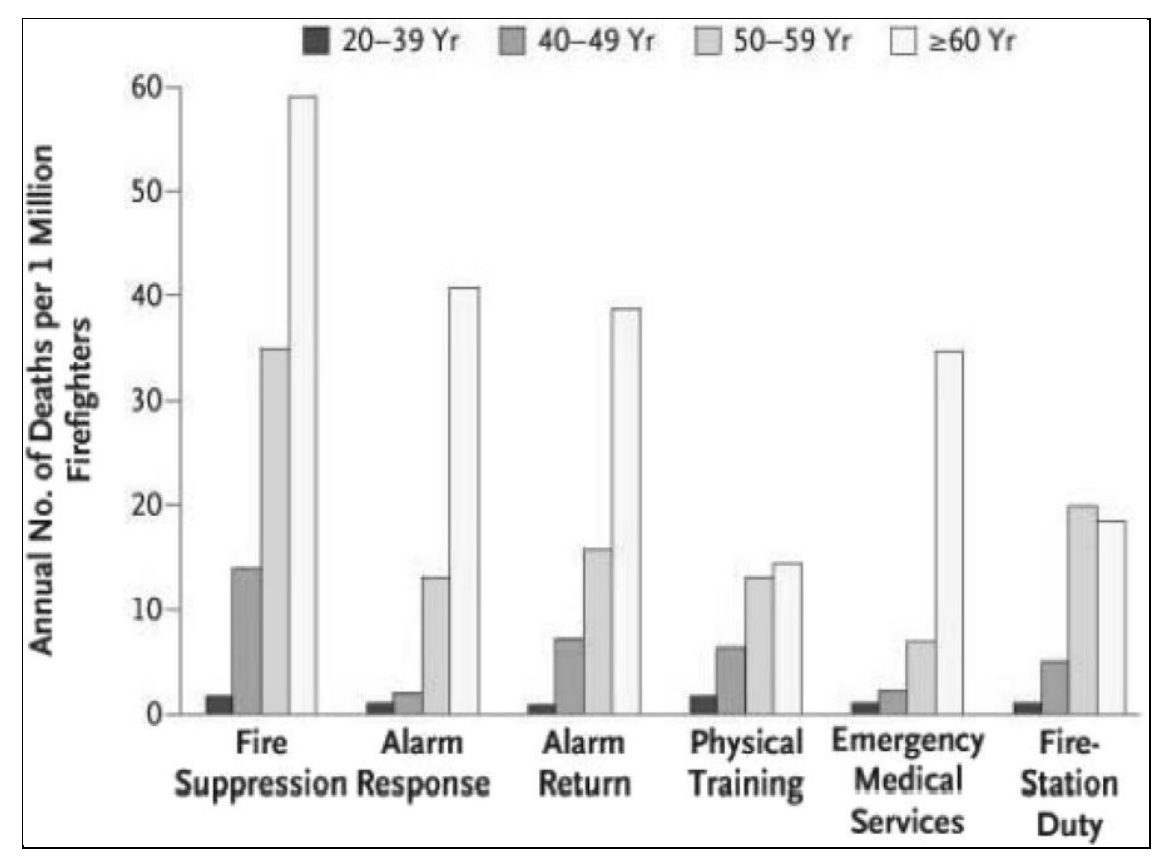

Figura 2 - Risco de morte em serviço por faixa etária, por doença coronariana, em bombeiros americanos

Fonte: KALES et al. (2007, Adaptação)

Além da observação dos riscos associados ao tipo de atividade operacional, a pesquisa na área também tem identificado os principais fatores de risco a que bombeiros estão, usualmente, submetidos, seja de forma crônica ou aguda, como se observa no Quadro 1. 
Quadro 1 - Riscos cardiovasculares crônicos e agudos associados à atividade profissional de bombeiros

\begin{tabular}{|l|l|}
\hline \multicolumn{1}{|c|}{ CRÔNICOS } & \multicolumn{1}{c|}{ AGUDOS } \\
\hline Longos períodos sedentários & $\begin{array}{l}\text { Esforço físico irregular } \\
\text { Exposição a fumaça } \\
\text { Exposição a fumaça }\end{array}$ \\
Exposição aos gases e partículas & $\begin{array}{l}\text { Exposição aos gases e partículas } \\
\text { Exposição ao ruído }\end{array}$ \\
Exposição ao ruído & $\begin{array}{l}\text { Exposição ao excesso de calor } \\
\text { Perigos específicos da }\end{array}$ \\
Trabalho por turnos / privação parcial do sono & $\begin{array}{l}\text { atividade } \\
\text { Combate a incêndios }\end{array}$ \\
Padrão alimentar no Quartel & $\begin{array}{l}\text { Treinamento físico insuficiente } \\
\text { Falta de atividade física }\end{array}$ \\
Estresse ocupacional & Resposta ao alarme \\
Transtornos de estresse pós-traumático & \\
Alta demanda de trabalho e pouco poder de decisão & \\
\hline
\end{tabular}

Fonte: SOTERIADES et al. (2011, Adaptação)

Sabe-se que a atividade de combate a incêndios leva a um rápido aumento da frequência cardíaca por excitação fisiológica simpática, iniciada desde o toque da sirene de alarme de incêndio, conhecida no meio como "brado". Subsequentemente, as frequências cardíacas máximas ou quase máximas são alcançadas durante atividades de combate a incêndios fisicamente extenuantes. Pesquisa realizada com bombeiros americanos mostrou uma redução no volume sistólico após a atividade de combate a incêndios. Observou-se uma redução de $35 \%$ no volume sistólico (usando ecocardiografia Doppler) após uma atividade de combate a incêndio de curto prazo. Os autores observaram, ainda, uma redução no volume plasmático $(-14,8 \%)$ após 18 min de combate a incêndio. Ressalte-se que a hipovolemia prejudica a função cardíaca e aumenta a viscosidade do sangue. Observa-se aumento no número e função das plaquetas e alterações no tempo parcial de tromboplastina e nos níveis de fibrinogênio após atividades de combate a incêndio de curta duração. Estas alterações sugerem um estado pró-coagulatório que pode aumentar o risco de formação de trombos, aumentando, assim, o risco cardiovascular de bombeiros em serviço (SMITH et al., 2011).

Também no ano de 2011, estudo identificou que a atividade de combate a incêndios gerou aumento da rigidez arterial. Além disso, os bombeiros obesos apresentaram uma rigidez arterial aumentada em repouso em comparação com os bombeiros não obesos (FAHS et al., 2011). Em um estudo que envolveu entre 3 a 4 treinamentos simulados de ocorrência de 
combate a incêndio, cada um durando aproximadamente $20 \mathrm{~min}$, encontraram-se evidências de disfunção diastólica após um período de 2,5 a 3,0 h ( FERNHALL et al., 2012).

No contexto dos riscos da profissão, destacam-se abaixo algumas características de exposição a fatores tipicamente encontrados na rotina de trabalho de bombeiros e suas relações com o risco cardiovascular.

\subsubsection{Exposição à fumaça}

A exposição à fumaça durante o trabalho de combate a incêndios, bem como a quantidade de gases e partículas inaladas, foi anteriormente um risco mais significativo e, portanto, considerado um importante contribuinte para doenças cardiovasculares (DCV). Nas últimas décadas, tal exposição foi significativamente reduzida pelo uso do aparato de respiração autônomo durante as operações de extinção a incêndios (BRANDT-RAUF et. al., 1988).

No entanto, os profissionais, muitas vezes por não utilizarem aparelho de respiração autônomo ou similares durante o rescaldo, ou seja, o período imediatamente posterior à extinção do incêndio, quando o local é inspecionado para verificar a possibilidade do potencial de reignição, padecem do mal que poderia ser evitado. (BAXTER et al., 2010).

Observa-se que a inalação de fumaça pode produzir hipoxia tecidual devido ao monóxido de carbono, cianeto, além de hipoxemia direta, levando à isquemia do miocárdio em pessoas com DCV subjacentes. Além disso, as partículas têm sido associadas à disfunção autonômica, incluindo aumento da frequência cardíaca, diminuição da variabilidade da frequência cardíaca e aumento da ocorrência de arritmias cardíacas (DOCKERY, 2001).

Embora as consequências de DCV a longo prazo de exposição à fumaça em bombeiros não tenham sido devidamente examinadas, mecanismos plausíveis para aumento da DCV foram relacionados com a exposição à fumaça, incluindo o aumento da formação de radicais livres, a subsequente disfunção endotelial, o aumento da coagulação e aumento da progressão da arteroesclerose (SIMKHOVICH; KEINMAN; KLONER, 2009).

\subsubsection{Exposição a ruídos}

O ruído é outra exposição intermitente, com um impacto negativo para DCV, principalmente pelo aumento da pressão dos alarmes, sirenes, motores de veículos e equipamentos de resgates mecanizados, que habitualmente produzem exposições médias de 
ruído na faixa de 63-85 dBA. Monitores individuais têm consistentemente documentado exposições intermitentes superiores a 90 dBA, ultrapassando-se o limite de exposição permitido pela legislação federal (KALES et al., 2009).

Estima-se que para cada aumento de 5 decibéis em exposição ao ruído ocupacional agudo, há um aumento agudo correspondente de $0,51 \mathrm{mmHg}$ na pressão arterial sistólica. Assim, o som das sirenes pode elevar a pressão arterial sistólica de 5,9 para 11,8 mmHg. Há um consenso geral de que os efeitos hemodinâmicos de ruído ocupacional intermitente persistem durante exposição ativa (SAWADA, 1993).

Em um estudo anterior, sobre o brado/sirene, pesquisadores documentaram que os bombeiros alcançaram número de batimentos máximo previsto durante ações de emergência. Tais valores chegam a atingir 188 batimentos por minuto, para 15 minutos por período. Vários grupos confirmaram que os batimentos cardíacos aumentam drasticamente após o alarme inicial e atingem os máximos valores previstos, seja em situações simuladas ou reais (SOTHMANN et al., 1992).

\subsubsection{Estresse psicológico}

Os bombeiros também estão expostos a uma variedade de estressores psicológicos no curso de várias emergências, incluindo incêndios, desastres naturais, ações de terrorismo, salvamentos, bem como a prestação de serviços médicos, configurados como demandas ocupacionais elevadas (DE LANGE et al., 2009).

Tais circunstâncias potencialmente contribuem para o aumento dos níveis de estresse, levando à elevada taxa cardíaca e pressão arterial, aliadas a pouco sono, fazendo com que bombeiros mais suscetíveis possam desenvolver transtornos pós-traumáticos, associados a outros efeitos adversos sobre a frequência cardíaca, pressão arterial, além de síndrome metabólica (JONSSON; SEGESTEN; MATTSSON et al., 2003).

\subsubsection{Exigência Física para Combater Incêndios com Efetividade}

Incêndios estruturais são caóticos, ruidosos, de baixa visibilidade, configurando ambientes de trabalho com limitações de tempo severas e com várias situações de risco de morte. Assim, a ativação simpática é um mediador crucial da fisiologia alterada no combate a incêndios. O combate a incêndios estruturais inclui entrada forçada, busca e salvamentos, ventilação da estrutura, extinção, dentre outras atividades (LEMON; HERMISTON, 1977). 
Tal trabalho demanda elevados níveis de aptidão aeróbica, dinâmica e estática, bem como esforço físico (escalada, rastejamento de cócoras, em movimento, além de habilidade para levantar objetos pesados, utilizando ferramentas de porte). Essas funções são exercidas com equipamentos de proteção individual (EPI), muitas vezes pesando mais de $25 \mathrm{~kg}$. Assim, o combate a incêndios com EPI tem o condão de acrescentar mais esforço às já existentes demandas metabólicas e térmicas de cada indivíduo (ELSNER; KOLKHORST, 2008, SMITH et al., 2016a).

Estudos simulados de tarefas sugerem que a capacidade mínima aeróbica com o uso de EPI e demandas térmicas, medida pelo consumo de oxigênio $\left(\mathrm{VO}_{2}\right)$ necessária para executar com segurança o combate a incêndios gravita em faixas 33,9-45 $\mathrm{mL}(\mathrm{kg} \cdot \mathrm{min})^{-1}(9,7$ - 12,8 METs). Também foi medido o consumo de oxigênio em um ritmo auto-selecionado, percebendo-se que os bombeiros ficam em média com $62 \%$ do $\mathrm{VO}_{2} \max \left(29 \mathrm{~mL}(\mathrm{~kg} . \mathrm{min})^{-1}\right)$ ao longo de 8,5 minutos) (ELSNER; KOLKHORST, 2008).

A National Fire Protection Association (NFPA) sugere 12 METs (cerca de 42 $\mathrm{mL}(\mathrm{kg} . \mathrm{min})^{-1}$ de $\mathrm{VO}_{2}$ ) como a capacidade de exercício mínimo exigido para o bom desempenho no combate a incêndios. Um recente estudo de coorte com profissionais bombeiros da carreira ativa constatou que pouco mais de um terço têm capacidades aeróbias de 12 METs (NFPA, 2007).

Em estudo de nosso grupo, a mediana da aptidão cardiorrespiratória em pesquisa realizada com bombeiros brasileiros foi de 42,4 $\left(18,2\right.$ - 64,7) $\mathrm{mL}(\mathrm{kg} . \mathrm{min})^{-1}$, sendo que 2240 participantes $(52,9 \%)$ tiveram $\mathrm{VO}_{2}$ max maior que 12 METs. (NOGUEIRA et al., 2016). Neste estudo, observou-se forte associação entre a aptidão cardiorrespiratória de bombeiros com a composição corporal avaliada por diferentes indicadores. Na comparação da ACR entre bombeiros com excesso de peso (IMC $>=25,0 \mathrm{~kg} / \mathrm{m}^{2}$ ) em relação aos demais, identificou-se diferenças entre 0,4 e 1,6 METs, dependendo da faixa etária. No mesmo estudo, observou-se ainda que bombeiros com indicadores de composição corporal ruim apresentaram odds-ratio para uma ACR insuficiente ( $<12$ METs) entre 2,9 a 7,0, dependendo do indicador de composição corporal. 


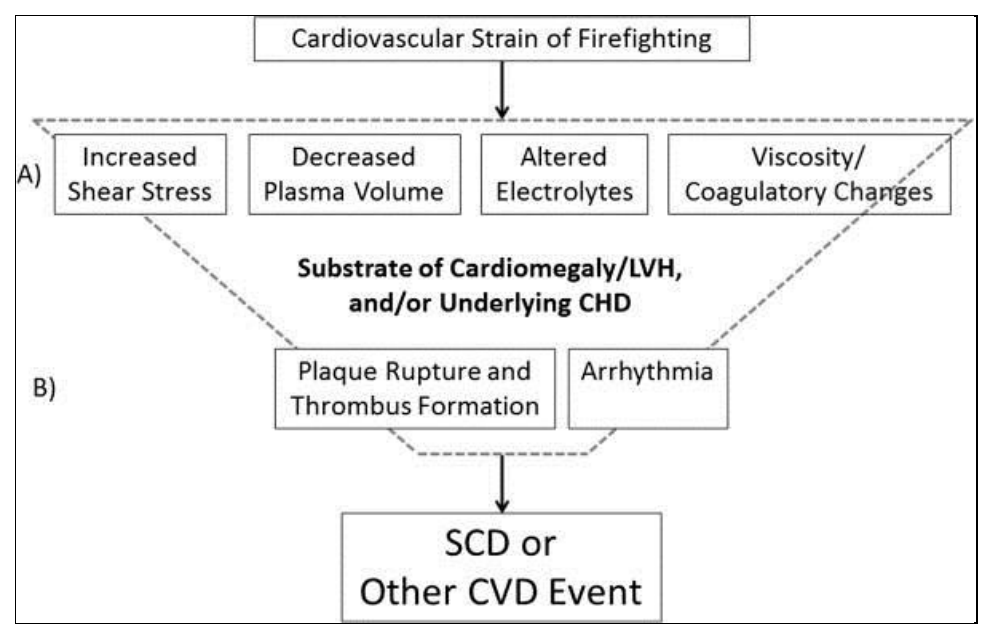

Figura 3 - Modelo teórico de eventos cardíacos súbitos em bombeiros Fonte: SMITH; BARR; KALES (2013)

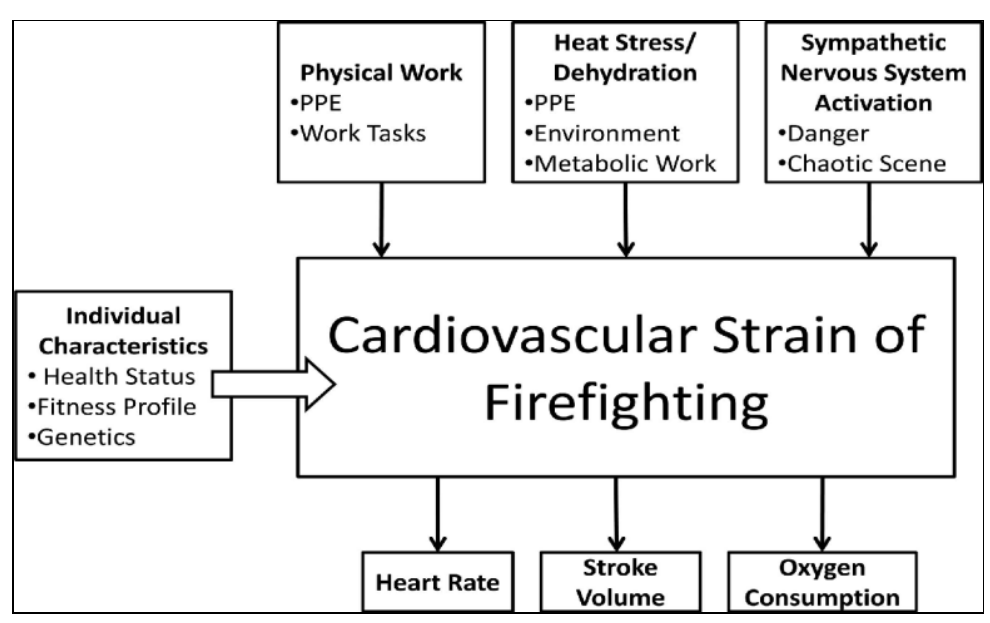

Figura 4 - Sobrecarga cardiovascular em bombeiros Fonte: SOTERIADES et al. (2011)

Em síntese, observa-se que os bombeiros são expostos a uma variedade de estressores no curso de várias emergências, incluindo incêndios, desastres naturais, terrorismo, resgate e serviços médicos. As elevadas exigências ocupacionais potencialmente contribuem para o aumento dos níveis de estresse, elevando a frequência cardíaca e pressão arterial, bem como o risco cardiovascular, conforme se observa nos modelos teóricos de sobrecarga cardiovascular a que bombeiros são expostos, propostos por SMITH; BARR; KALES (2013) e SOTERIADES et al. (2011) (Figuras 3 e 4 ).

Dos modelos acima, depreende-se o papel da regulação cardiovascular de curto prazo, mediada pelo sistema nervoso autônomo, que passamos a descrever. 


\subsection{Regulação Cardiovascular e Função Autonômica Cardíaca}

É sabido que mecanismos de regulação cardiovascular dividem-se em três diferentes grupos, ou seja, regulação lenta, intermediária e rápida. Os mecanismos de ação lenta são aqueles que normalmente acontecem em horas ou dias e que são mediados principalmente pela regulação hormonal, afetando, entre outros, o controle do volume dos líquidos corporais (JUNQUEIRA JÚNIOR, 2007).

A regulação de curto prazo age usualmente de forma reflexa e em poucos segundos, caracterizando-se pela ação de mecanismos neurais, de natureza autonômica. Os processos de regulação, chamados de intermediários, são aqueles que se realizam em minutos ou horas, notadamente frutos de interações neuro-hormonais. O conjunto desses mecanismos permite o perfeito funcionamento do organismo graças aos ajustes que ocorrem momento-a-momento, dependendo das diferentes necessidades funcionais e metabólicas dos diversos órgãos (JUNQUEIRA JÚNIOR, 2007).

Observa-se que os ramos simpático e parassimpático atuam de forma antagônica sobre o coração e vasos sanguíneos, aumentando ou reduzindo o débito cardíaco e a resistência vascular periférica de acordo com a demanda imposta ao sistema. Entretanto, para que tais ajustes cardiovasculares ocorram, é necessário que informações sobre níveis pressóricos, condição metabólica, volume sanguíneo e atividade muscular sejam constantemente enviadas ao centro de controle cardiovascular.

A atividade simpática tende a estimular a função cardíaca. Sobre o coração, promove aumento do automatismo, da excitabilidade, da condutibilidade e da contratilidade (HURTADO, 2004). Por essas características de estimulação geral das propriedades da fibra cardíaca, essa porção do SNA assume também uma característica pró-arritmogênica. Este aspecto nos remete à importância da avaliação da FAC entre bombeiros, rotineiramente submetidos a situações associadas a grandes descargas simpáticas, seja por estímulos físicos ou emocionais.

Por outro lado, a ação vagal no coração é de natureza depressora, atuando mais intensamente na diminuição da frequência cardíaca e da excitabilidade elétrica do coração. Essa ação confere ao sistema parassimpático uma ação anti-arritmogênica. Por esse motivo, uma ação tônica aumentada do vago sobre o coração pode ser considerada como fator protetor das funções cardiovasculares. Do ponto de vista conceitual, é plausível admitir que a FAC de repouso de bombeiros apresente tanto dominância simpática quanto parassimpática. Por um 
lado, as condições de risco de vida, o estresse térmico, a desidratação relativa e as demandas físicas e emocionais a que bombeiros estão sujeitos diuturnamente se associam com uma importante ativação simpática (SMITH et al., 2013; VON HEIMBURG; RASMUSSEN; MEDBO, 2006; SMITH et al., 1996). Por outro lado, o treinamento físico sistemático pode levar a adaptações funcionais, tais como o aumento da ACR e a bradicardia de repouso, relativa e/ou absoluta (KANNEL et al., 1987; CORNELISSEN et al., 2010), compatíveis com o predomínio vagal (CORNELISSEN et al., 2010; MACIEL et al., 1985; ROUTLEDGE et al., 2010).

Tais condições, ou seja, atividade profissional estressante, com simultâneo preparo físico sistemático, justificam sobremaneira a necessidade de caracterização da função autonômica em bombeiros. Destaca-se, ademais, a escassez de estudos publicados até o momento com caracterização da FAC desta categoria tão singular de trabalhadores, a despeito da depressão da FAC fazer parte do espectro de potenciais fatores de risco cardiovascular associados à profissão (CHOI et al., 2014).

Neste contexto, a FAC desempenha um papel importante na regulação dos processos fisiológicos do organismo humano tanto em condições normais quanto patológicas. Dentre as técnicas utilizadas para sua avaliação, a variabilidade da frequência cardíaca (VFC) aparece como uma medida simples e não-invasiva dos impulsos autonômicos, caracterizando-se como importante marcador do balanço vago-simpático (TASK FORCE, 1996). A premissa da avaliação da VFC é o estudo do ritmo cardíaco. Seja por meio do eletrocardiograma ou de frequencímetros, mede-se o intervalo de tempo entre ondas $\mathrm{R}$ consecutivas que correspondem à contração dos ventrículos, ou seja, mede-se o intervalo R-R (iRR) (PORTO; JUNQUEIRA JÚNIOR, 2009). Assim, a análise da VFC se baseia em uma série temporal de iRR que flutuam batimento a batimento em seres humanos por meio de disparos fisiológicos do nódulo sinusal.

Em situações de repouso, seja supino ou ortostático, a VFC é gerada mediada principalmente por alterações momento a momento da respiração e da pressão arterial. Estas modulações periódicas podem ser avaliadas no domínio do tempo e/ou da frequência espectral (TASK FORCE, 1996; MALLIANI et al.,1991).

A frequência cardíaca aumenta e diminui durante a inspiração e expiração, respectivamente. Isto é provocado principalmente por uma questão fisiológica, em que a saída parassimpática para o centro cardiovascular é inibida durante a inspiração. (HIRSCH; BISHOP, 1981). 
A análise temporal da VFC baseia-se em índices estatísticos comuns de séries de intervalos R-R registradas continuamente em determinado período de tempo (Figura 5). São exemplos de índices temporais utilizados em registros de curta duração: a média e mediana dos intervalos R-R; o desvio padrão dos intervalos $\mathrm{R}-\mathrm{R}$, que fornece estimativa da variabilidade total; o coeficiente de variação, que é a razão entre o desvio padrão e a média, usado para se verificar mudanças na variabilidade independentemente de mudanças na média dos intervalos R-R; o número de intervalos R-R com diferença superior a $50 \mathrm{~ms}$ do intervalo imediatamente anterior e o percentual de intervalos com diferença maior que $50 \mathrm{~ms}$ (pNN50) (KLEIGER et al., 1995).

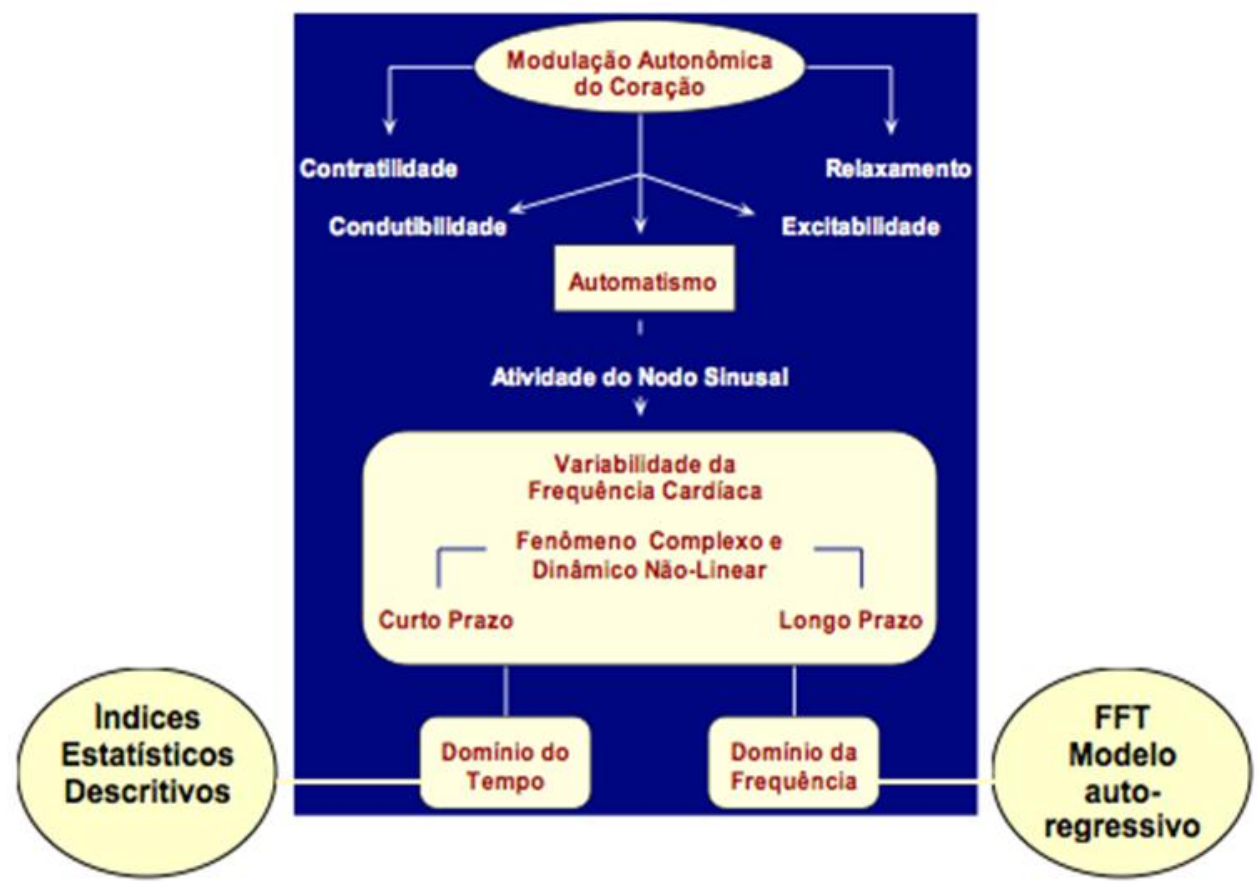

Figura 5 - Esquema da modulação autonômica sobre o coração e as possibilidades de análise da variabilidade da frequência cardíaca, tanto no domínio do tempo quanto da frequência espectral Fonte: JUNQUEIRA JÚNIOR (Adaptação de aula não publicada)

A indicação gráfica dos valores obtidos dos intervalos R-R em função do tempo caracteriza o periodograma. Esses registros podem ser obtidos em curta duração (até cerca de 5 minutos), ou em longa duração (24 horas). Visando padronização metodológica e para evitar possíveis prejuízos de registros muito curtos, a força tarefa citada anteriormente recomenda que os registros de curto prazo tenham pelo menos 5 minutos de duração (TASK FORCE, 1996).

A análise espectral da função autonômica cardíaca fornece também, a exemplo da análise no domínio do tempo, uma série de índices, como área espectral total, área espectral 
absoluta de cada uma das faixas de frequências espectrais, área espectral relativa de cada uma das faixas de frequências espectrais, área espectral normalizada das bandas de baixa e alta frequências espectrais e a razão entre as áreas absolutas das faixas de baixa e de alta frequências espectrais, que traduz o balanço autonômico vago-simpático (TASK FORCE, 1996). A Figura 5 ilustra um esquema da ação integrada da modulação autonômica sobre o coração, bem como de possibilidades de sua avaliação por meio da análise da variabilidade da frequência cardíaca.

\subsection{Estresse Cardiovascular}

Contrariamente às preocupações comuns, a maior parte da mortalidade em serviço dos bombeiros não está relacionada com a queimadura, trauma ou inalação de fumaça, mas com a doença cardiovascular, em grande parte associada à doença cardíaca coronariana (KALES et al., 2007). A mortalidade cardiovascular em serviço é particularmente elevada nos bombeiros em comparação com outros profissionais que também atuam em condições limites, como policiais e pessoal de serviços médicos de emergência (FRANKE; ANDERSON, 1994). Presumivelmente, a combinação de tensões físicas e psicológicas com condições ambientais perigosas produz uma singularidade de combate a incêndios que pode desencadear eventos cardiovasculares em indivíduos susceptíveis (SOTERIADES et al., 2011). Portanto, essa singularidade deve ser levada em consideração nas análises epidemiológicas e fisiopatológicas (MELIUS, 2001). No contexto fisiopatológico, deve-se considerar que muitas das atividades relacionadas ao trabalho dos bombeiros necessitam de ajustes constantes do sistema cardiovascular em que a função autonômica cardíaca (FAC) desempenha um papel importante (JUNQUEIRA JÚNIOR, 2008). Conforme comentado, a hiperatividade simpática e uma atividade parassimpática deficiente são arritmogênicas e associadas à morte súbita cardíaca (FUKUDA et al., 2015).

Ao operar em estrutura de incêndios, os bombeiros realizam trabalho físico extenuante, adotam vestimenta extremamente pesada, com equipamento isolante de proteção individual. Em muitas ocasiões, o trabalho deve ser realizado em ambiente quente e sob condições estressantes. Como resultado da combinação do trabalho pesado e das condições ambientais hostis, tem-se uma resultante de tensão fisiológica significativa, que afeta quase todos os sistemas do corpo. O esforço cardiovascular e o estresse térmico, no entanto, representam o maior risco para o bombeiro (SMITH et al., 2016a; SOTERIADES et al., 2011) 
Diante das atividades desenvolvidas por esses profissionais ser estressora, estudos demonstram que boa parte dessa categoria apresenta cardiomegalia (aumento de tamanho e volume do coração) e/ou HVE (espessura aumentada da parede ventricular), que são, em muitos casos, anormalidades estruturais associadas a Morte Súbita Cardíaca (MSC). Apesar dessas condições ainda representarem um desafio de diagnóstico entre bombeiros, sua elevada prevalência em bombeiros falecidos em serviço por causa não cardíaca evidencia a extensão do problema nesta categoria profissional (KORRE et al., 2016a; 2016b). A hipertrofia ventricular esquerda apresenta-se como um poderoso preditor de morbidade e mortalidade cardiovascular em estudos de base populacional. O risco de morte súbita é aproximadamente seis vezes maior para homens com HVE do que os homens sem HVE, detectada por eletrocardiograma (SMITH et. al., 2016a).

Além disso, uma forte associação graduada entre a massa ventricular esquerda e aumento do risco cardiovascular foi demonstrado. Vários estudos confirmaram que o risco aumentado associado com HVE é independente de outros fatores, tais como idade, sexo, tabagismo, diabetes e colesterol sérico e têm demonstrado a associação progressiva entre o aumento da massa ventricular esquerda e morbidade e mortalidade cardiovascular (KALES et al., 2003). Na maioria dos casos, a HVE é tipicamente um resultado da hipertensão e / ou doença coronária. Na ausência de hipertensão ou doença coronária, a principal causa de HVE é cardiomiopatia, que muitas vezes carrega um maior risco de MSC. Embora os mecanismos exatos através dos quais a HVE causa morbidade e mortalidade cardiovascular não estejam completamente compreendidos, trabalho recente indicou que a fibrose do miocárdio desempenha um papel importante. A hipertrofia ventricular esquerda é frequentemente associada a arritmias fatais e provavelmente contribui para a fisiopatologia da MSC quando presente (DURAND et al., 2011).

Embora há muito tenha sido reconhecido que as pessoas que morrem de DAC tendem a ter corações mais pesados do que aqueles que morrem de causas não-cardíacas (CARTER et al., 2007), a prevalência e relevância de cardiomegalia / HVE têm recebido muito menos atenção do que a presença de aterosclerose e estenose. Em um estudo retrospectivocom adultos que morreram de MSC, as mortes foram atribuídas à cardiomegalia/HVE, doença coronariana, ou ambos (SYTKOWSKI et al.,1996). Este estudo concluiu que cardiomegalia / HVE é uma causa frequente de MSC no público em geral e é altamente associada à obesidade e morte em uma idade mais jovem do que MSC. Uma revisão de mortes de combate a incêndios em serviço também documentou que cerca de $60 \%$ das vítimas tinham evidência de 
HVE / cardiomegalia na autópsia (GOLDBERG, et al., 2001). Estudo recente também evidenciou proporções de cardiomegalia entre bombeiros que faleceram por causas não cardíacas variando entre 33-56\% entre diferentes faixas etárias ou categorias de IMC, quando se usou o ponto de corte de parede ventricular $>=1,2 \mathrm{~cm}$ (KORRE et al., 2016a).

Assim, tanto a doença cardíaca aterosclerótica quanto e a hipertrofia ventricular esquerda/cardiomegalia são substratos importantes que aumentam significativamente o risco de morte súbita cardíaca. São necessárias pesquisas adicionais para entender o risco associado a um determinado nível de carga aterosclerótica, cardiomegalia, ou hipertrofia ventricular esquerda. Além disso, a investigação é necessária para identificar quando e como os bombeiros devem ser rastreados para estas condições e qual o papel da disfunção autonômica cardíaca nos mecanismos desencadeadores de MSC.

É evidente que atividades de combate a incêndios envolvem estimulação simpática, principalmente pelo trabalho extenuante e as condições ambientais adversas que podem levar à hipertermia e desidratação, com considerável esforço cardiovascular associado aos bombeiros. O modelo teórico proposto no artigo é baseado em diversas linhas de evidência, incluindo estudos fisiológicos de bombeiros em situações de emergência extenuantes, estudos epidemiológicos que ligam doença cardiovascular risco de evento a tipos específicos de direito, bem como os dados da autópsia confirmam a presença de doença cardíaca subjacente em quase todas as vítimas. O modelo sugere que, em indivíduos susceptíveis com doença cardíaca estrutural subjacente (na maioria das vezes de CHD e HVE), a estirpe cardiovascular associado com combate a incêndios pode desencadear um evento cardíaco súbito através de várias vias biológicas. Os aumentos na tensão de corte podem provocar a ruptura da placa vulnerável, resultando em oclusão das artérias coronárias, e isso pode ser exacerbado por hipercoagulação, o que aumenta o risco de acontecimentos trombóticos. A isquemia (devido a um aumento na demanda de oxigênio do miocárdio) pode exceder a procura do miocárdio, resultante de disfunção elétrica, mecânica e bioquímica do músculo cardíaco, precipitando arritmias fatais. Mudanças nos eletrólitos e exposição a condições ambientais (tais como gases tóxicos e de partículas na fumaça) também podem aumentar a suscetibilidade a arritmias (KALES; CHRISTIANI, 2004),

A outra análise consiste nas respostas fisiológicas para combate a incêndios, a fim de compreender melhor a mecânica pela qual o estresse pode precipitar um evento cardíaco repentino. Estudos desse tipo têm claramente documentado o fato de que o combate a incêndios é muito estressante para o corpo e leva a várias alterações fisiológicas que podem 
causar eventos cardíacos súbitos em indivíduos vulneráveis (VON HEIMBURG et al., 2006; SMITH et al., 1996).

O esforço cardiovascular da atividade de combate a incêndio, leva a um rápido aumento da frequência cardíaca iniciada pela excitação fisiológica simpática, o sinal de alarme de incêndio na unidade operacional. Subsequentemente, as frequências cardíacas máximas ou quase máximas são alcançadas durante as atividades de combate a incêndios fisicamente extenuantes. Talvez de maior importância funcional, uma redução no volume de AVC após a atividade de combate a incêndios. Uma redução de $35 \%$ no volume de acidente vascular cerebral (usando ecocardiografia Doppler) após uma atividade de combate a incêndio de curto prazo (HOLDER et al., 2006). Redução no volume plasmático (-14,8\%) após 18 min de combate a incêndio. Hipovolemia prejudica a função cardíaca e aumenta a viscosidade do sangue. Especificamente, constata-se um aumento no número e função das plaquetas e alterações no tempo parcial de tromboplastina e nos níveis de fibrinogênio após atividades de combate a incêndio de curto prazo (MELIUS et al., 2001). Estas alterações sugerem um estado pró-coagulatório que pode aumentar o risco de formação de trombos.

\subsection{Prevalência de Doenças Crônicas Não Transmissíveis em Bombeiros: Impactos no Risco Cardiovascular Global}

Apesar da natureza extenuante do serviço de emergência, a prevalência de baixa aptidão, obesidade e outros fatores de risco para doenças cardiovasculares têm acometido os bombeiros.

\subsubsection{Hipertensão}

Hipertensão é um preditor independente de condições externas, com resultados adversos na atividade laboral, gerando aposentadorias por incapacidade devido a doenças hipertensivas, infarto em serviço, dentre outros. As evidências sugerem que os riscos associados à hipertensão estão concentrados entre indivíduos com descontrole da pressão arterial. Um aumento de aproximadamente três vezes em resultados adversos foi atribuído para bombeiros com hipertensão estágio 2 que não faziam uso de anti-hipertensivo (KALES et al., 2003). 


\subsubsection{Obesidade}

A prevalência de obesidade entre bombeiros tem aumentado de forma constante ao longo do tempo, vislumbrando-se uma epidemia da doença. Atualmente, cerca de $40 \%$ dos bombeiros americanos estão obesos. Na década de 1980 e início de 1990, o veterano médio possuía um IMC de 25,4 a 26,7 kg/m² e 1996-1997, a média de IMC aumentou para quase 29 $\mathrm{kg} / \mathrm{m}^{2}$, e em 2001, foi de $29,7 \mathrm{~kg} / \mathrm{m}^{2}$. Hoje, estudos demonstram que mesmo bombeiros muito mais jovens apresentam elevados valores de IMC, como no estudo que avaliou bombeiros com média de 26 anos e que apresentaram IMC médio de 28,5 kg/m² (POSTON et. al., 2011).

Constata-se, em pesquisa realizada em 2011 com Bombeiros Militares brasileiros que tinham idade média de 39 (22-49) anos e um IMC de 26,6 (16,9-43,8) kg/m², que $8(0,2 \%)$ dos voluntários estavam abaixo do peso, 1.306 (30,8\%) possuíam peso normal, 2.301 (54,3\%) foram classificados como excesso de peso, e 622 (14,7\%) eram obesos, de acordo com a classificação do IMC (NOGUEIRA et al., 2016).

Apesar da forte evidência de efeitos negativos da obesidade, atualmente não há diretrizes ocupacionais para a obesidade, como uma condição limitadora para o serviço ativo entre os bombeiros, sendo que médicos devem avaliar objetivamente o status de peso com IMC, circunferência de cintura, bem como medidas de gordura corporal caso a caso.

Acresce-se ao fato de muitos bombeiros têm equivocadas percepções de seu peso e não foram adequadamente instruídos pelos profissionais de saúde a respeito, com as respectivas orientações para a perda de peso com base em exercícios, dieta e higiene do sono como medidas de primeira linha (TZIOMALOS et al., 2010; SNOW et al., 2005).

Além do fator de risco obesidade, estudo recente evidenciou forte associação entre uma composição corporal inadequada, avaliada por diferentes indicadores, e a baixa aptidão cardiorrespiratória, que é outro fator de risco cardiovascular entre bombeiros (NOGUEIRA et al., 2016)

\subsubsection{Diabetes mellitus}

A prevalência de diabetes mellitus tipo 2 (DM 2) entre bombeiros, sucumbindo a eventos coronarianos em serviço e aposentadorias por doença coronariana é muito elevada: $21 \%$ e $26 \%$, respectivamente. A DM 2 está associada a um risco de 10 a 13 vezes maior de morte por doença coronária em serviço ou aposentadoria (HOLDER et al., 2004; KALES et al., 2003). No entanto, após o ajuste multivariado, a DM 2 não é um preditor independente 
significativo em estudos retrospectivos. Assim, a DM 2 está associada a riscos e provavelmente mediada através de efeitos simultâneos sobre a pressão sanguínea, o metabolismo lipídico e doença aterosclerótica previamente estabelecida.

Feitas as considerações de ordem teórica, passa-se à apresentação dos materiais e métodos empregados nesta pesquisa. 


\section{MATERIAIS E MÉTODOS}

\subsection{Aspectos Metodológicos Gerais}

Trata-se de um estudo transversal analítico, com seleção da amostra por conveniência, entre membros do Corpo de Bombeiros Militar do Distrito Federal (BASTOS; DUQUIA, 2007).

Para a realização da pesquisa, estabeleceu-se contato prévio com os quartéis no intuito de identificar a viabilidade do estudo nas unidades operacionais específicas e os potenciais voluntários para o estudo. A seleção dos voluntários limitou-se entre aqueles em pleno exercício de suas funções no CBMDF e que atendiam aos critérios de inclusão e exclusão abaixo descritos. As avaliações ocorreram nas dependências do Laboratório de Cardiologia da UnB e nos quartéis do CBMDF onde os voluntários desempenham suas funções.

A pesquisa foi aprovada pelo Comitê de Ética em Pesquisa em Seres Humanos da Faculdade de Ciências da Saúde desta Universidade (CEP-FS-UnB-CAAE: 16473613.9.0000.0030), e todos os participantes assinaram um Termo de Consentimento Livre e Esclarecido.

\subsection{Indivíduos Avaliados}

A amostra foi constituída de 30 bombeiros do sexo masculino, recrutados por conveniência, do Corpo de Bombeiros Militar do Distrito Federal (CBMDF). Todos voluntários eram bombeiros militares de carreira, com no mínimo dez anos em funções operacionais, sem nenhuma restrição médica para as atividades laborais, com idades entre 28 e 50 anos, não fumantes, normotensos, sem doenças cardiometabólicas conhecidas e sem uso de medicação regular. O tempo médio (extremos) de atividade na corporação foi de 20 anos (15 - 24 anos).

Todos participantes tinham consumo considerado normal de bebidas estimulantes como chá, café, refrigerantes, guaraná em pó e/ou xarope de guaraná. Quanto ao consumo de álcool, todos relataram fazer uso eventual e/ou socialmente.

A mediana da pressão arterial sistólica do grupo, no repouso supino na primeira avaliação, foi de $120 \mathrm{mmHg}$, extremos de 105 e $143 \mathrm{mmHg}$. Na mesma condição, a pressão diastólica variou entre 60 e $100 \mathrm{mmHg}$, com mediana igual a 73,5 mmHg. Para caracterização da frequência cardíaca (FC) de repouso foram considerados os valores aferidos após o 
primeiro minuto de registro em cada condição fisiológica avaliada. A mediana da frequência cardíaca (FC) de repouso foi de 58 bpm, próprio da condição de repouso supino. Os extremos da FC nessa condição foram de 46 e 74 bpm, indicando uma faixa de variação que abrange desde os indivíduos mais bradicárdicos, até aqueles com ritmo cardíaco um pouco mais acelerado. Os valores correspondentes para a frequência respiratória (FR) no repouso foram, mediana de 14,5 cpm, com extremos de 9 e $22 \mathrm{cpm}$. O detalhamento da caracterização da amostra está expresso na Tabela 1.

Tabela 1 - Valores amostrais medianos (min - max) de variáveis de caracterização da amostra

\begin{tabular}{|c|c|c|}
\hline IDADE (anos) & 40,5 & $(35,0-47,0)$ \\
\hline $\operatorname{IMC}\left(\mathrm{kg} / \mathrm{m}^{2}\right)$ & 26,0 & $(18,0-31,8)$ \\
\hline FC (Sup - AVA 1) bpm & 58,0 & $(46,0-74,0)$ \\
\hline PAS (Repouso - AVA 1) mmHg & 120,0 & $(105,0-143,0)$ \\
\hline PAD (Repouso - AVA 1) mmHg & 73,5 & $(60,0-100.0)$ \\
\hline NATF (Inativo) IPAQ & 4 & $13,3 \%$ \\
\hline NATF (Ativo) IPAQ & 26 & $86,7 \%$ \\
\hline FR (cpm) & 14,5 & $(9-22)$ \\
\hline $\mathrm{VO}_{2} \max \left[\mathrm{mL}(\mathrm{kg} \cdot \min )^{-1}\right]$ & 39,9 & $(30,3-49,3)$ \\
\hline $\mathrm{VO}_{2} \max \left[\mathrm{mL}(\mathrm{kg} \cdot \min )^{-1}\right]$ & $<42,0$ & $20(66,7 \%)$ \\
\hline $\mathrm{VO}_{2} \max \left[\mathrm{mL}(\mathrm{kg} \cdot \min )^{-1}\right]$ & $\geq 42,0$ & $10(33,3 \%)$ \\
\hline
\end{tabular}

Min: valor mínimo; max: valor máximo; IMC: índice de massa corporal; FC: frequência cardíaca; PAS: pressão arterial sistólica; PAD: pressão arterial diastólica; NATF: nível de atividade física; IPAQ: questionário internacional de atividade física; FR: frequência respiratória; $\mathrm{VO}_{2}$ max: consumo máximo de oxigênio

\subsection{Critérios de Inclusão e/ou Exclusão de Indivíduos e/ou Registros}

Os critérios de participação aqui estipulados são de natureza variável, uma vez que deveriam atender pressupostos clínico-funcionais e metodológicos, especialmente no que se refere à análise da variabilidade dos intervalos R-R do ECG. Alguns dos critérios de inclusão já foram citados anteriormente, mas julga-se necessário um breve resumo em forma de tópicos a fim de agrupá-los, conforme se expõe no Quadro 2.

A faixa etária e a condição física foram consideradas apenas para efeito de análise, mas não como critério de inclusão, uma vez que se objetiva caracterizar as variáveis nas 
situações reais em que ocorrem. Foram excluídos apenas aqueles que relataram terem impedimento médico ou de outra natureza, para o trabalho.

Quadro 2 - Critérios de inclusão dos voluntários na amostra

\begin{tabular}{|l|l|}
\hline \multicolumn{1}{|c|}{ CRITÉRIO } & \multicolumn{1}{c|}{ LIMITE } \\
\hline Tempo de serviço & Tempo mínimo de serviço10 anos \\
\hline Condição física & Apto no teste de aptidão física - TAF \\
\hline Sexo & Masculino \\
\hline Condição clínica & $\begin{array}{l}\text { Compatível com a normalidade em exame clínico-cardiológico e sem } \\
\text { restrição para o desempenho de atividades operacionais }\end{array}$ \\
\hline Ritmo cardíaco & Ritmo sinusal ao longo de todos os registros \\
\hline Frequência respiratória & Superior ou igual a 9 ciclos por minuto \\
\hline Composição corporal & IMC $<30,0 \mathrm{~kg} / \mathrm{m}^{2}$ ou Circunferência de cintura $\leq 102 \mathrm{~cm}$ \\
\hline
\end{tabular}

Os critérios de exclusão são, por definição, representados por condições que não atenderam integralmente os critérios apontados na tabela acima, acrescidos de alguma outra condição que tenha impedido o seguimento completo do protocolo experimental e/ou de análise dos registros. Apresenta-se na Quadro 3 o número de voluntários excluídos, bem como o respectivo motivo.

Quadro 3 - Critérios de exclusão e motivo da exclusão dos voluntários da amostra

\begin{tabular}{|c|c|c|}
\hline CRITÉRIO DE EXCLUSÃO & MOTIVO DA EXCLUSÃO & $\mathbf{N}^{\circ}$ \\
\hline \multirow{6}{*}{$\begin{array}{llr}\text { Condição clínica não-normal e/ou com } \\
\text { potencial interferência na análise da } \\
\text { variabilidade dos intervalos R-R do ECG. }\end{array}$} & $\begin{array}{l}\text { Pressão arterial de repouso compatível com } \\
\text { hipertensão arterial }\end{array}$ & 02 \\
\hline & $\begin{array}{l}\text { Estado emocional alterado no dia da } \\
\text { avaliação }\end{array}$ & 01 \\
\hline & Obesidade & 02 \\
\hline & Uso de medicação & 03 \\
\hline & $\begin{array}{l}\text { Uso de bebida alcoólica e/ou bebidas } \\
\text { estimulantes com menos de } 12 \text { horas da } \\
\text { avaliação }\end{array}$ & 02 \\
\hline & $\begin{array}{l}\text { Alteração no ECG de repouso sugestiva de } \\
\text { condição cardiológica alterada que } \\
\text { demandava investigação futura }\end{array}$ & 02* \\
\hline $\begin{array}{l}\text { Limitação metodológica para a análise da } \\
\text { variabilidade dos intervalos R-R do ECG no } \\
\text { domínio da frequência com as bandas de } \\
\text { frequência fixas }\end{array}$ & $\begin{array}{l}\text { Frequência respiratória menor que } 9 \text { ciclos } \\
\text { por minuto }\end{array}$ & 02 \\
\hline
\end{tabular}

*Ambos os sujeitos foram posteriormente avaliados pelo quadro clínico do CBMDF e um deles transferido para funções administrativas em razão de suas condições clínicas. 
A exclusão de voluntários por questões inerentes à metodologia de análise da variabilidade dos intervalos R-R do ECG deu-se pelo pressuposto teórico-matemático quando do uso da transformada no domínio da frequência, que impõe a necessidade da obtenção de um sinal estacionário, devendo para isso ter origem única.

Em função da aquisição dos intervalos R-R ter sido feita com registro automático pelo frequencímetro Polar, a verificação do ritmo foi feita no traçado de ECG de repouso, bem como por meio da análise do periodograma após os registros. Por rotina do Laboratório Cardiovascular da Faculdade de Medicina da UnB, adota-se a sistemática de exclusão de qualquer traçado que sugira ritmo não-sinual. No presente estudo não houve nenhum caso nessas condições.

No presente estudo foram excluídos ainda todos voluntários que apresentaram frequência respiratória (FR) inferior a $9 \mathrm{cpm}$ frente aos erros de análise que isso implicaria, especialmente na banda de baixa frequência espectral. Nesse particular, observou-se ponderações feitas em publicação anterior (BROWN et al., 1993). Dois voluntários foram excluídos da análise por esta razão.

\subsection{Procedimentos de Coleta de Dados}

Os voluntários foram convidados, em suas unidades operacionais, para participarem da pesquisa, sendo as avaliações divididas em três etapas, a saber: Avaliação 1 (AVA 1), realizada em ambiente laboratorial controlado (Laboratório de Cardiologia da Faculdade de Medicina da UnB); Avaliação 2 (AVA 2), realizada antes do início de um turno diurno rotineiro de trabalho. AVA 2 ocorreu nas unidades operacionais (quartéis), porém antes de iniciar qualquer atividade profissional e respeitando-se um mínimo de 12 horas anteriores sem qualquer atividade física e um período mínimo de 24 horas sem atividades físicas vigorosas. Ao final do turno diurno de aproximadamente $12 \mathrm{~h}$ de atividade operacional, realizou-se a terceira avaliação (AVA3) no mesmo ambiente da AVA2. Objetivou-se realizar as avaliações nos quartéis (AVA2 e AVA3) com o menor intervalo possível após AVA1, respeitando-se a disponibilidade do voluntários e as limitações de serviço. O intervalo mediano foi de 12 dias, com extremos de 2 e 130 dias. Apenas 10\% dos voluntários tiveram intervalo entre as avaliações superior a 60 dias. Os períodos de monitoração da sobrecarga cardiovascular durante atividade laboral rotineira, que correspondem aos intervalos entre AVA2 e AVA3 variaram entre 6 a 12 horas, com valor mediano de 10h 38min. Apenas 2 voluntários (7\%) 
tiveram menos de $9 \mathrm{~h}$ de monitoramento. A Figura 6 ilustra as principais etapas do protocolo experimental.

Após a marcação da data da avaliação inicial, todos os voluntários foram orientados a não consumirem bebidas estimulantes (chá, café, refrigerantes, guaraná em pó e xarope de guaraná), nem bebidas alcoólicas, por um período mínimo de 12 horas anteriores aos testes. Foi solicitado um período de sono na noite anterior ao dia do teste de pelo menos 6 horas. O não cumprimento desse último quesito era motivo de remarcação de algumas avaliações. Os indivíduos sempre foram orientados a fazer sua refeição matinal normalmente, restringindo apenas o consumo das bebidas já citadas.

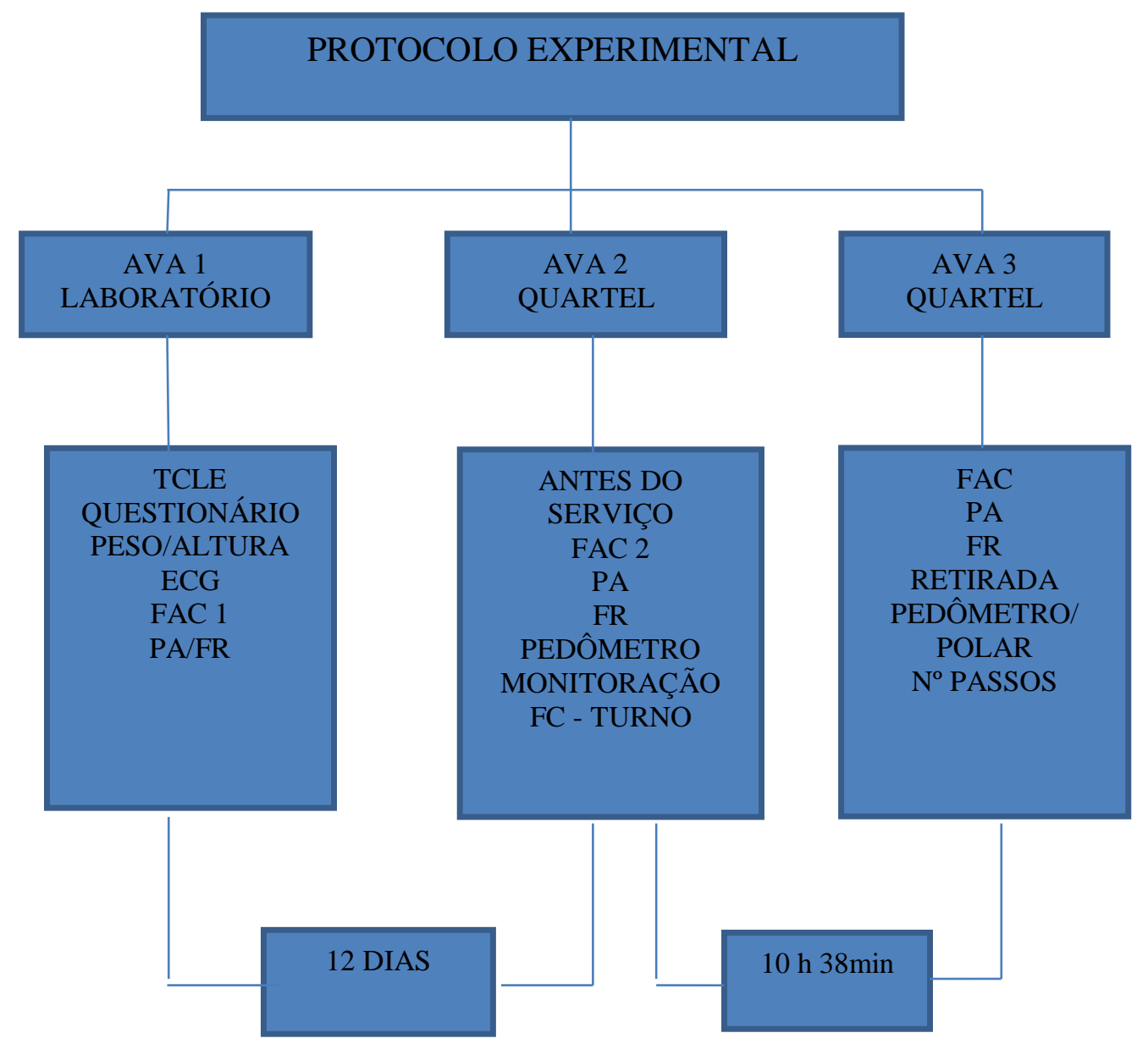

Figura 6 - Protocolo experimental

No momento de AVA1, após assinarem o TCLE (Figura 7), todos os voluntários responderam a uma anamnese, que consistia de questionamentos sobre dados pessoais, profissão, uso de medicamentos, condição física, presença de doenças anteriores, história familiar e outros fatores de risco para doenças crônico-degenerativas, além de hábitos de vida 
como tabagismo, consumo de bebidas alcoólicas e bebidas estimulantes (chá, café, refrigerantes, guaraná em pó e xarope de guaraná).

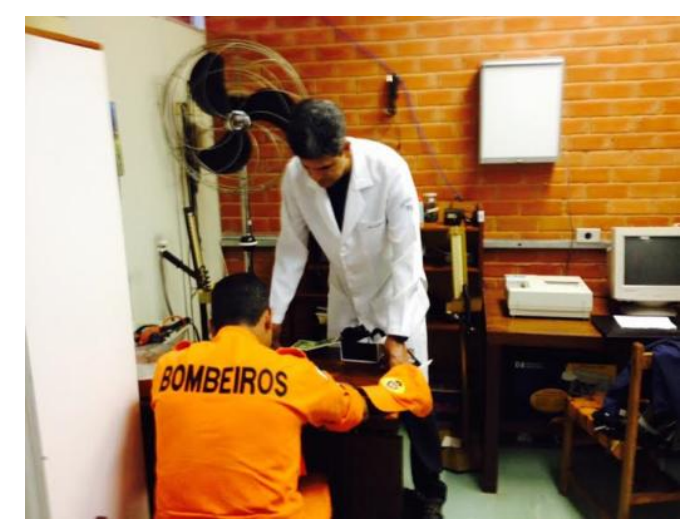

Figura 7 - Assinatura do TCLE por bombeiro militar participante da pesquisa

Essas características, assim como informações com finalidade de estratificação de risco, foram obtidas por meio de questionário adaptado do formulário de estratificação de risco de 2006 do Colégio Americano de Medicina Desportiva (ACSM). Não houve nenhuma contraindicação à realização da avaliação, no protocolo aqui usado, entre os voluntários que atendiam aos critérios de inclusão.

Sequencialmente, os voluntários preencheram um conjunto de questionários que compreendia: 1) o Questionário Internacional de Atividade Física (IPAQ) para classificação do nível atual de atividade física; 2) questionário sobre tempo sentado, adaptado de Kartzmarzik (2009); o questionário da Organização Mundial da Saúde sobre Qualidade de Vida - WHOQOL (FLECK et al., 2000) e o questionário de auto-relato de atividade física que estima o consumo máximo de oxigênio (JACKSON et al, 1990). Na sequência foram submetidos a avaliação da massa corporal e da estatura (descalços e sem blusa), utilizando-se balança analógica, da marca Filizola - modelo 31, com estadiômetro acoplado. Com exceção da estimativa do consumo de oxigênio, as informações colhidas por esses questionários visavam essencialmente caracterizar a amostra quanto ao nível de atividade física, o tempo sentado e a qualidade de vida, mas não foram critério de análise.

Antes de iniciar os registros dos testes de avaliação da função autonômica cardíaca, foram registrados os traçados eletrocardiográficos de repouso em 12 derivações para caracterização da normalidade da amostra. Ainda, todos voluntários estavam em pleno exercício de atividades operacionais, com exames periódicos em dia no CBMDF, atestando não haver qualquer restrição clínico-cardiológica para o exercício profissional. 
Após a seleção, os participantes foram submetidos às avaliações e aos testes de avaliação da Função Autonômica Cardíaca (FAC), conforme detalhamento a seguir.

\subsection{Instrumentos de Medida e Avaliação}

\subsubsection{Avaliação da atividade física e do tempo sentado}

Quanto ao nível de atividade física, além do IPAQ, empregou-se também o pedômetro para avaliação da atividade física durante o turno de trabalho. A quantificação do número de passos foi introduzida com vistas à verificação da atividade física global, no sentido de avaliar quanto um turno de trabalho diurno contribui para o alcance da recomendação mínima de passos diários, qual seja, 10.000. Várias evidências apresentam diferentes indicadores de saúde associados à atividade física, mensurados pelo pedômetro. Dentre os estudos, evidenciam-se importantes parâmetros entre o número de passos/dia com obesidade, hipertensão, síndrome metabólica, doenças cardiovasculares, diabetes mellitus e outros (ARAIZA et al., 2006; ALBRIGHT; THOMPSON, 2006; BJORGASS et al., 2006; SONE et al., 2002; IWANE et al., 2000).

No mesmo dia da segunda avaliação da FAC, ou seja, no início da jornada de trabalho em análise (AVA2), os voluntários foram solicitados a iniciar o uso do pedômetro, para quantificação da atividade física, ou seja, a quantidade de passos realizados durante o plantão (Figura 8).

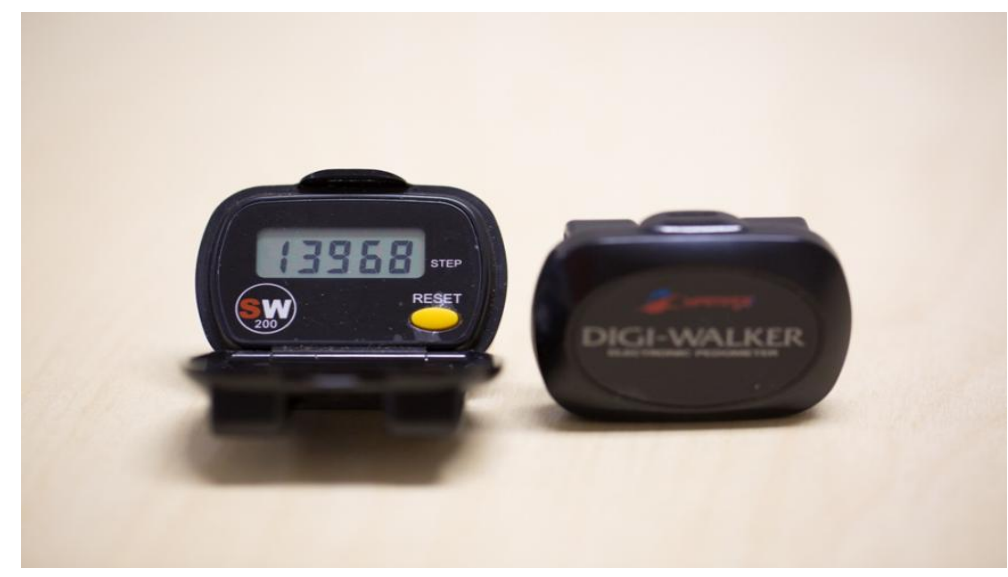

Figura 8 - Modelo de pedômetro usado no estudo 
O pedômetro é um instrumento que mensura a atividade física relacionada com o deslocamento a pé, registando o número de passos acumulados. O pedômetro Yamax DigiWalker é um sensor de movimento com mecanismos de funcionamento muito simples e de baixo custo. A sua utilização é prática, sendo colocado na altura do quadril, preso à roupa, próximo à crista ilíaca.

O equipamento é considerado como padrão ouro dentre os diferentes tipos disponíveis no mercado, indicados e empregados em pesquisas científicas (CHAN et al., 2003; MCCORMACK; GILES-CORTI; MILLIGAN, 2006; WELK et al., 2000; BASSETT et al., 2000). A validação quanto à precisão na detecção e adequada quantificação do número de passos é feita tradicionalmente em ambiente de laboratório ou em atividades de campo. Nesse tipo de validação os modelos da marca Yamax Digi-Walker são validados e considerados como aqueles que sistematicamente apresentam as melhores acurácias (CROUTER et. al., 2003).

Os pedômetros foram utilizados durante todo o turno de trabalho monitorado. Os voluntários foram previamente instruídos quanto ao uso, posicionamento e foram orientados a não instituírem nenhuma mudança em suas rotinas em decorrência da participação na pesquisa.

Paralelamente à monitoração da ATF espontânea por meio do registro de passos durante o turno e a avaliação do nível de ATF global pelo IPAQ, avaliou-se também a estimativa de tempo sentado (TS), como marcador do comportamento sedentário. O TS foi avaliado por meio de questionário adaptado de Katzmarzyk et al. (2009), no qual o voluntário identifica seu padrão de TS em cinco possíveis categorias: menor parte do dia sentado; cerca de $1 / 4$ do tempo, cerca da metade do tempo; $3 / 4$ do tempo sentado ou a maior parte do dia na posição sentada.

\subsubsection{Avaliação da qualidade vida}

A qualidade de vida foi avaliada pelo questionário da Organização Mundial da Saúde (WHOQOL-Bref), que é um instrumento composto por 26 questões que averiguam a qualidade de vida em quatro domínios: físico, psicológico, social, ambiental. (FLECK et al., 2000). Os domínios e facetas do WHOQOL-bref são: 
Domínio 1 - Físico: 1- Dor e desconforto; 2- Energia e fadiga; 3- Sono e repouso; 9Mobilidade; 10- Atividades da vida cotidiana; 11- Dependência de medicação ou de tratamentos; 12- Capacidade de trabalho.

Domínio 2 - Psicológico: 4- Sentimentos positivos; 5- Pensar, aprender, memória e concentração; 6- Autoestima; 7- Imagem corporal e aparência; 8- Sentimentos negativos; 24Espiritualidade, religião, crenças pessoais.

Domínio 3 - Relações Sociais: 13- Relações pessoais; 14- Suporte (apoio) social; 15Atividade sexual.

Domínio 4 - Meio Ambiente: 16- Segurança física e proteção; 17- Ambiente do lar; 18- Recursos financeiros; 19- Cuidados de saúde e sociais: disponibilidade e qualidade; 20Oportunidade de adquirir novas informações e habilidades; 21- Participação em e oportunidade de recreação / lazer; 22- Ambiente físico (poluição / ruído/ trânsito/ clima); 23 Transporte.

O WHOQOL fornece um escore de 0-100 pontos, sendo $100 \mathrm{o}$ valor que indica melhor qualidade de vida. Não existem pontos de corte padronizados para se classificar os respondentes quando ao nível de qualidade de vida. A alternativa de interpretação é baseada no percentual atingido em relação ao máximo possível.

\subsubsection{Avaliação da Função Autonômica Cardíaca}

Após completarem o preenchimento dos questionários, os voluntário foram medidos quanto ao peso e à altura e realizaram o teste de função autonômica cardíaca. Após a obtenção dos dados, iniciou-se o procedimento de avaliação da FAC, por meio da análise da variabilidade da frequência cardíaca, conforme a sequência a seguir.

A primeira posição avaliada foi a supina (Figura 9). Para avaliar a função autonômica cardíaca, os voluntários foram deitados em um ambiente calmo e com temperatura controlada (Laboratório Cardiovascular da Faculdade de Medicina da Universidade de Brasília). O voluntário foi instruído a permanecer cinco minutos em repouso nessa posição, com o objetivo de adaptar seu corpo e deixá-lo o mais próximo possível do repouso basal.

Ao término desse período a pressão arterial foi aferida, seguindo as diretrizes da Sociedade Brasileira de Cardiologia (SBC - 2010). Iniciou-se, então, um período de mais cinco minutos em repouso supino para registro das séries de intervalos $\mathrm{R}-\mathrm{R}$, com base no frequencímetro da marca Polar®, fabricado pela Polar (V 800 - Finlândia) (Figura 9). 
Após os primeiros 90 segundos, a frequência respiratória (FR) foi aferida, com vistas a excluir voluntários que apresentassem menos de 9 ciclos por minuto. Ao final dos cinco minutos foi interrompida a marcação e o voluntário foi orientado a se levantar, para que uma marcação na posição ortostática pudesse ser feita.

Na posição ortostática, ou seja, em pé, foram contados dois minutos para a adaptação do indivíduo, momento em que a PA era aferida, com vistas à avaliação de eventual hipotensão postural (Figura 10). Iniciou-se, então, novo registro com o Polar V 800, para aquisição de nova série de intervalos R-R. Após os 90 segundos iniciais nessa postura a FR era novamente avaliada. Ao fim dos cinco minutos na posição ortostática, o frequencímetro foi novamente interrompido e, assim, terminada a coleta.

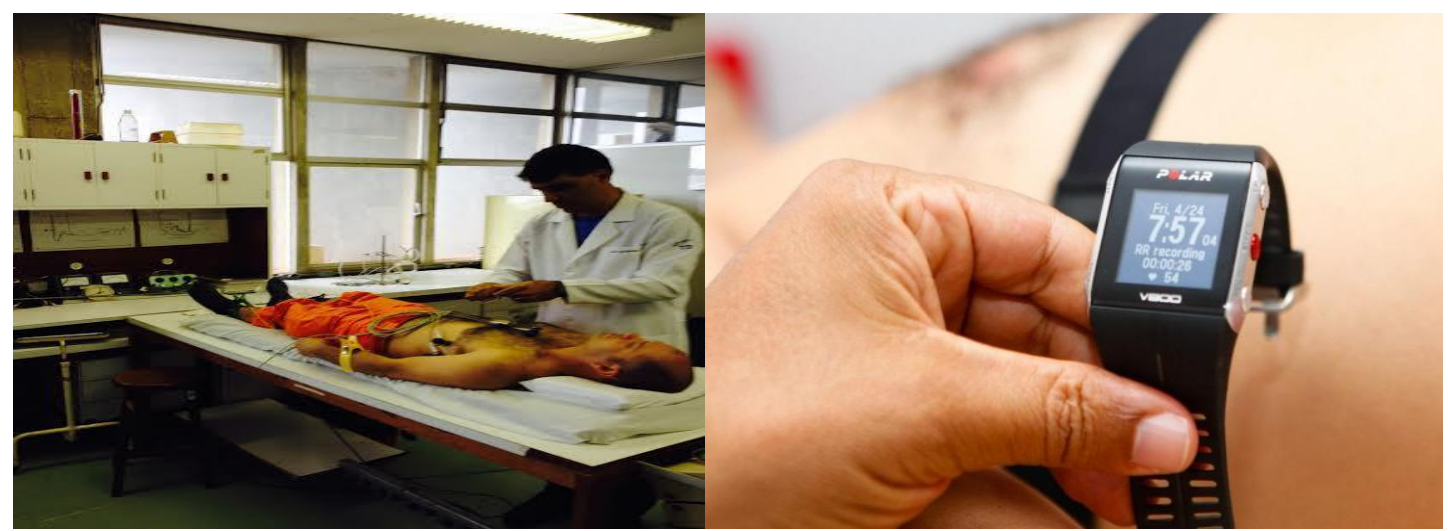

Figura 9 - Registro da série temporal dos intervalos R-R para avaliação da VFC na posição supino

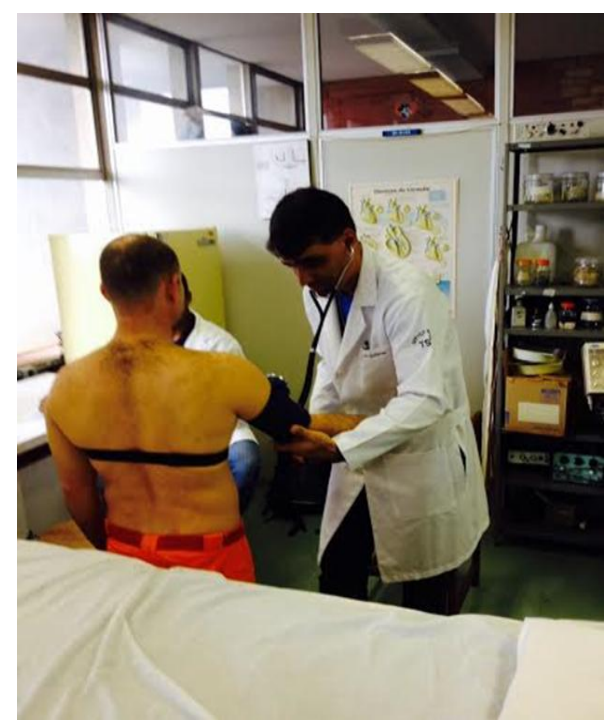

Figura 10 - Registro da série temporal dos intervalos R-R para avaliação da VFC na posição ortostáticaO registro das séries de intervalos R-R para análise temporal e espectral da 
variabilidade da frequência cardíaca foi feito também nos quartéis, no início dos plantões, antes de atendimentos externos no período matutino, entre 8 e 12 horas, seguindo-se o mesmo protocolo do registro em laboratório. Essa segunda avaliação teve por objetivo permitir a análise dos possíveis efeitos de um turno diurno de trabalho sobre a FAC.

Durante a execução dos testes de avaliação autonômica, os participantes foram orientados a não dormir, evitar alterações conscientes no ritmo respiratório (inspirações profundas), não falar (exceção à situação em que eventualmente estivessem se sentido mal por qualquer motivo) e para se manterem o mais relaxados possível.

A variabilidade da frequência cardíaca fora analisada por meio do registro dos intervalos R-R do ECG, com uso do frequencímetro da marca Polar®, modelo V-800, fabricado pela Polar - Finlândia. A escolha pelo registro das séries temporais dos intervalos RR do ECG por meio desse aparelho foi feita em razão de ser um instrumento anteriormente validado como alternativa aceita para esse fim, bem como por sua facilidade de operação (PORTO; JUNQUEIRA JÚNIOR, 2009).

Os critérios adotados antes do início dos registros, em relação ao uso do frequencímetro, foram:

a. Centralizar a correia rígida ao tórax, a fim de facilitar a captação dos impulsos elétricos do coração (Figura 11);

b. Ajustar a correia ao diâmetro do tórax de cada indivíduo, de modo que ficasse bem ajustada, sem causar desconforto ao voluntário ou dificuldade do movimento respiratório;

c. Umedecer a fita na parte mais rígida para facilitar a captação do sinal da frequência cardíaca.

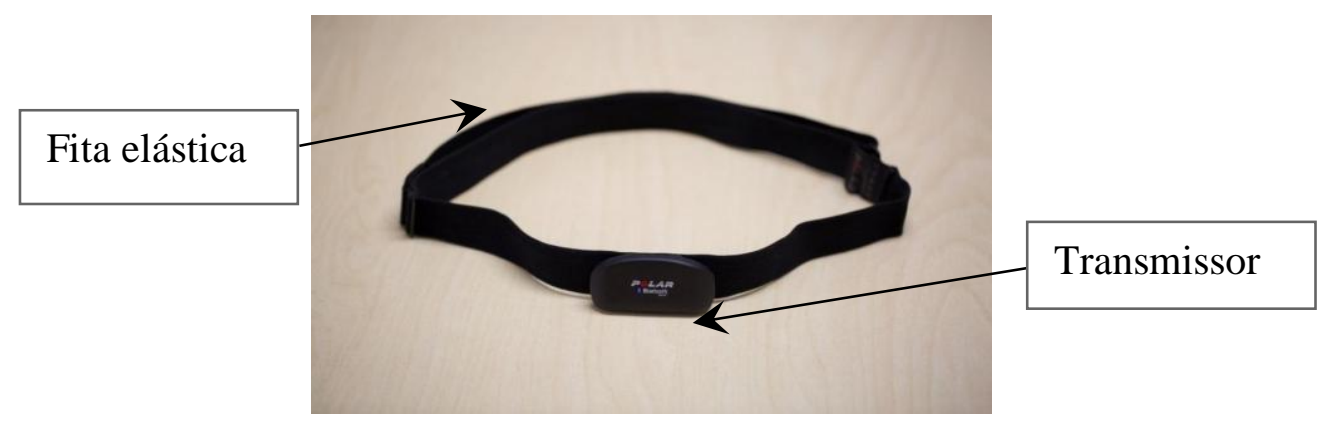

Figura 11 - Correia fixa que capta e transmite os intervalos R-R do ECG para o receptor, acoplada a uma correia elástica para colocação do aparelho em volta do tórax. 
Após a obtenção das séries individuais de intervalos R-R do ECG, houve o processamento dos dados para obtenção dos índices temporais e espectrais da variabilidade da frequência cardíaca por meio do software ECGLAB, desenvolvido no Laboratório Cardiovascular da Faculdade de Medicina, em parceria com o Departamento de Engenharia Elétrica, ambos da Universidade de Brasília (CARVALHO et al. 2002), tendo como base a série temporal de intervalos R-R do ECG, obtida automaticamente por meio do frequencímetro Polar®.

Também procedeu-se à avaliação da pressão arterial (PA) antes do início e término dos plantões avaliados, tanto na posição supina quanto ortostática, com aparelho automático (Microlife $®)$.

Para a avaliação da sobrecarga cardiovascular associada à jornada de trabalho, os voluntários foram orientados a usar o frequencímetro (Polar $\mathrm{V}$ 800) durante o turno de trabalho (Figura 12). O frequencímetro foi programado para registrar a frequência cardíaca (FC) a cada 5 segundos, para posterior análise. A sobrecarga cardiovascular foi avaliada, considerando-se a faixa de intensidade relativa da $\mathrm{FC}$, em relação à $\mathrm{FC}$ máxima prevista para a idade. Os registros foram armazenados no monitor cardíaco, para posterior transferência dos dados por meio do Polar Interface, que armazena os dados "online" no site da própria Polar, permitindo acesso remoto e posterior análise. Foram avaliados os tempos absolutos e relativos de permanência em quatro zonas de intensidade em relação a valores de FC máxima prevista para a idade (220 - idade). Assim, adotaram-se as seguintes zonas de intensidade: leve (>64\% FCmax) moderada (64 a 76\% FCmax), vigorosa (77 a 93\% FCmax) e muito vigorosa ( $\geq 94 \%$ FCmax), seguindo-se classificação sugerida pelo Colégio Americano de Medicina do Esporte (ACSM, 2006).

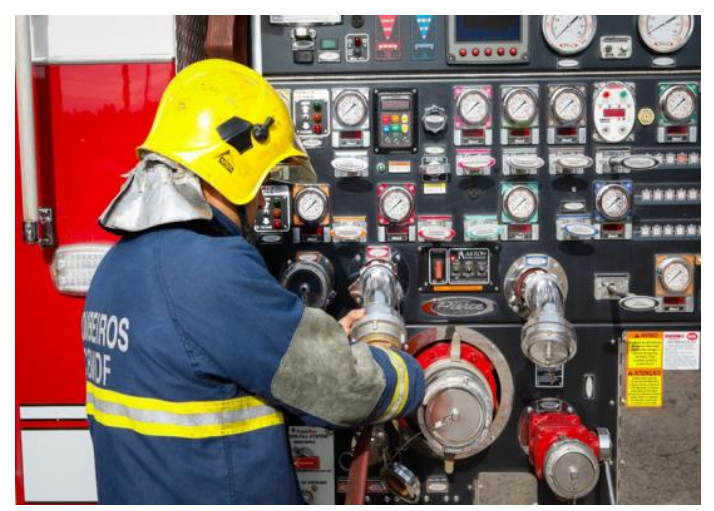

Figura 12 - Exemplo de atividade operacional desenvolvida durante o turno de trabalho, em monitoração. 
A variabilidade da frequência cardíaca (VFC) foi analisada no domínio do tempo e da frequência espectral por diferentes índices, a saber:

a. No domínio do tempo: a média normal de intervalo R-R (NRR); um marcador de índice variabilidade global da modulação combinado autonômico, que é o coeficiente de variação (CV: desvio padrão/média intervalo $\mathrm{R}-\mathrm{R})$ * 100), e dois índices de variabilidade instantânea, que são a porcentagem dos intervalos RR sucessivos superiores a $50 \mathrm{~ms}$ (pNN50) e a raiz quadrada da média dos quadrados das diferenças de intervalos sucessivos (rMSSD), o que reflete a modulação rápida batimento a batimento parassimpático;

b. No domínio espectral: a potência total da área espectral (TP - 0-0,50 Hz), que reflete a modulação autonômica global, as áreas de energia de baixa e alta frequência, tanto em valores absolutos (ABF e AAF) quanto em unidades normalizadas (ABFn e AAFn), expressas como percentagens e calculada como a área de energia absoluta de cada banda dividido pela soma de ambas as áreas absolutas, multiplicado por 100 e a relação entre a área absoluta (Razão $B F / A F)$ que reflete o balanço simpático. ABFn e AAFn expressam o valor relativo de cada componente em proporção com a área total menos o componente de frequência muito baixa. Isso permite uma comparação entre os dois ramos do sistema autonômico cardíaco (CAS). Supõe-se que a AAF é quase exclusivamente dependente do ramo parassimpático e $\mathrm{ABF}$ é um marcador de um ramo simpático, mesmo que ambos os ramos da CAS possam influenciá-la. Para uma Razão BF/AF <1 considera-se uma modulação parassimpática dominante e Razão BF/AF > 1 uma dominância simpática relativa (JUNQUEIRA 2007).

\subsection{Análise Estatística dos Dados}

Além da estatística descritiva das diversas variáveis registradas, a análise dos dados estatística incluiu cinco abordagens diferentes. Em todas as situações a estatística empregada para todas as análises e variáveis estudadas foi a não-paramétrica, em função da maioria das distribuições das variáveis amostrais ter sido do tipo não-normal, especialmente nos índices da variabilidade da FC. Para a verificação da normalidade de distribuição empregou-se o teste de Shapiro-Wilk.

Inicialmente procedeu-se à descrição do nível de atividade física, do tempo sentado e da qualidade de vida. Nesta última, foram comparados os valores entre os 4 domínios da 
qualidade de vida por meio do teste Kruskal-Wallis e teste post-hoc de Dunn. Sequencialmente foram comparadas as variáveis funcionais de repouso entre as posturas SUP e ORT e entre as 3 avaliações, empregando-se os testes de Wilcoxon e Friedman (post-hoc de Dunn), respectivamente. O terceiro conjunto de análise foi sobre a sobrecarga cardiovascular durante um turno de trabalho, onde foram calculados os tempos (absolutos e relativos) de permanência nas 4 zonas de intensidade de esforço, conforme descrito anteriormente. Foram também comparadas as sobrecargas por subgrupos segundo: a) o tipo de atendimento prestado durante a prontidão no turno de trabalho avaliado (atendimento a incêndios vs outros atendimentos) e b) a quantidade de atendimentos realizados no turno (até 2 vs mais que 2).

$\mathrm{O}$ quarto conjunto de análise de dados é relativo à $\mathrm{FAC}$, onde se procedeu à análise pareada dos índices temporais e espectrais da VFC entre as 3 avaliações (teste de Friedman com post-hoc de Dunn) e das posturas supina e ortostática (teste de Wilcoxon) a fim de avaliar a resposta à mudança postural. Nesse particular também foram analisados os índices da VFC por subgrupos segundo o estado de equilíbrio autonômico basal no repouso supino em AVA1, constituindo-se assim um grupo de indivíduos vagotônicos no repouso supino no ambiente controlado (razão $\mathrm{BF} / \mathrm{AF}<1,0$ ) em comparação àqueles que apresentaram dominância simpática na mesma situação funcional (razão BF/AF >=1,0). Além da análise do comportamento dos índices da VFC separadamente em cada subgrupo, comparam-se também os valores de cada índice da VFC entre esses subgrupos. Nesta análise procedeu-se inicialmente à comparação das variáveis de caracterização da amostra por subgrupos empregando-se o teste não pareado de Mann-Whitney.

Finalmente, procedeu-se a uma análise de associação de eventos, por meio do estudo da correlação entre variáveis representativas da VFC com a aptidão cardiorrespiratória, empregando-se a correlação de Spearman.

As diferenças entre as diversas comparações instituídas foram consideradas estatisticamente significativas quando as probabilidades bi-caudais das suas ocorrências devidas ao acaso (erro tipo I) foram menores ou iguais a $5 \%(\mathrm{p} \leq 0,05)$. Considerou-se ainda essas diferenças como tendência estatística quando $0,05<\mathrm{p}<0,10$.

Para os cálculos matemáticos e composição gráfica, utilizaram-se os aplicativos estatísticos GraphPad Prism 5 e SPSS versão 20.0, ambos para MAC OSX.

A apresentação dos dados foi feita em grupos de tabelas correspondentes a cada tipo de análise, com acréscimo de alguns gráficos para ilustrar pontos de destaque. A expressão dos dados em tabelas ou gráficos do tipo box plot incorpora sempre valores medianos, os 
quartis $25 \%$ (inferior) e $75 \%$ (superior), bem como os valores extremos inferior e superior. 


\section{RESULTADOS}

Tendo em vista o grande volume de informações e análises, optou-se por apresentar os resultados em blocos. Neste contexto, apresentam-se inicialmente os dados de caracterização do nível de atividade física, tempo sentado e qualidade de vida. Sequencialmente são apresentados os dados das variáveis funcionais de repouso nas três avaliações instituídas. $\mathrm{O}$ terceiro bloco agrega os resultados relativos à sobrecarga cardiovascular durante o turno de trabalho, avaliada por meio do comportamento da FC durante o expediente. No bloco 4 são apresentados os dados da função autonômica cardíaca, por meio dos índices temporais e espectrais da variabilidade da frequência cardíaca (VFC). Finalmente, no quinto conjunto de resultados, são apresentados os valores das correlações entre a aptidão cardiorrespiratória e os índices autonômicos.

\subsection{Caracterização do Nível de Atividade Física, do Tempo Sentado e da Qualidade de Vida.}

Conforme se observa na tabela de caracterização da amostra, com base no IPAQ havia 86,7\% dos voluntários classificados como ativos. Os valores medianos (extremos) do número de passos acumulado foi de 6566 (2155 - 16416). Durante o turno avaliado, apenas 27,6\% dos voluntários atingiram 10.000 passos. Extrapolando-se a média de passos acumulados por hora para um total de uma vigília estimada de 15 horas, o percentual de voluntários que acumularia o mínimo recomendado de 10 mil passos no dia de trabalho subiria para 44,8\%.

Já em relação ao tempo sentado, observou-se que 70\% (21) relataram sentar cerca de $1 / 4$ do dia, $16,7 \%$ (5) relataram praticamente não ficarem sentados e apenas $13,3 \%$ (4) indicaram sentar cerca da metade do dia. Destaca-se assim que nenhum dos voluntários relatou sentar mais do que a metade do tempo de vigília.

Os valores da qualidade de vida avaliada pelo WHOQOL estão expressos na Figura 13, onde se observa mediana $\leq 75 \%$ do valor máximo em todos os domínios, com destaque para o domínio ambiente, que mostrou valores significativamente menores que os demais. 


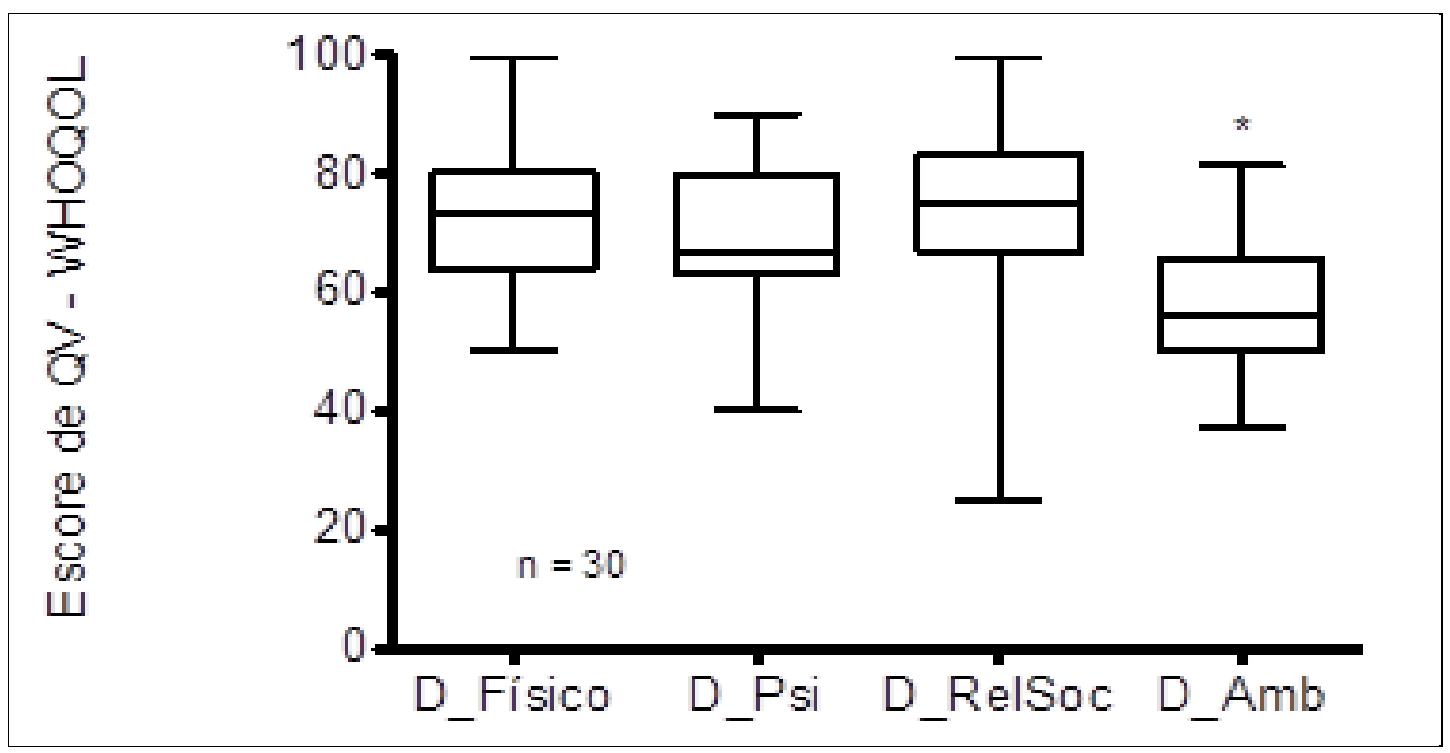

Figura 13 - Valores amostrais dos escores de qualidade de vida avaliada em bombeiros militares em escala de "prontidão", por meio do WHOQQOL

*: Teste de Kruskal-Wallis com post-hoc de Dunn <0,05 na comparação do D_Amb com todos os demais; D: domínio; Psi: Psicológico; RelSoc: Relações Sociais; Amb: Ambiente

\subsection{Caracterização Funcional de Repouso}

Os dados de PA e FC de repouso, tanto supino quanto ortostático, durante as 3 avaliações estão expresso nas Tabelas 2 e 3. Observa-se absoluta estabilidade da pressão arterial ao longo das 3 avaliações. Além de não terem sido registrados episódios de hipotensão postural. Os valores de PA sistólica não se alteraram de forma significativa entre o repouso supino e o ortostático. Por outro lado, observou-se significativo aumento da PA diastólica na postura ortostática comparativamente ao repouso supino, em todos os 3 momentos avaliados.

Tabela 2 - Valores medianos (extremos) da PA no repouso supino (SUP) e ortostático (ORT) nas 3 avaliações (AVA1-AVA3) $(\mathrm{n}=30)$

\begin{tabular}{|c|c|c|c|c|}
\hline & AVA 1 & AVA 2 & AVA 3 & $\# \mathbf{p}$ \\
\hline PAS SUP & $120,0(105,0-143,0)$ & $122,5(102,0-140,0)$ & $125,0(106,0-158,0)$ & 0,65 \\
\hline PAS ORT & $120,5(98,0-144,0)$ & $119,0(96,0-146,0)$ & $124,0(89,0-174,0)$ & 0,27 \\
\hline$* \mathbf{p}$ & 0,21 & 0,11 & 0,97 & \\
\hline PAD SUP & $73,5(60,0-100,0)$ & $74,0(57,0-85,0)$ & $76,0(62,0-100,0)$ & 0,25 \\
\hline PAD ORT & $80,0(60,0-104,0)$ & $79,0(59,0-104,0)$ & $82,5(60,0-107,0)$ & 0,07 \\
\hline$* \mathbf{p}$ & 0,006 & 0,011 & $<0,001$ & \\
\hline
\end{tabular}

PAS: pressão arterial sistólica (mmHg); PAD: pressão arterial diastólica (mmHg); *: teste de Wilcoxon; \#: teste de Friedman 
Quanto à FC, observou-se aumento significativo quando da adoção da postura ortostática nas três avaliações, indicando ajuste fisiológico típico da mudança postural. Destaca-se ainda que em AVA3 houve aumento significativo da FC avaliada nos quartéis (AVA2 e AVA3) comparativamente à situação controle no laboratório. Entretanto a FC de repouso após um turno rotineiro de trabalho se mostrou semelhante ao valor de início de expediente (Tabela 3).

Tabela 3 - Valores medianos (extremos) da FC no repouso supino (SUP) e ortostático (ORT) nas 3 avaliações (AVA1-AVA3) $(n=30)$

\begin{tabular}{l|c|c|c|c|c|}
\hline & AVA 1 & AVA 2 & AVA 3 & $\# \mathbf{p}$ & Post Hoc \\
\hline FC SUP & 58,0 & 64,0 & 65,5 & & AVA1 Vs AVA2 \\
& $(46,0-74,0)$ & $(48,0-88,0)$ & $(46,0-108,0)$ & 0,0001 & AVA1 Vs AVA3 \\
\hline FC ORT & 69,0 & 75,0 & 78,5 & & AVA1 Vs AVA2 \\
& $(53,0-83,0)$ & $(52,0-105,0)$ & $(49,0-146,0)$ & $<0,0001$ & AVA1 Vs AVA3 \\
\hline *p & $<0,0001$ & $=0,0001$ & $<0,0001$ & & \\
\hline
\end{tabular}

FC: frequência cardíaca (bpm); *: teste de Wilcoxon; \#: teste de Friedman, post-hoc de Dunn indicando as comparações com $\mathrm{p}<0,05$

Observou-se ainda correlação significativa entre a FC repouso supino em AVA3 com a FC de pico atingida durante o turno de trabalho $(\mathrm{Rs}=0,50 ; \mathrm{p}=0,005)$. Por outro lado, não houve correlação da FC de pico com a FC de repouso pré-turno de trabalho $(\mathrm{Rs}=0,04 ; \mathrm{p}=$ 0,83 no supino e Rs $=0,05 ; \mathrm{p}=0,81$ no ortostatismo). Esses achados sugerem que a FC pico foi independente da condição basal pré-turno, porém influenciou, por sua fez, o valor da FC de repouso pós-turno.

\subsection{Sobrecarga Cardiovascular Durante o Turno de Trabalho Operacional}

A avaliação da sobrecarga cardiovascular foi estimada por meio da análise do comportamento da FC ao longo de todo o expediente rotineiro de atividade operacional. $\mathrm{O}$ tempo mediano de monitoração dos voluntários durante o turno diurno foi de $10 \mathrm{~h} 38 \mathrm{~min}$ ( $5 \mathrm{~h}$ $56 \mathrm{~min}$ - $12 \mathrm{~h} 06 \mathrm{~min}$ ), sendo que $70 \%$ dos voluntários foram monitorados por pelo menos $10 \mathrm{~h}$ de atividade operacional e $93 \%$ tiveram ao menos $9 \mathrm{~h}$ de acompanhamento. Por razões operacionais, 2 voluntários tiveram tempo de monitoramento menor que $9 \mathrm{~h}$.

Quanto à intensidade das atividades realizadas, constata-se que em 97,3 \pm 4,2\% do tempo do turno diurno foi de atividades leves, $1,8 \pm 2,8 \%$ de intensidades moderadas. Por 
outro lado, deve-se observar que os bombeiros foram expostos, ainda que por pouco tempo, a atividades bastante intensas. Houve períodos de atividades vigorosas ( $5 \pm 10 \mathrm{~min}$ ) e muito vigorosas (1 $\pm 3 \mathrm{~min})$. Ainda, 10 voluntários $(33,3 \%)$ foram expostos a atividades vigorosas e $2(6,7 \%)$ a atividades muito vigorosas, totalizando $40 \%$ da amostra submetida a atividades que superaram $76 \%$ da FCmax máxima prevista para a idade durante a jornada de trabalho. A mediana do percentual da FCmax prevista para a idade atingida durante o turno de trabalho foi de $73 \%$ (50 - 121\%). Esse valor mediano é muito próximo do limite inferior de percentual da FC no qual se considera uma atividade física como vigorosa. Digno de nota ainda, é o fato de que, 40,0\% (12) dos voluntários atingiram ao menos $80 \%$ da FCmax prevista, 13,3\% (4) passaram de $90 \%$ e 1 voluntário $(3,3 \%)$ ultrapassou $100 \%$, indicando uma sobrecarga cardiovascular extremamente elevada e potencialmente de alto risco, durante um turno de trabalho rotineiro. Os valores medianos e extremos de permanência absoluta e relativa nas 4 diferentes zonas de intensidade estão expressos na Tabela 4. Os valores relativos à comparação da sobrecarga por tipo e número de ocorrências estão expressos na Tabela 5.

Tabela 4 - Valores amostrais do tempo de permanência nas 4 zonas de intensidade

\begin{tabular}{|c|c|c|c|c|}
\hline Intensidade & \multicolumn{2}{|c}{ Absoluta } & \multicolumn{2}{c|}{ Relativa (\%) } \\
\hline & Média \pm DP (min) & Extremos (min) & Media & Extremos \\
\hline Leve & $592 \pm 62$ & $463-713$ & $97,3 \pm 4,2$ & $84,1-100$ \\
\hline Moderada & $12 \pm 18$ & $0-74$ & $1,8 \pm 2,8$ & $0-11$ \\
\hline Vigorosa & $5 \pm 10$ & $0-47$ & $0,8 \pm 1,7$ & $0-8,5$ \\
\hline Muito Vigorosa & $1 \pm 3$ & $0-15$ & $0,1 \pm 0,4$ & $0-2,1$ \\
\hline
\end{tabular}

Tabela 5 - Comparação dos valores de FCmax e do \% da FCmax prevista para a idade atingidos durante um turno de atividade operacional de bombeiros militares segundo o tipo e a quantidade de ocorrências

\begin{tabular}{|c|c|c|c|c|c|}
\hline \multicolumn{2}{|c|}{ FCmax atingida } & & \multicolumn{2}{|c|}{$\%$ FCmax prevista idade } & \\
\hline $\begin{array}{c}\text { Incêndios } \\
(\mathbf{n}=11)\end{array}$ & $\begin{array}{l}\text { Outras ocorr. } \\
(\mathrm{n}=19)\end{array}$ & $* \mathrm{p}$ & $\begin{array}{c}\text { Incêndios } \\
(\mathrm{n}=11)\end{array}$ & $\begin{array}{l}\text { Outras ocorr. } \\
\quad(\mathrm{n}=19)\end{array}$ & $* \mathrm{p}$ \\
\hline $151(102-163)$ & $124(88-190)$ & 0,30 & $82,5(55,4-91,0)$ & $68,3(50,9-106,1)$ & 0,33 \\
\hline \multicolumn{2}{|c|}{ Número de atendimentos } & & \multicolumn{2}{|c|}{ Número de atendimentos } & \\
\hline$>2(n=18)$ & $\leq 2(\mathrm{n}=12)$ & & $>2(\mathrm{n}=18)$ & $\leq 2(n=12)$ & \\
\hline $149(102-190)$ & $119,5(88-170)$ & 0,07 & $82,1(55,4-106,1)$ & $67,7(50,9-93,9)$ & $<0,05$ \\
\hline
\end{tabular}

As Figuras 14 a 18 ilustram os registros da FC durante um turno diurno de atividade operacional na escala de prontidão nos quarteis. 


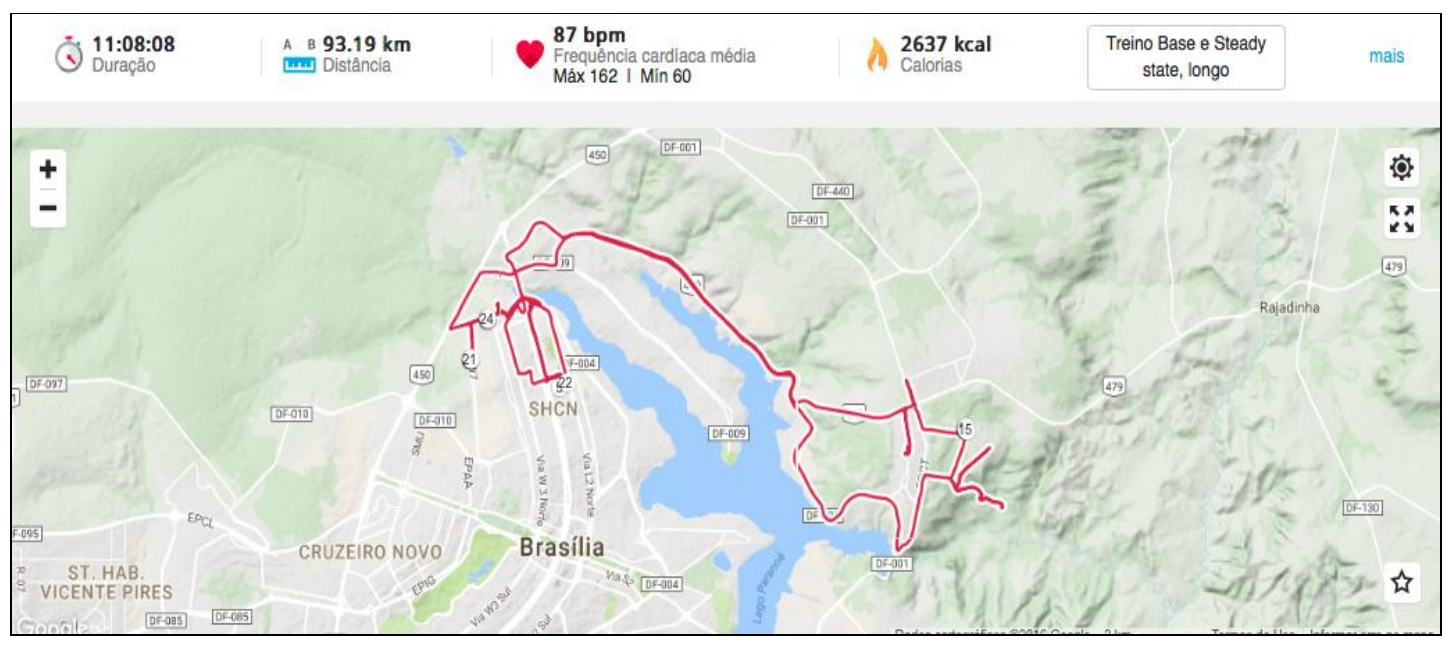

Figura 14 - Ilustração de registro efetuado com frequencímetro Polar V800 em voluntário de 42 anos, IMC: 25,1 kg/m2; que acumulou 9319 passos e atuou em incêndio florestal. Registra o deslocamento, a pé e/ou em viatura, do voluntário $(93,19 \mathrm{~km})$, a duração do registro (11h 08min), bem como valores mínimo (60 bpm), médio (87 bpm) e máximo (162 bpm) do voluntário

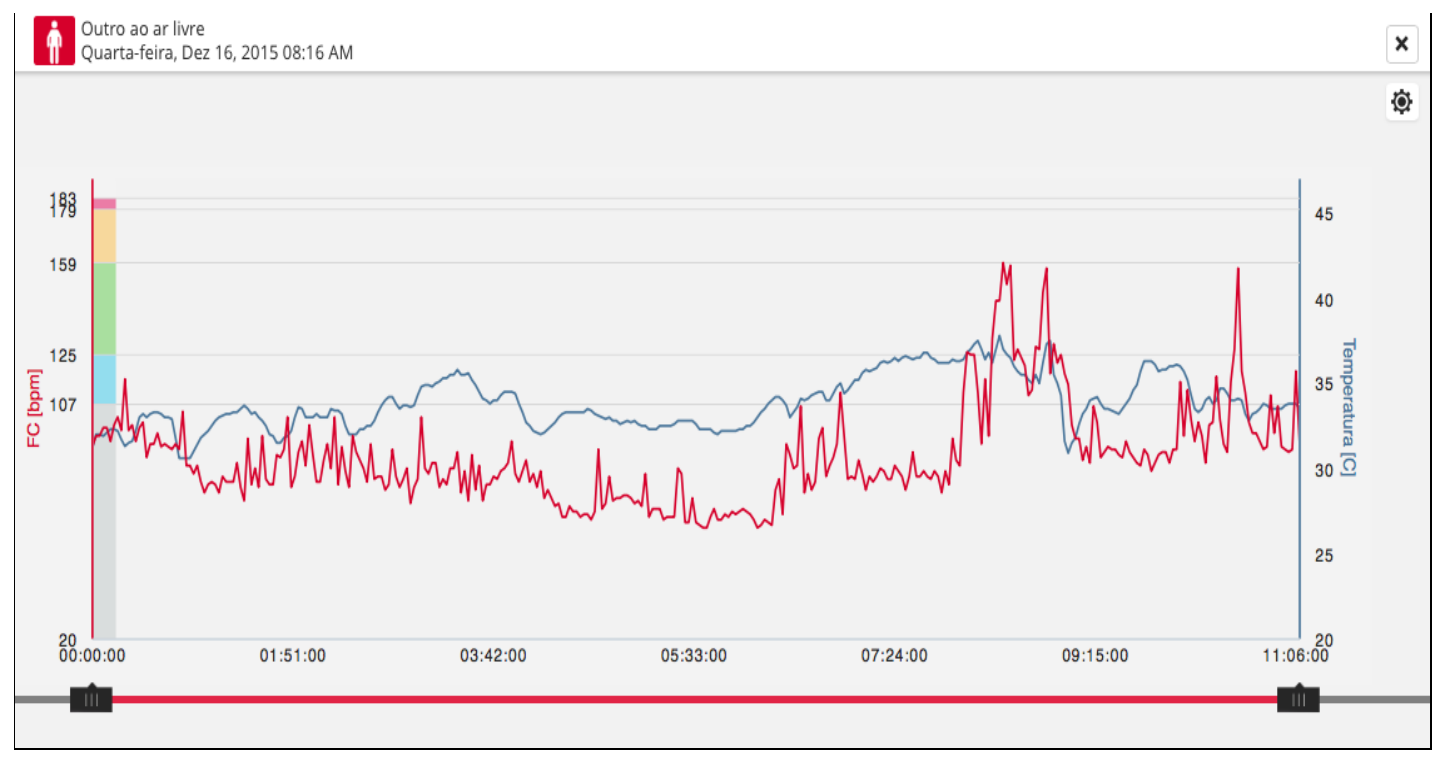

Figura 15 - Ilustração de registro da FC e da temperatura ambiente durante turno rotineiro de trabalho em atividades operacionais de prontidão de voluntário de 42 anos, IMC: $25,1 \mathrm{~kg} / \mathrm{m} 2$; que acumulou 9319 passos e atuou em incêndio florestal 


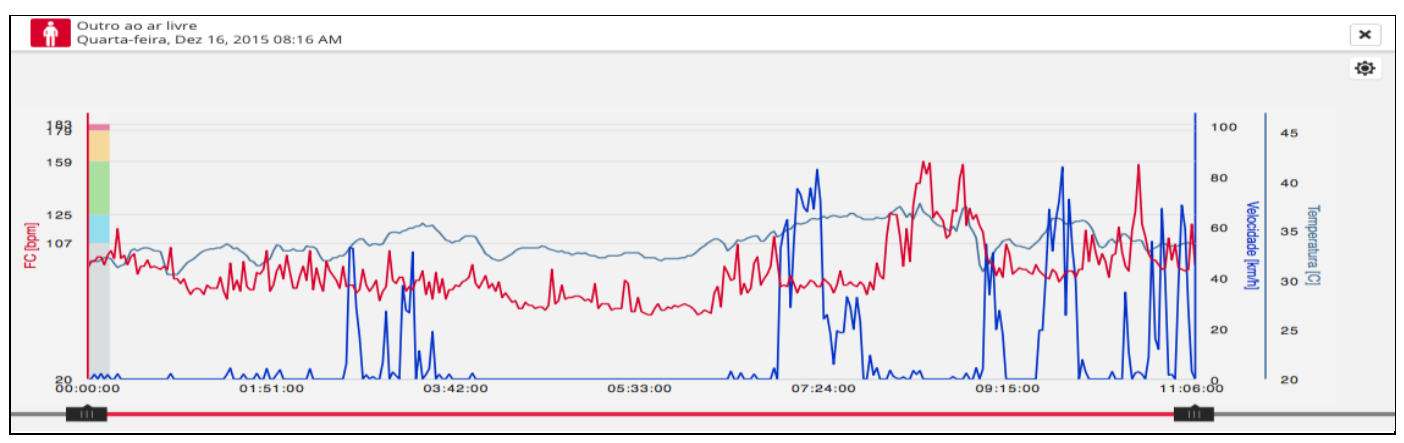

Figura 16 - Ilustração de registro da FC, da temperatura ambiente e a velocidade dos deslocamentos durante turno rotineiro de trabalho em atividades operacionais de prontidão de voluntário de 42 anos, IMC: 25,1 kg/m2; que acumulou 9319 passos e atuou em incêndio florestal. Destaca-se o deslocamento em automóvel (aumento da velocidade) antecedendo períodos de incremento da FC ocorrido durante a atuação do bombeiro no combate a incêndio florestal

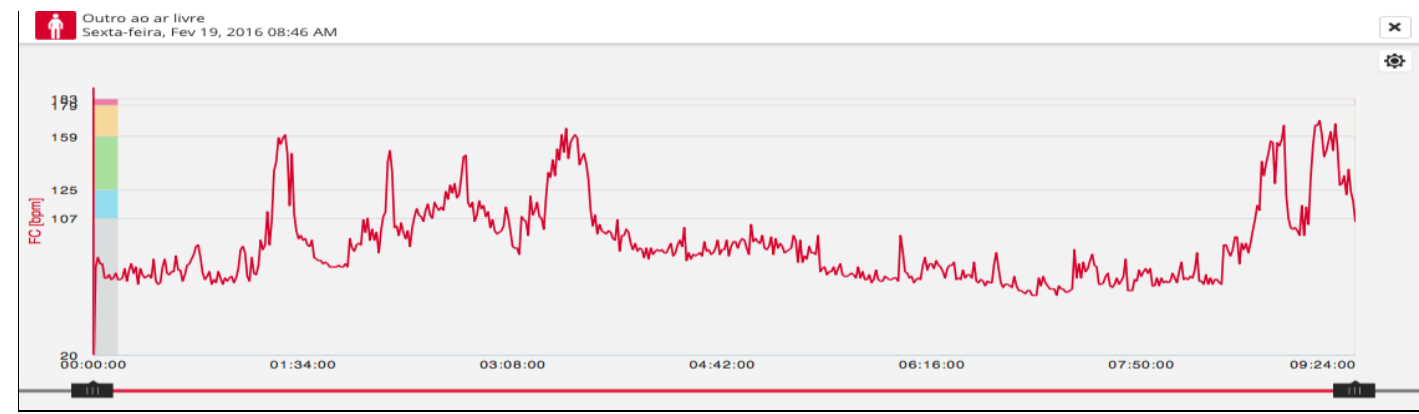

Figura 17 - Ilustração de registro da FC durante turno rotineiro de trabalho em atividades operacionais de prontidão de voluntário de 39 anos, IMC: $27,4 \mathrm{~kg} / \mathrm{m} 2$; que acumulou 16416 passos e atuou em dois atendimentos a acidentes automobilísticos. Evidenciam-se aqui vários períodos de elevação importante da FC, sendo que alguns chegaram a durar entre 10 e 15 min

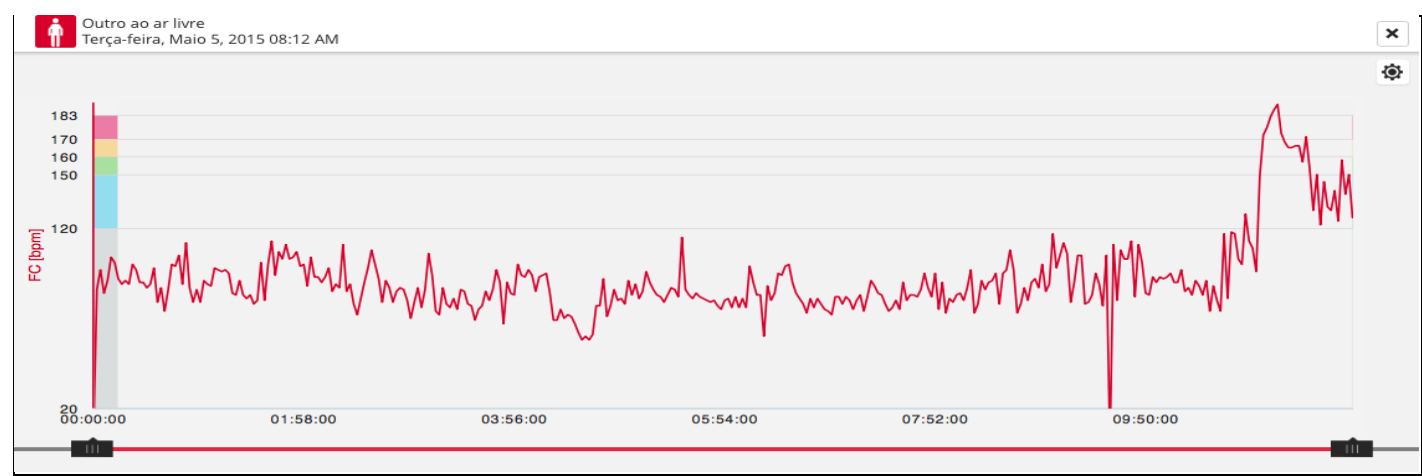

Figura 18 - Ilustração de registro da FC durante turno rotineiro de trabalho em atividades operacionais de prontidão de voluntário de 41 anos, IMC: $26,7 \mathrm{~kg} / \mathrm{m} 2$; que acumulou 12190 passos e atuou em atendimento de salvamento. Evidencia-se aqui longo período de baixa intensidade de esforço, mas atingiu intensidade muito vigorosa no final do turno ( $\mathrm{FC}=190$ bpm; 106,1\% FCmax prevista para a idade) 


\subsection{Avaliação da Função Autonômica Cardíaca por Meio da Variabilidade da Frequência Cardíaca}

6.4.1 Índices temporais resultantes das séries de 5 minutos de intervalos $R-R$ do ECG, obtidos por meio do frequencímetro Polar

A Tabela 6 apresenta as comparações dos índices temporais da VFC entre as posturas supina e ortostática e entre as três avaliações instituídas. São apresentados os valores absolutos, bem como as variações absolutas e relativas, adotando-se para as últimas a postura supina como referência. Observa-se que o grupo apresentou resposta fisiológica frente à mudança postural, com redução significativa da média dos $\mathrm{iRR}$, indicando a taquicardia reflexa, assim como do PNN50\% e do RMSSD, que indicam redução da modulação vagal frente à adoção ativa da postura ortostática. Destaca-se ainda na mesma tabela a grande dispersão dos dados, indicada pela amplitude dos valores extremos. Como exemplo, cita-se o PNN50\% em AVA1 que variou entre 0 e 54\% no repouso supino e apresentou variações relativas entre $-100 \%$ a $62,5 \%$, indicando que, apesar do grupo todo ter manifestado resposta fisiológica, o padrão individual variou enormemente.

Quanto à comparação entre os três momentos, observa-se semelhança estatística na maioria das situações, bem como no grau de resposta frente à mudança postural. Entretanto, observou-se redução significativa da média dos iRR nas avaliações realizadas nos quartéis no repouso supino, comparativamente à situação controle no laboratório. O mesmo ocorreu quando se comparou a média dos iRR em AVA3 comparativamente a AVA1. Em conjunto, esses achados indicam que parece haver um grau de taquicardia relativa quando os voluntários foram avaliados no ambiente de trabalho, comparativamente a um ambiente controle.

Digno de nota ainda o fato do PNN50\% ter sido significativamente menor $(\mathrm{p}<0,05)$ na posição ortostática em AVA3 (mediana = 0,35) em comparação com AVA1 (mediana = 2,6). Do ponto de vista relativo, significa dizer que a mediana do PNN50\% em AVA1 foi 7,4 vezes maior que em AVA3, o que representa importante diminuição da modulação vagal no final do turno de trabalho em comparação com a condição basal controle desses militares avaliados. A comparação dos valores de PNN50\% estão destacadas na Figura 19. 
Tabela 6: Caracterização da análise temporal da VFC nas postura de repouso supino (SUP) e ortostático (ORT), na condição de registro basal (AVA1), no início (AVA2) e após (AVA3) o término do turno de trabalho, de bombeiros militares do Distrito Federal do sexo masculino (n=30)

\begin{tabular}{|c|c|c|c|c|c|}
\hline & SUP & ORT & VAbs & VRel & $\mathbf{p}^{*}$ \\
\hline & \multicolumn{5}{|c|}{ Média } \\
\hline AVA 1 & $999,5(786-1321)$ & $809(616-1141)$ & $-174,0(-439,0 /-48,0)$ & $-18,3(-39,1 /-5,6)$ & $<0,0001$ \\
\hline AVA 2 & $919,5(676-1230)$ & $759,5(562-1043)$ & $-161,5(3070 / 120,0)$ & $-18,2 \quad(35,3 / 17,8)$ & $<0,0001$ \\
\hline AVA 3 & $892(548-1284)$ & $754,5(435-1177)$ & $-154,5(-331,0 / 31,0)$ & $-17,7(-33,6 / 4,2)$ & $<0,0001$ \\
\hline \multirow[t]{4}{*}{ p\# } & 0,002 & 0,02 & 0,18 & 0,79 & \\
\hline & Ava 1 vs Ava2: <0,05 & Ava 1 vs Ava3: <0,05) & & & \\
\hline & Ava 1 vs Ava3: $<0,05$ & & & & \\
\hline & \multicolumn{5}{|l|}{ (1) } \\
\hline AVA 1 & $4,4(2,5-10,3)$ & $5,2(2,3-14,8)$ & $0,5(-3,7 / 8,1)$ & $14,4(-48,7 / 120,9)$ & 0,03 \\
\hline AVA 2 & $4,4(2,9-13,7)$ & $5,0(2,4-14,9)$ & $0,4(-6,2 / 6,2)$ & $6,7(-45,3 / 87,3)$ & 0,21 \\
\hline AVA 3 & $4,8(1,9-9,4)$ & $4,9(3,2-10,4)$ & $0,2(-4,0 / 5,7)$ & $4,2(-51,4 / 289,5)$ & 0,75 \\
\hline \multirow[t]{2}{*}{ p\# } & 0,99 & 0,94 & 0,58 & 0,27 & \\
\hline & \multicolumn{5}{|c|}{ PNN50\% } \\
\hline AVA 1 & $11,4(0,0-54,0)$ & $2,6(0,0-31,5)$ & $-4,0(-42,9 / 8,0)$ & $-63,9(-100 / 62,5)$ & $<0,0001$ \\
\hline AVA 2 & $7,8(0,0-53,6)$ & $1,0(0,0-25,2)$ & $-5,4(-39,8 / 17,0)$ & $-72,9(-100 / 2000)$ & 0,0007 \\
\hline AVA 3 & $11,4(0,0-61,4)$ & $0,35(0,0-60,3)$ & $-9,0(-53,6 / 31,0)$ & $-93,6(-100 / 228,6)$ & 0,0004 \\
\hline \multirow[t]{3}{*}{ p\# } & 0,67 & 0,0009 & 0,85 & 0,14 & \\
\hline & & Ava1 vs Ava3: $<0,05$ & & & \\
\hline & \multicolumn{5}{|c|}{ RMSSD } \\
\hline AVA 1 & $33,85(13,3-102,0)$ & $21,7(5,3-59,5)$ & $-10,75(-73,4 / 6,3)$ & $-31,5(-80,7 / 17,10)$ & $<0,0001$ \\
\hline AVA 2 & $29,65(12,3-89,3)$ & $16,9(5,9-54,3)$ & $-15,2(-46,8 / 23,4)$ & $-43,65(-83,9 / 75,7)$ & 0,0002 \\
\hline AVA 3 & $33,4(5,6-83,9)$ & $16,75(3-73,10)$ & $-15,4(-52,6 / 23,6)$ & $-46,45(-79,7 / 57,10)$ & $<0,0001$ \\
\hline p\# & 0,69 & 0,43 & 0,59 & 0,79 & \\
\hline
\end{tabular}

VAbs: Valores absolutos; VRel: valores relativos; *: p-valor do teste de Wilcoxon; \#: p-valor do teste de Friedman com post-hoc de Dunn 


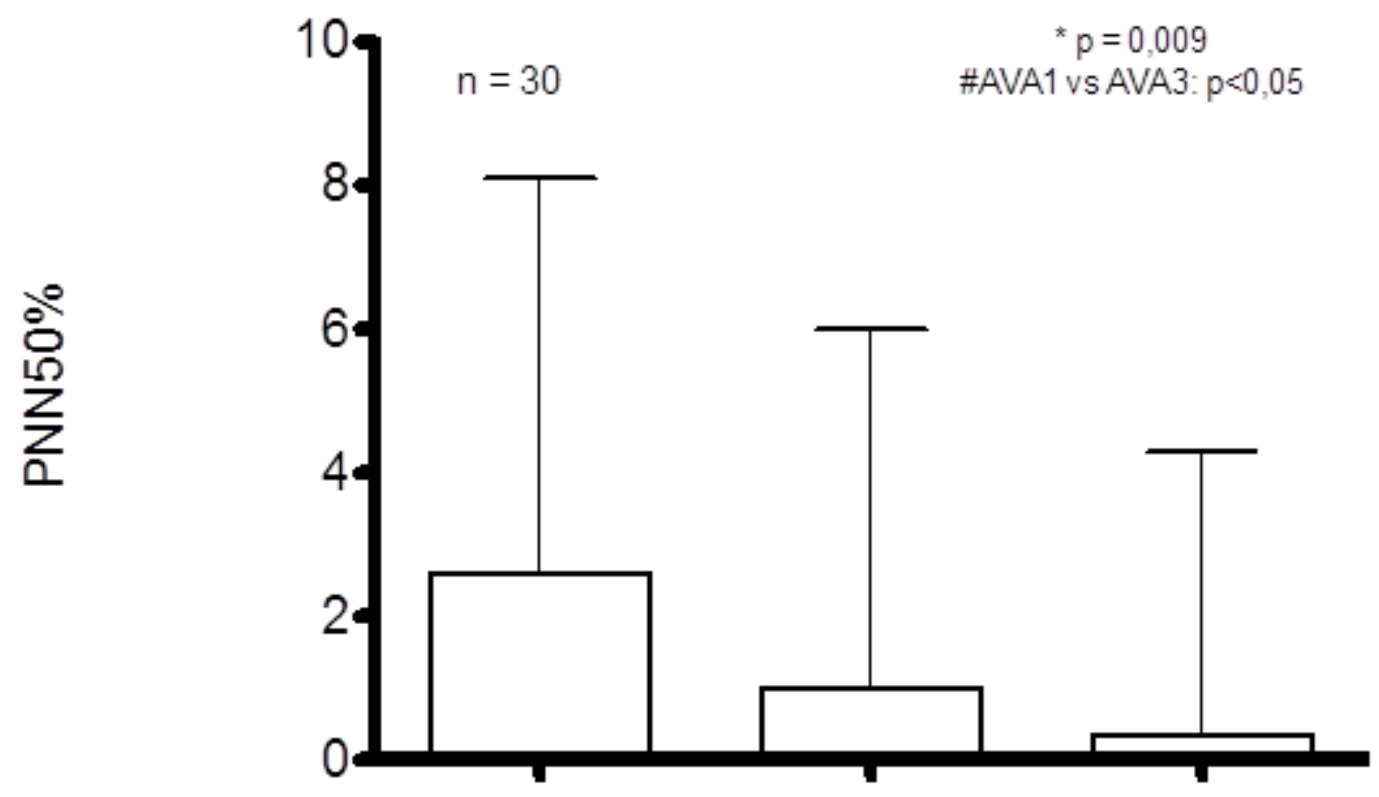

Figura 19 - Valores medianos (intervalo interquartil) do PNN50\% na postura ortostática nas 3 avaliações instituídas

* Teste de Friedman; \# post-hoc de Dunn

\subsection{2 Índices espectrais resultantes das séries de 5 minutos de intervalos $R-R$ do ECG,} obtidos por meio do frequencímetro Polar

A Tabela 7 apresenta as comparações dos índices espectrais da VFC entre as posturas supina e ortostática e entre as três avaliações instituídas. A exemplo dos índices temporais, são apresentados os valores absolutos, bem como as variações absolutas e relativas, adotando-se para as últimas a postura supina como referência. Novamente se observou resposta fisiológica do grupo frente à mudança postural. Observou-se estabilidade na modulação global avaliada pela semelhança de valores da área espectral total nas posturas supina e ortostática nas 3 avaliações. Entretanto, houve estabilidade da área absoluta de baixa frequência e simultânea redução da área absoluta de alta frequência, também nas 3 avaliações. Essa redução mediana média nas 3 avaliações foi de praticamente $70 \%$. O reflexo disso foi um aumento significativo na área normalizada de baixa frequência e redução da área normalizada de alta frequência espectral. Vale destacar que o aumento da área marcadora da atividade simpática foi da ordem de $36 \%$ (média dos aumentos medianos nas 3 avaliações), enquanto a redução da área que expressa a modulação vagal foi de $57 \%$, ou seja, quase o dobro.

Quanto ao balanço vago-simpático expresso pelo valor da razão BF/AF (Tabela 7), é importante observar que, em valores medianos, o grupo mostrou predomínio simpático 
no repouso supino (razão $\mathrm{BF} / \mathrm{AF}>1 \mathrm{em}$ todas as avaliações). No que se refere à comparação das variáveis espectrais entre as 3 avaliações, diferentemente dos índices temporais, observou-se semelhança estatística dos valores de repouso supino e ortostático, assim como na magnitude das respostas frente à mudança postural ativa, seja do ponto de vista absoluto quanto relativo. Entretanto, merece destaque o fato do da comparação entre os aumentos absolutos da razão BF/AF ter resultado em valor de "p" na faixa de tendência estatística $(p=0,13)$. Observados os valores medianos, esta tendência indicaria um possível aumento na magnitude de variação do balanço vago-simpático em favor de maior predomínio simpático nas avaliações realizados nos quartéis, comparativamente àqueles em condição basal em ambiente controlado.

Sequencialmente à Tabela 7, são apresentados espectros de frequência de um voluntário, a título de exemplo, nas posturas supina e ortostática e nas 3 avaliações instituídas. Destaca-se que a escolha deste voluntário se deu em razão de um padrão de resposta bastante acentuado, como se observará nos indicadores de modulação autonômica apresentados junto das Figuras 20 a 25.

Destaca-se ainda sobre esse voluntário uma drástica redução na modulação global quando se compara a condição basal de referencia no ambiente controlado do laboratório com as situações do quartel. Em SUP e ORT em AVA1, a área espectral total desse voluntário foi de 677 e $151 \mathrm{~ms}^{2}$, respectivamente. Já em AVA2 esses valores caíram para 303 e $119 \mathrm{~ms}^{2}$. De modo impressionante e inesperado, os indicadores de modulação global ao final de um turno diurno de trabalho mostraram quase ausência de modulação autonômica, com AT $=13,4 \mathrm{~ms}^{2}$ no repouso supino e $31,4 \mathrm{~ms}^{2}$ na postura ortostática. Finalmente, destaca-se que este é exatamente o mesmo voluntário exemplificado na curva de FC durante o expediente que mostrou baixa intensidade de esforço ao longo de quase todo o turno, mas que chegou a 106,3\% da FC máxima prevista durante um atendimento perto do final do turno de trabalho em análise. Registra-se ainda que seus valores de pressão arterial em repouso se mostram nos limites superiores de normalidade e significativa taquicardia de repouso em AVA3 (108 e 146 bpm, SUP e ORT, respectivamente), comparativamente à AVA2 (64 e 98 bpm) e AVA1 (52 e 77 bpm). 
Tabela 7 - Caracterização da análise espectral da VFC nas postura de repouso supino (SUP) e ortostático (ORT), na condição de registro basal (AVA1), no início (AVA2) e após (AVA3) o término do turno de trabalho, de bombeiros militares do Distrito Federal do sexo masculino (n=30)

\begin{tabular}{|c|c|c|c|c|c|}
\hline & SUP & ORT & VAbs & Vrel & $\mathbf{p}$ \\
\hline & \multicolumn{5}{|c|}{ Área total } \\
\hline AVA 1 & $361,8(92,0 / 2206,0)$ & $286,0(26,1 / 2238,0)$ & $-48,5(-1352,0 / 1273,0)$ & $-28,4(-85,9 / 211,6)$ & 0,41 \\
\hline AVA 2 & $318,5(112,7 / 2504,0)$ & $242,9(64,5 / 3214,0)$ & $-42,5(-1688,0 / 2313)$ & $-18,6(-85,0 / 261,8)$ & 0,16 \\
\hline AVA 3 & $336,5(13,4 / 1490,0)$ & $241,0(31,4 / 1124,0)$ & $-84,5(-943,0 / 902,0)$ & $-35,2(-81,7 / 406,3)$ & 0,008 \\
\hline \multirow[t]{2}{*}{$P$} & 0,24 & 0,50 & 0,90 & 1,0 & \\
\hline & \multicolumn{5}{|c|}{ Área absoluta de baixa frequência } \\
\hline AVA 1 & $118,2(18,7 / 1673,0)$ & $103,0(13,2 / 1946,0)$ & $3,0(-1230,0 / 1262,0)$ & $7,7(-84,3 / 301,2)$ & 0,55 \\
\hline AVA 2 & $95,6(21,2 / 1657,0)$ & $99,9(17,9 / 2867,0)$ & $7,2(-1080,0 / 2775,0)$ & $4,7(-73,6 / 3006,0)$ & 0,43 \\
\hline AVA 3 & $93,5(8,3 / 1087,0)$ & $109,3(1,2 / 949,0)$ & $15,2(-887,0 / 810,0)$ & $35,4(-85,5 / 582,7)$ & 0,52 \\
\hline \multirow[t]{2}{*}{$\mathrm{P}$} & 0,24 & 0,88 & 0,88 & 0,67 & \\
\hline & \multicolumn{5}{|c|}{ Área absoluta de alta frequência } \\
\hline AVA 1 & $83,7(7,2$ / 494,0) & $26,7(1,4 / 148,6)$ & $-35,0(470,3 / 11,8)$ & $-59,0(-95,2 / 11,2)$ & $<0,0001$ \\
\hline AVA 2 & $57,9(9,2 / 523,0)$ & $21,4(3,3 / 130,0)$ & $-44,6(-418,0 / 69,0)$ & $-70,6(-96,6 / 113,1)$ & 0,0001 \\
\hline AVA 3 & $60,9(1,2 / 840,0)$ & $21,9(0,2 / 361,0)$ & $-39,6(-762,1 / 256,4)$ & $-77,0(-93,6 / 245,1)$ & 0,0002 \\
\hline \multirow[t]{2}{*}{$\mathrm{P}$} & 0,97 & 0,39 & 0,79 & 0,79 & \\
\hline & \multicolumn{5}{|c|}{ Área normalizada de baixa frequência \% } \\
\hline AVA 1 & $67,5(23,0 / 40,0)$ & $82,0(55,0 / 95,0)$ & $14,5(-3933,0 / 53,0)$ & $20,8(-98,3 / 165,0)$ & $<0,0001$ \\
\hline AVA 2 & $60,0(10,0 / 91,0)$ & $84,5(47,0 / 95,0)$ & $25,0(-17,0 / 38,0)$ & $38,6(-26,6 / 370,0)$ & $<0,0001$ \\
\hline AVA 3 & $56,0(21,0 / 91,0)$ & $83,5(30,0 / 96,0)$ & $20,5(-15,0 / 59,0)$ & $41,2(-33,3 / 281,0)$ & $<0,0001$ \\
\hline \multirow[t]{2}{*}{$\mathrm{P}$} & 0,39 & 0,36 & 0,66 & 0,79 & \\
\hline & \multicolumn{5}{|c|}{ Área normalizada de alta frequência } \\
\hline AVA 1 & $36,0(14,0 / 76,0)$ & $18,0(5,0 / 44,0)$ & $-15,5(-53,0 / 4,0)$ & $-51,5(-89,8 / 15,4)$ & $<0,0001$ \\
\hline AVA 2 & $41,0(13,0 / 90,0)$ & $15,5(5,0 / 53,0)$ & $-25,0(-66,0 / 17,0)$ & $-63,5(-87,5 / 64,0)$ & $<0,0001$ \\
\hline AVA 3 & $43,5(9,0 / 78,0)$ & $16,0(4,0 / 70,0)$ & $-21,0(-58,0 / 15,0)$ & $-55,6(-89,8 / 66,7)$ & $<0,0001$ \\
\hline \multirow[t]{2}{*}{$\mathrm{P}$} & 0,53 & 0,41 & 0,64 & 0,24 & \\
\hline & \multicolumn{5}{|c|}{ Razão BF/AF } \\
\hline AVA 1 & $1,7(0,30 / 6,2)$ & $4,8(1,2 / 20,4)$ & $2,5(-0,6 / 18,9)$ & $198,7(-20,7 / 2463)$ & $<0,0001$ \\
\hline AVA 2 & $1,5(0,12 / 10,7)$ & $5,6(0,89 / 23,7)$ & $3,9(-7,5 / 20,4)$ & $345,9(-70,1 / 1360,0)$ & $<0,0001$ \\
\hline AVA 3 & $1,3(0,26 / 10,5)$ & $5,4(0,4 / 25,5)$ & $3,7(-4,6 / 23,4)$ & $243,9(-50,0 / 2260,0)$ & $<0,0001$ \\
\hline $\mathrm{p}$ & 0,66 & 0,28 & 0,13 & 0,41 & \\
\hline
\end{tabular}

*: p-valor do teste de Wilcoxon; \#: p-valor do teste de Friedman com post-hoc de Dunn 


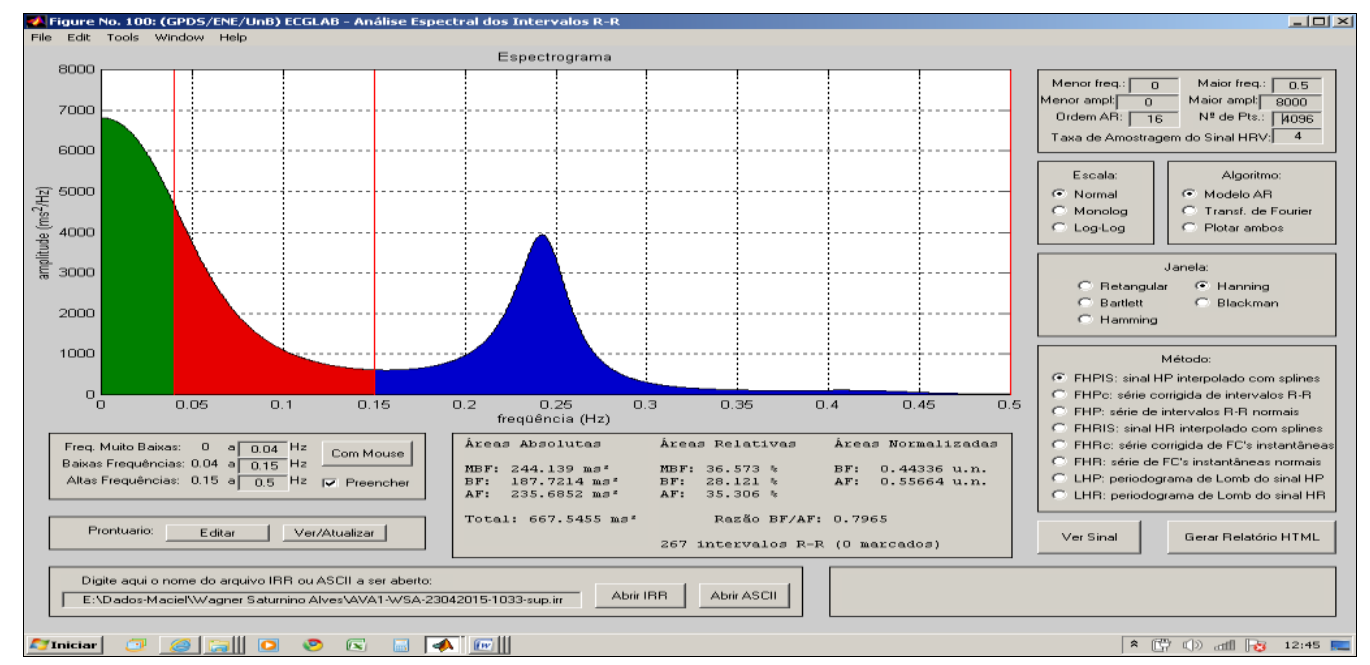

Figura 20 - Espectrograma de um voluntário de 41 anos na condição de repouso supino em AVA1, onde se registrou a razão BF/AF igual a 0,79

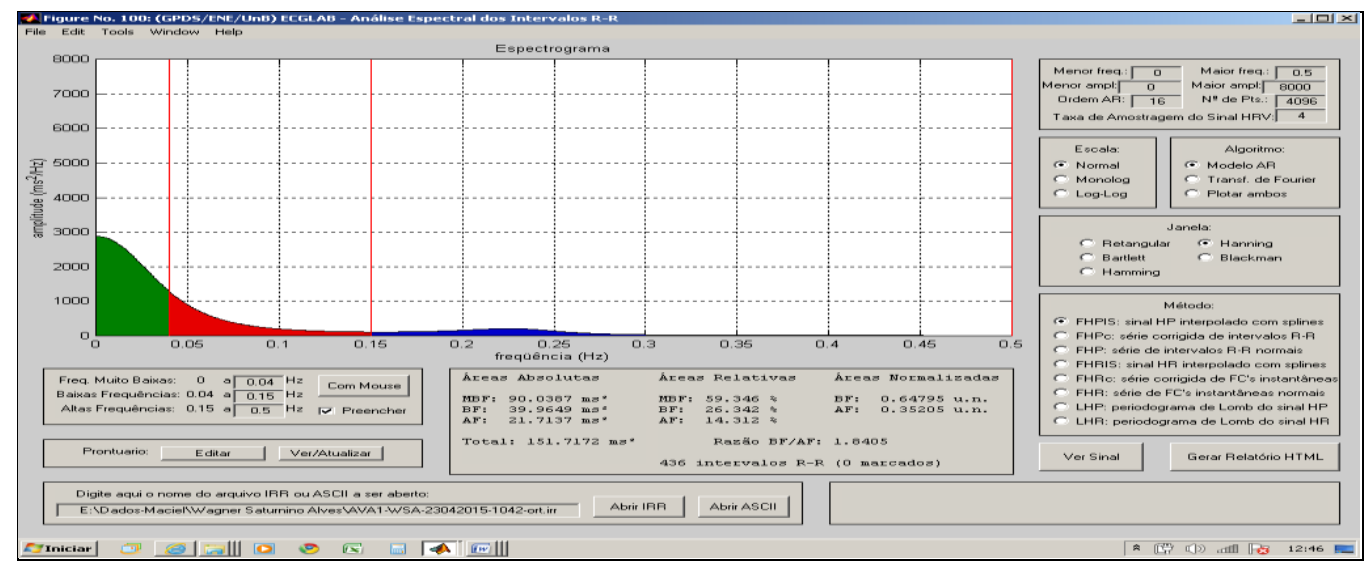

Figura 21 - Espectrograma de um voluntário de 41 anos na condição de repouso ortostático em AVA1, onde se registrou a razão BF/AF igual a 1,8

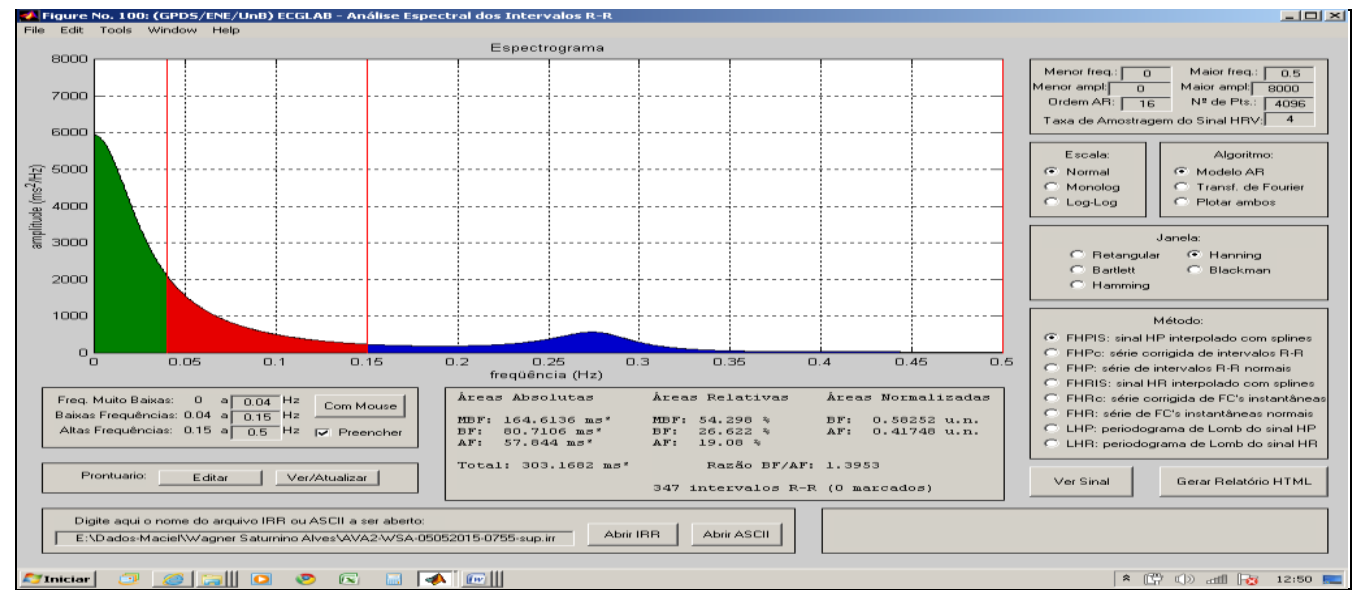

Figura 22 - Espectrograma de um voluntário de 41 anos na condição de repouso supino em AVA2, onde se registrou a razão BF/AF igual a 1,3 


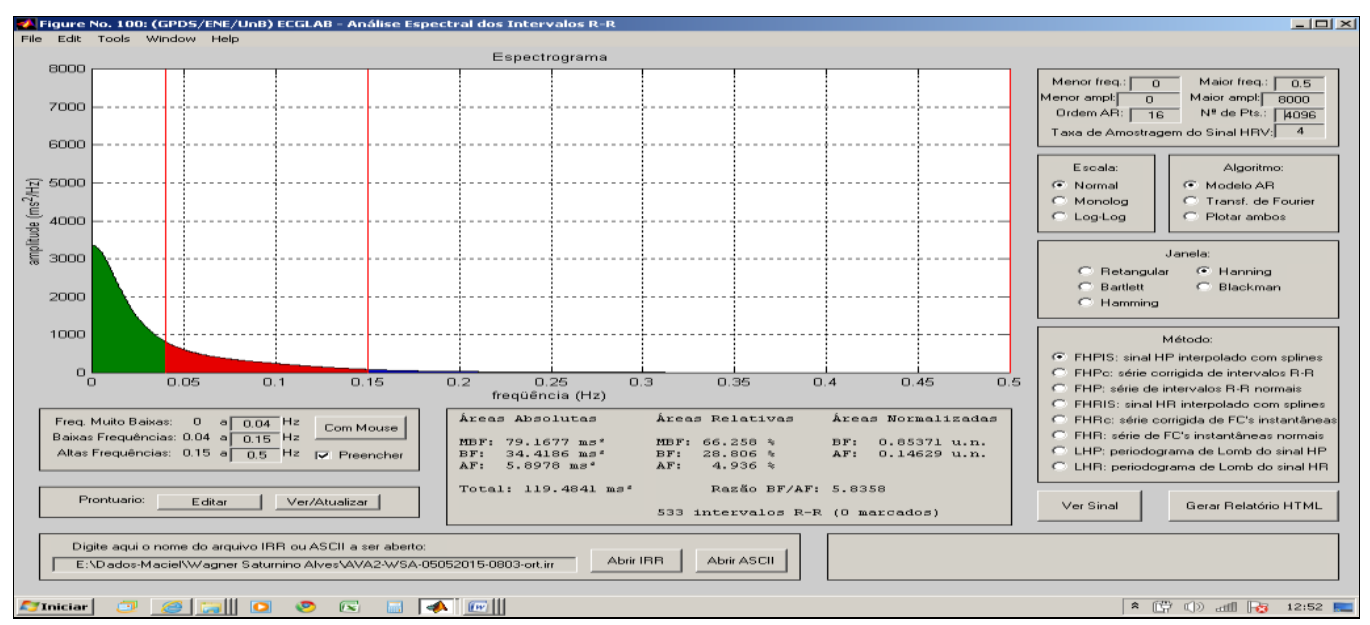

Figura 23 - Espectrograma de um voluntário de 41 anos na condição de repouso ortostático em AVA2, onde se registrou a razão BF/AF igual a 5,8

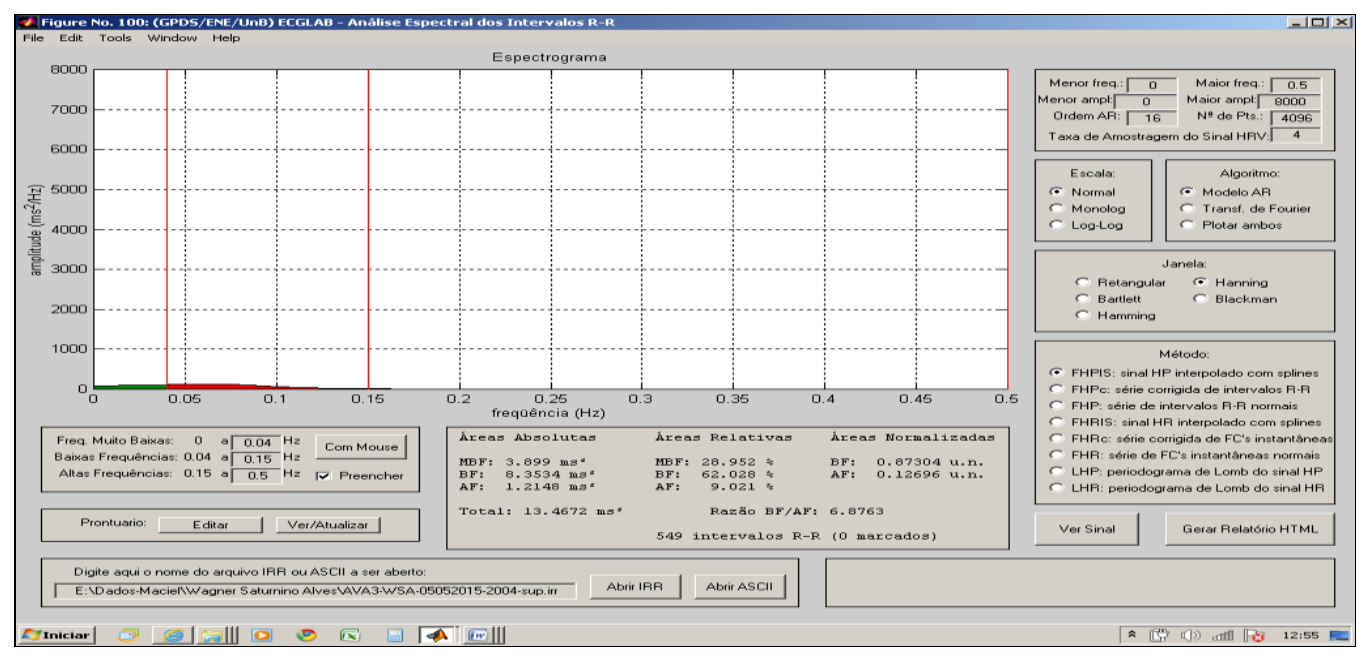

Figura 24 - Espectrograma de voluntário de 41 anos na condição de repouso supino em AVA3, onde se registrou a razão BF/AF igual a 6,8

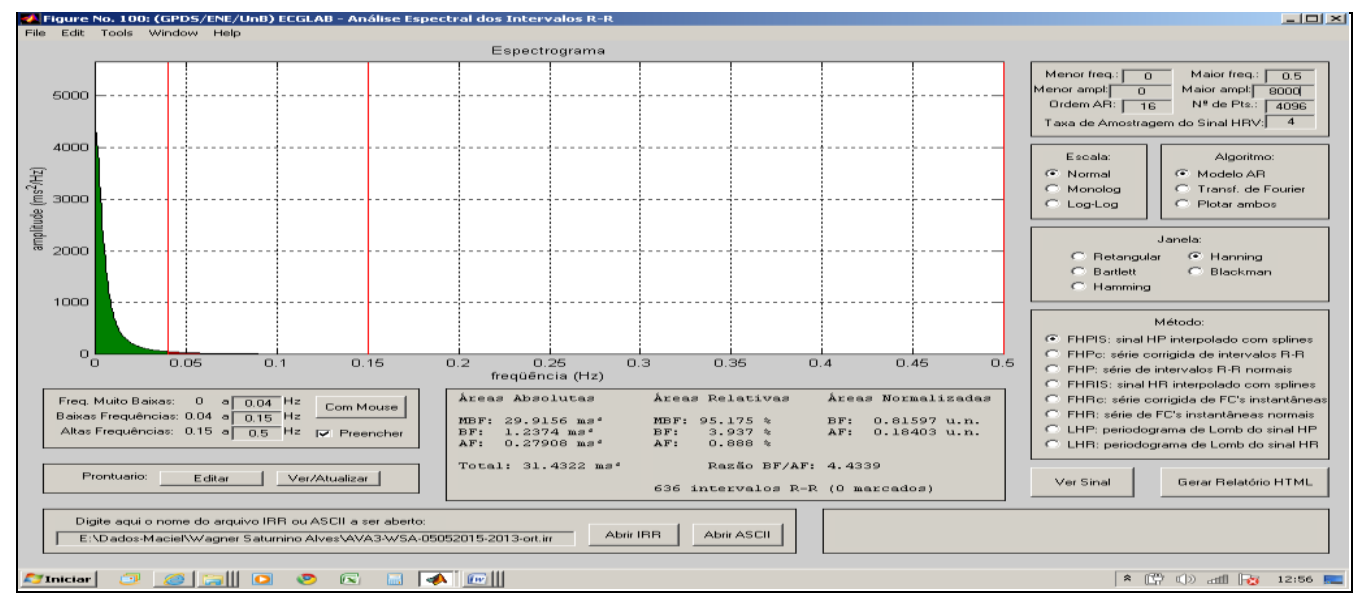

Figura 25 - Espectrograma de um voluntário de 41 anos na condição de repouso ortostático em AVA3, onde se registrou a razão BF/AF igual a 4,4 
6.4.3 Comparação dos índices da VFC nas três avaliações, segundo o padrão autonômico basal no repouso supino na condição controle (medida no laboratório)

A Tabela 8 expressa os valores das variáveis de caracterização da amostra nos subgrupos constituídos segundo o valor da razão BF/AF no repouso supino em AVA 1. Observou-se absoluta semelhança estatística em todos os valores, indicando que o padrão de equilíbrio vago-simpático não se associou com as variáveis funcionais em questão.

Tabela 8 - Valores medianos (mínimo-máximo) das variáveis amostrais de caracterização amostral segundo o estado autonômico basal

\begin{tabular}{|c|c|c|c|}
\hline & \multicolumn{3}{|c|}{ Razão BF/AF } \\
\hline & $\geq 1,0$ & $<1,0$ & $\mathbf{p}$ \\
\hline $\mathrm{n}(\%)$ & $20(66,7)$ & $10(33,3)$ & \\
\hline Idade (anos) & $41,0(35,0-47,0)$ & $39,5(35,0-45,0)$ & 0,23 \\
\hline $\operatorname{IMC}\left(\mathrm{kg} / \mathrm{m}^{2}\right)$ & $26,6(21,4-31,0)$ & $26,0(18,0-31,8)$ & 0,66 \\
\hline FC repouso SUP (bpm) & $54,0(46,0-67,0)$ & $58,5(47,0-74,0)$ & 0,71 \\
\hline PAs rep SUP (mmHg) & $125,5(114,0-141,0)$ & $117,0(105,0-143,0)$ & 0,19 \\
\hline PAd rep SUP (mmHg) & $74,5(60,0-92,0)$ & $72,5(60,0-100,0)$ & 0,95 \\
\hline FR rep SUP & $14,0(12,0-19,0)$ & $16,5(9,0-22,0)$ & 0,45 \\
\hline $\mathrm{VO}_{2} \max \left[\mathrm{mL}(\text { kg.min })^{-1}\right]$ & $39,8(34,5-46,3)$ & $39,9(30,3-49,3)$ & 0,63 \\
\hline
\end{tabular}

No grupo com razão BF/AF <1 (doravante chamado de grupo vagotônico - VG) observou-se diferença significativa na média dos iRR ao longo das 3 avaliações ( $\mathrm{p}=0,001)$, sendo os valores em AVA1 significativamente maiores: 1000 (947 - 1321 ms) que em AVA2: 885 (826 - $1127 \mathrm{~ms})$ e em AVA3: 892 (548 - $1148 \mathrm{~ms})(\mathrm{p}<0,05)$. Todas as demais comparações entre as variações dos índices temporais nas 3 avaliações não mostraram diferença significativa nem no grupo dos vagotônicos nem naqueles com dominância simpática (razão $\mathrm{BF} / \mathrm{AF}>1,0$, doravante chamados de grupo simpaticotônico - GS).

Nas comparações dos índices temporais entre os grupos VG vs GS, observou-se semelhança estatística em todos, tanto na postura supina quanto na ortostática e nas 3 avaliações, com exceção da média dos iRR em SUP AVA2, o RMSSD em SUP AVA1 e AVA2, onde os valores de " $p$ " foram limítrofes $(0,05)$.

Nos índices espectrais da VFC, o comportamento foi semelhante, ou seja, tendência global de semelhança de resposta nas 3 avaliações tanto no GV quanto em GS, sendo que algumas variáveis apresentaram diferença estatística, a saber:1 - No GV: 
a área absoluta de alta frequência na postura ortostática teve p-valor de 0,02 na análise de variância, porém nas comparações por pares não houve diferença entre os conjuntos de AVA1, AVA2 e AVA3. O mesmo ocorreu com a razão BF/AF no supino. Já em ORT, evidenciaram-se maiores valores da razão BF/AF em AVA2: 5,8 (0,9 - 9,8) em comparação a AVA1: 1,28 $(0,53$ - 17,5) $(\mathrm{p}<0,05)$.

2 - No GS: o teste de Friedman indicou diferença entre a área de baixa frequência normalizada entre as 3 avaliações $(\mathrm{p}=0,04)$, porém novamente as comparações por pares não apontaram diferenças $(p>0,05)$. A única diferença que persistiu na comparação entre pares foi na área normalizada de alta frequência espectral onde AVA2: $34,5(13,0$ - 90,0) foi superior a AVA1: $26,0(14,0$ - 47,0). No que se refere à comparação dos índices entre GV e GS, , foram comparados apenas os índices de valores absolutos (área total, de baixa e alta frequência), visto que os índices relativos são diretamente afetados pelo critérios de constituição dos grupos, qual seja, o equilíbrio autonômico no repouso supino. Nesse contexto, apenas a AT se mostrou maior no GS: $282,5(71,8-1124,0) \mathrm{ms}^{2}$ em relação ao GV: 170,6 $(31,4-340,0) \mathrm{ms}^{2}$ $(\mathrm{p}=0,02)$.

6.4.4 Correlações entre índices temporais e espectrais da VFC com a aptidão cardiorrespiratória

A Tabela 9 expressa os coeficientes de correlação de Spearman entre os valores de aptidão cardiorrespiratória e os índices temporais e espectrais da VFC nas 3 avaliações. Para efeito de maior clareza da tabela, são apresentados somente os valores das correlações que se mostraram estatisticamente significativas ou na faixa de tendência estatística $(0,5<\mathrm{p}<0,1)$. Destaca-se que houve significativas correlações positivas em todos os índices temporais no supino em AVA1, assim como na maioria dos índices de ortostatismo em AVA1, com exceção da média dos iRR. Quanto aos índices espectrais, observaram-se também correlações significativas em todos os índices de áreas absolutas (total, de baixa e alta frequência) em AVA1, tanto em SUP quanto em ORT. Interessante notar que a quase todas essas correlações deixam de ser significativas em AVA2. Já em AVA3, observou-se novamente correlação significativa e positiva entre a aptidão cardiorrespiratória e os índices temporais marcadores da atividade vagal, além das áreas absolutas de baixa e alta frequências espectrais na posição ortostática (Tabela 9). 
Tabela 9 - Coeficiente de correlação de Spearman entre a capacidade cardiorrespiratória (VO2max estimado) e os índices temporais e espectrais da VFC nas posições supina (SUP) e ortostática (ORT) nas 3 avaliações instituídas (AVA1-AVA3), de bombeiros militares do sexo masculino

\begin{tabular}{|c|c|c|c|c|c|c|}
\hline & \multicolumn{2}{|c|}{ AVA1 } & \multicolumn{2}{|c|}{ AVA2 } & \multicolumn{2}{|c|}{ AVA3 } \\
\hline & $\begin{array}{c}\text { SUP } \\
\mathbf{r}_{\mathrm{s}}(\text { valor-p) }\end{array}$ & $\begin{array}{c}\text { ORT } \\
\mathbf{r}_{\mathrm{s}}(\text { valor-p }) \\
\end{array}$ & $\begin{array}{c}\text { SUP } \\
\mathbf{r}_{\mathrm{s}}(\text { valor-p) }\end{array}$ & $\begin{array}{c}\text { ORT } \\
\mathbf{r}_{\mathrm{s}}(\text { valor-p) }\end{array}$ & $\begin{array}{c}\text { SUP } \\
\mathbf{r}_{\mathrm{s}}(\text { valor-p }) \\
\end{array}$ & $\begin{array}{c}\text { ORT } \\
\mathbf{r}_{\mathrm{s}}(\text { valor-p) }\end{array}$ \\
\hline $\begin{array}{l}\text { Média } \\
\text { iRR }\end{array}$ & $0,37(0,04)$ & & & & & \\
\hline $\mathrm{CV}$ & $0,40(0,03)$ & $0,55(0,002)$ & & $0,37(0,04)$ & & \\
\hline PNN50\% & $0,46(0,01)$ & $0,44(0,02)$ & & & $0,41(0,02)$ & $\begin{array}{c}0,49 \\
(0,006)\end{array}$ \\
\hline RMSSD & $0,44(0,02)$ & $0,44(0,02)$ & & & $0,38(0,04)$ & $0,40(0,03)$ \\
\hline AT & $0,45(0,01)$ & $0,51(0,004)$ & & & & \\
\hline $\mathrm{AABF}$ & $0,45(0,01)$ & $0,40(0,03)$ & & & & $0,35(0,06)$ \\
\hline AAAF & $0,44(0,02)$ & $0,37(0,04)$ & & & & $0,36(0,05)$ \\
\hline ANBF & & & & & & \\
\hline ANAF & & & & & & \\
\hline Razão & & & & & & \\
\hline
\end{tabular}

iRR: intervalo R-R; CV: coeficiente de variabilidade; AT: área espectral total; AABF: área espectral absoluta de baixa frequência; AAAF: área espectral absoluta de alta frequência; ANBF: área espectral normalizada de baixa frequência; ANAF: área espectral normalizada de alta frequência; Razão: razão BF/AF 


\section{DISCUSSÃO}

\subsection{Considerações Preliminares}

Tendo em vista o volume de informações produzidas, a discussão dos resultados será apresentada seguindo, sempre que possível, a estrutura e sequência apresentada no capítulo de resultados. Entretanto, como muitos dados possuem relação entre si, em alguns momentos as análises serão abordadas em conjunto.

Antes da discussão e interpretação específicas dos diversos achados desta pesquisa, faz-se necessária uma apreciação preliminar de algumas considerações genéricas que possuem implicações diretas em vários aspectos da discussão, especialmente no que se refere às características da amostra estudada, à natureza do principal fenômeno fisiológico investigado: a função autonômica cardíaca e às características das atividades operacionais desenvolvidas por bombeiros militares.

O grupo estudado constituiu-se de militares jovens e/ou de meia-idade (35 a 47 anos), apresentando normalidade clínico-cardiológica observada nos exames bianuais de rotina do CBMDF, onde todos foram considerados aptos para o serviço operacional e sem qualquer restrição para as diferentes atividades laborais a que os bombeiros podem ser submetidos. A despeito da relativa homogeneidade da faixa etária e das condições laborais, o fato de serem adultos aparentemente saudáveis e potencialmente ativos, cria, por si só, uma expectativa de amplas faixas de variação em diversas variáveis fisiológicas em análise. Especialmente no que se refere à função autonômica cardíaca, esta constatação se traduz em índices, tanto temporais quanto espectrais, com grande dispersão, em uma faixa de normalidade bastante ampla e ainda carente de delimitações. Considerando-se evidências científicas que indicam redução da variabilidade da FC com o avanço da idade (OGLIARI et al., 2015), é plausível admitir que alguns voluntários da amostra estejam ainda na fase onde se manifesta grande capacidade funcional da regulação autonômica cardíaca, enquanto outros podem estar passando da fase auge da VFC (VOSS et al., 2015; MEERSMAN; STEIN, 2007).

Por outro lado, a referida homogeneidade da idade, aliada à pequena amplitude de variação da composição corporal e o fato de serem todos bombeiros com no mínimo 10 anos de serviço, fundamenta a hipótese de um possível padrão característico do grupo no que se refere à VFC. Entretanto, há que se considerar que existe uma ampla 
variedade de atividades operacionais a que bombeiros são expostos em suas rotinas (SMITH et al., 2016a; SOTERIADES et al., 2011). No caso do CBMDF existem quatro grandes grupos de atribuições: 1 - combate incêndios urbanos; 2 - combate a incêndios florestais; 3 - salvamentos e 4 - atendimento pré-hospitalar em emergências médicas. Essas são condições que possuem claramente uma base comum no que se refere a algumas características inerentes à profissão, como o trabalho em escalas, o estado de alerta constante, exposição a ruídos e alarmes, entre outras. Entretanto existem peculiaridades que podem implicar diferentes intensidades e quantidades de sobrecarga física e/ou emocional. Os voluntários aqui avaliados estavam todos em escalas de prontidão nos quartéis e podiam ser requisitados para atividades de qualquer um dos 4 grandes grupos de atribuições acima listados. Como a prontidão é caracterizada por atendimentos de múltiplas naturezas, que podem requerer maior ou menor aptidão física, composição corporal e/ou equilíbrio emocional, aumenta-se a expectativa de ampla faixa de variação em diversas variáveis em análise. Observe-se nesse aspecto que algumas variáveis funcionais de caracterização da amostra já evidenciam grande amplitude de valores, como na FC de repouso supino (variando entre 46 e $74 \mathrm{bpm}$ ) e na aptidão cardiorrespiratória (ACR), que apresentou amplitude de valores correspondentes a praticamente 5 METs.

No intuito de melhor caracterizar a amostra para permitir mais adequada interpretação dos resultados, há que se considerar, ainda, que a quase totalidade dos voluntários foi considerada ativa pelo IPAQ $(86,7 \%)$ e nenhum relatou permanecer na posição sentada por mais da metade do dia. Esses dois dados em conjunto nos permitem afirmar que o grupo estudado é significativamente mais ativo que a população em geral e também permanece menos tempo sentado em comparação à média populacional. Interessante notar que o cruzamento das informações obtidas pelo IPAQ e pelo pedômetro indicam que a caminhada não é uma alternativa prioritária de atividade física entre esses profissionais, visto que pelo padrão de passos acumulados no expediente e/ou pelo projetado por horas de vigília, um percentual relativamente pequeno dos voluntários atingia a recomendação de $10 \mathrm{mil} \mathrm{passos} /$ dia. Ao mesmo tempo, em detalhamento das resposta do IPAQ, convertidas para acúmulo de METs/semana, foi possível perceber que as caminhadas representaram, em valores medianos, apenas $20 \%$ do total da atividade física semanal. Este é um achado importante visto que esses profissionais poderiam se beneficiar de aumento da atividade física global (mais passos por dia), a despeito das demais atividades de intensidade moderada e/ou vigorosa que 
realizam, tendo em vista as fortes evidências que demonstram benefícios à saúde com aumento do número de passos dia, da atividade física leve e redução do tempo sentado, que é uma consequência natural do aumento dos passos diários (KATZMARZYK et al., 2009; PILLAY et al., 2015; DWYER et al., 2015). Há que se considerar ainda a limitação inerente do pedômetro para captar algumas atividades físicas da rotina de trabalho de bombeiros, como verificação diária de equipamentos, que envolve demandas de força e resistência muscular mas exigem pouco deslocamento.

É digno de nota, ainda, quanto a caracterização da amostra, o fato de que a qualidade de vida se mostrou relativamente comprometida, com todos valores medianos abaixo de $75 \%$ do máximo da escala, sendo que no domínio ambiente a mediana foi inferior a $60 \%$ desse máximo. Não existem pontos de corte nesta escala para classificação qualitativa da QV. Entretanto, os valores medianos aqui observados se assemelharam aos achados de QV, avaliada pelo mesmo instrumento, em industriários brasileiros trabalhando em linha de produção no turno noturno (COSTA et al., 2012), reforçando-se assim ser um valor abaixo do esperado dadas as melhores condições de trabalho e reconhecimento social de que os bombeiros disfrutam. Além de valores medianos relativamente reduzidos em relação ao máximo possível, observou-se que no domínio físico $17 \%$ dos voluntários apresentaram valores $\leq 50 \%$ do máximo e esse percentual foi de $37 \%$ no domínio ambiente. No outro extremo da escala, apenas $23 \%$ obtiveram escores $\geq 80 \%$ no domínio físico e $17 \%$ alcançaram esse patamar no domínio psicológico. Destaca-se neste aspecto que a QV não se constituiu em objeto específico de análise deste estudo, mas foi empregada com o intuito de caracterizar o grupo. Nesse sentido, há que se considerar que os dados de VFC aqui avaliados, que traduzem o estado da regulação autonômica do coração, devem ser interpretados neste contexto de uma QV auto-percebida que, além de relativamente diminuída, também apresentou ampla dispersão entre os voluntários, conforme se observa na Figura 13.

\subsection{Caracterização Funcional de Repouso}

As comparações dos valores de pressão arterial (Tabela 2), tanto sistólica quanto diastólica, ao longo das três avaliações mostrou equivalência estatística, o que indica absoluto equilíbrio de uma das principais variáveis alvo do aparelho cardiovascular, criando-se assim uma base semelhante do estado hemodinâmico dos voluntários nos três momentos. De outra forma, pode-se interpretar esse achado como 
demonstração de eficácia do sistema de regulação cardiovascular desses voluntários haja vista que em três momentos distintos, após repouso prévio de 5 minutos, o resultado final da regulação pressórica foi semelhante, a despeito de um deles (AVA3) estar teoricamente sujeito a influências diversas em relação a AVA1 e AVA2 (JUNQUEIRA JÚNIOR, 2007; GUYTON; HALL, 2002; HURTADO, 2004).

Um achado inesperado foi o aumento significativo da pressão arterial diastólica após mudança postural ativa, em todas as três avaliações. Sabe-se que a hipertensão postural, definida como aumentos da PA sistólica $>20 \mathrm{mmHg}$ e/ou a PA diastólica $>10$ mmHg após adoção das postura ortostática é relativamente comum em pessoas diabéticas e tem se associado a aumento de risco de doença cerebrovascular silenciosa no idoso e redução de risco de eventos cardiovasculares em diabéticos tipo II (WIIJKMAN et al., 2016). No caso do aumento aqui observado, há que se considerar que os aumentos medianos foram inferiores ao critério diagnóstico de $10 \mathrm{mmHg}$ e todos dentro da faixa de normalidade para pressão diastólica. Por outro lado, observou-se que em AVA1 e AVA2 nove voluntários atendiam ao critério diagnóstico e em AVA3 foram 11. Desses, 6 (20\%) apresentaram a resposta de hipertensão postural pela PAd em apenas uma das avaliações, 7 (23\%) em duas ocasiões e em 3 (10\%) deles o fenômeno ocorreu em todas as medidas. Não se identificou, nesses 3 voluntários, nenhuma característica antropométrica ou funcional nitidamente característica entre eles. Todos com IMC entre 24,0 e 26,0 kg/m² e tendo atingido no máximo 82,5\% da FCmax durante o expediente. Único destaque foi o fato de um deles apresentar resposta exacerbada de ativação simpática com a mudança postural, com valores de razão BF/AF variando de 2,8 para 11,7 em AVA1; de 1,5 para 21,9 em AVA2 e de 9,7 para 16,1 em AVA3.

No conjunto, portanto, considera-se que esse achado inesperado não deve ter significado clínico nesta amostra, especialmente por serem todos clinicamente saudáveis e não ter sido identificada nenhuma condição que justificasse tal comportamento da PA diastólica frente à mudança postural. Nesse contexto, não se pode desprezar a chance, ainda que pouco provável dada a consistência do fato, de artefato de medida. Por outro lado, o achado não pode ser ignorado e merecerá atenção futura em novas investigações nesta população.

Já a comparação dos valores basais de FC (Tabela 3) mostrou um grau fisiológico de taquicardia característico da mudança postural ativa, mediado pelo barorreflexo com vistas a preservar estável a pressão arterial e evitar hipotensão postural (JUNQUEIRA JÚNIOR, 2007; GUYTON; HALL, 2002; HURTADO, 2004). 
A estabilidade dos valores de pressão sistólica após mudança postural confirmam esse entendimento.

Por outro lado, observou-se que a FC de repouso, tanto supino quanto ortostático, foi menor em AVA1 em comparação a AVA2 e AVA3 (Tabela 3). Parece portanto haver aumento relativo da FC pelo simples fato de estar em prontidão nos quartéis e também ao final de um turno de trabalho. Destaca-se que apesar dos valores de FC em AVA3 serem estatisticamente semelhantes aos de AVA2, os valores medianos, tanto em AVA2 e quanto em AVA3 em SUP estão nas faixas de FC de repouso (60 - 64 e 65 - $69 \mathrm{bpm}$ ), e podem ser associadas a aumentos significativos de risco de morte súbita cardíaca em comparação com aqueles que apresentavam $\mathrm{FC}<60$ bpm, verificado em estudo prospectivo com 23 anos de seguimento em trabalhadores do sexo masculino de semelhante faixa etária (JOUVEN et al., 2005).

\subsection{Sobrecarga Cardiovascular Durante o Turno de Trabalho}

Um dos importantes achados desta pesquisa foi a verificação da ocorrência de momentos de elevada sobrecarga cardiovascular, avaliada pelo comportamento da FC durante um turno de rotineiro de atividade operacional. Nesse aspecto, confirmou-se a hipótese número 3 desta pesquisa. A despeito do tempo de exposição a intensidades de esforço físico vigoroso e muito vigoroso ter sido relativamente curto $( \pm 10$ min e \pm 1 min, respectivamente), do ponto do vista do risco cardiovascular para eventos cardíacos agudos, esse períodos curtos não podem ser, em hipótese alguma, desconsiderados visto que podem representar fator desencadear de problemas graves. Há que se considerar ainda o fato desses achados de tempos médios de exposição à elevada sobrecarga cardiovascular serem fruto de análises em situações reais de trabalho, que podem gerar, para alguns, períodos mais prolongados de exigências intensas. Destaca-se ainda que cerca de $40 \%$ dos voluntários atingiram as zonas de intensidade vigorosa e muito vigorosa em algum momento da jornada. Pesquisas realizadas em condições de simulação de incêndios verificou valores médios de FC de $173 \pm 18$ bpm em atividades que duraram entre 12 e 20 minutos e valores ainda elevados após 15 minutos de recuperação (SMITH et al., 2016b). Nesse aspecto, os presentes achados são absolutamente coerentes com resultados de uma pesquisa entre bombeiros norteamericanos com amostragem de abrangência nacional que indicou uma desproporção entre o tempo da jornada de trabalho de bombeiros utilizada em efetivo combate a 
incêndios (1 - 5\% da carga horária anual) e a proporção de mortes por doença coronariana em serviço $(32,1 \%)$ (KALES et al., 2007). O mesmo estudo mostrou, em oposição, que o tempo gasto em atividades de não emergência ( $29 \%$ do tempo total de jornada) correspondia a $15,4 \%$ das mortes. Portanto, sob a ótica do risco cardiovascular associado à atividade profissional desenvolvida, não são os 97,3\% de atividades leves, como aqui se verificou, que devem nortear a tomada de decisão, seja na esfera do planejamento operacional, seja no âmbito da saúde ocupacional. Uma questão decisiva a ser observada portanto é o período de tempo de muito intensa sobrecarga que pode, em indivíduos mais suscetíveis, desencadear eventos graves e/ou fatais.

Estão bem descritos na literatura os ajustes cardiovasculares associados à atividade de combate a incêndio, que usualmente cursa com intensa descarga simpática, aumento do trabalho muscular e necessidade de ajuste térmico frente à produção de calor pelo exercício e a atuação em ambientes extremamente quentes com equipamento protetor que pode pesar cerca de $25 \mathrm{~kg}$ e que dificulta a troca de calor com o ambiente (SMITH et al., 2016a). O estresse térmico, tão marcante na atividade de combate a incêndio, parece estar relacionado, por si só, com aumento do risco de eventos agudos coronarianos, por prejudicar a função endotelial (IVES et al., 2016). Estudo avaliando o efeito de quatro sucessivos períodos de 15-30 de simulação de combate a incêndio, intercalados por 20-40 de recuperação, mostrou aumento progressivo tanto da temperatura corporal quanto da $\mathrm{FC}$, atingindo valores de $38,7^{\circ} \mathrm{C}$ e $188 \mathrm{bpm}$ ao final de três horas de treinamento, em grupo de bombeiros com média de idade de 33 anos (HORN et al., 2013). O efeito acumulado, tanto na sobrecarga cardiovascular quanto térmica, não foi objeto do presente estudo, mas merece consideração em nosso meio visto se assemelhar com situações de combate a incêndios florestais, muitas vezes de longa duração e em clima bastante quente e seco. Desta forma, a presente pesquisa demonstrou, de forma pioneira, resultados semelhantes em termos da intensidade do esforço a que são submetidos bombeiros, porém em situação real, e não simulada, além de envolver diferentes atividades, que não só o combate a incêndios.

Conforme salientado anteriormente, deve-se observar que os achados do presente estudo se basearam em indivíduos aptos para o serviço, aparentemente saudáveis, não fumantes, não obesos e clinicamente saudáveis. Entretanto, há que se considerar a análise de risco nos militares mais suscetíveis para doença cardiovascular. Sabe-se que a maior suscetibilidade tem sido associada a fatores de risco cardiovasculares clássicos, como atividade física irregular, tabagismo, obesidade, 
estresse, privação do sono, dieta inadequada, além de condições subclínicas e/ou doença cardiometabólica conhecida (SMITH et al., 2016a). Lamentavelmente, várias dessas condições tem sido documentada em elevadas proporções entre bombeiros (NOGUEIRA et al., 2016; POSTON et al., 2011; BAUR et al., 2012). Desta forma, frente ao observado nesta pesquisa, deve-se considerar que a sobrecarga cardiovascular atingida em atividades operacionais de rotina podem ser suficientes para desencadear eventos cardíacos agudos de gravidade variada. Nesse contexto é importante ainda observar que não se trata apenas dos graves casos de morte súbita cardíaca em serviço, mas considerar também que para cada caso de morte, existem cerca de 25 eventos não fatais, o que dá a exata dimensão do problema (HAYNES; MOLLIS, 2015).

Dentro do contexto de suscetibilidade, há que se considerar, ainda, o potencial efeito da disfunção autonômica cardíaca no possível desencadeamento de arritmias graves e/ou morte súbita cardíaca (JUNQUEIRA JÚNIOR, 2012; SHEN et al., 2014; FUKUDA et al., 2015). Nesse sentido, a avaliação da FAC ganha importância, pois sua disfunção pode ser um sinal inicial de maior susceptibilidade, especialmente quando se considera o elevado percentual de cardiomegalia/hipertrofia ventricular esquerda entre bombeiros, que reconhecidamente se associa com maior risco de arritmias (KORRE et al., 2016a; KORRE et al., 2016b).

Outra consideração a ser levada em conta na análise da perspectiva do risco cardiovascular é o treinamento físico regular que pode proteger o indivíduo para o risco de morte súbita. Posicionamento oficial do Colégio Americano de Medicina do Esporte demonstra o risco de infarto agudo do miocárdio em associação com a realização de atividade física vigorosa (> 6 METs) nas 24 horas que antecederam os eventos. Entre aqueles que realizavam atividade vigorosa regular (típica de um regime de treinamento sistemático) o risco dobrado em relação a quem não havia praticado atividade intensa nas 24 horas antecedentes. Entretanto, entre aqueles que não praticavam atividade vigora regularmente, o aumento de risco foi de 100 vezes. Portanto, considerando que bombeiros têm necessidade profissional de realizarem atividades muito vigorosas, esse posicionamento reafirma a necessidade imperiosa de adequado e sistemático treinamento físico. Observe-se ainda que, na perspectiva do risco associado à atividades intensas, o ponto de corte em 6 METs é provavelmente bastante inferior ao que foi aqui utilizado, indicando, portanto que mesmo aqueles bombeiros que realizaram atividades na zona de intensidade moderada talvez estivessem acima de 6 METs. 
A título de ilustração, foram apresentadas as Figuras 14-18 na seção de resultados. Dentre elas, merece destaque o traçado apresentado na Figura 21 que é de um militar que apresentou intensidade muito vigorosa apenas no final de seu turno de trabalho. Posteriormente, verificou-se quase ausência de atividade vagal durante AVA3, neste mesmo voluntário, sugerindo uma combinação de fatores que poderiam caracterizar situação de maior vulnerabilidade.

\subsection{Avaliação da FAC por Meio da VFC}

Considerando-se pesquisa bibliográfica realizada em bases de dados internacionais e ressalvada as limitações de uma busca absolutamente abrangente de toda pesquisa produzida na área, a presente pesquisa parece ser a pioneira na avaliação FAC por meio da VFC em bombeiros, seja em condição controle, seja na verificação dos possíveis efeitos de um turno de trabalho rotineiro. Existem pesquisas avaliando o controle autonômico sobre o coração em bombeiros, mas usualmente tendo por base as respostas da FC e/ou da PA frente a estímulos variados, em especial durante o exercício e/ou em sua recuperação (BAUR et al., 2012).

Nesse aspecto, uma importante contribuição desta pesquisa consiste na própria descrição do padrão autonômico desses profissionais, em ambas situações: controle e durante o expediente de trabalho. Característica marcante da FAC nesses bombeiros é a grande dispersão de valores em praticamente todos os índices da VFC, sejam eles temporais e/ou espectrais. O mesmo se observa nas variações absolutas e relativas frente à mudança postural ativa, indicando que não apenas o estado basal supino e/ou ortostático são dispersos, mas também o grau de resposta frente a um estímulo fisiológico como a mudança postural ativa.

Os achados descritos da FAC entre bombeiros contribuem de forma importante para o melhor entendimento do fenômeno da regulação autonômica cardiovascular, em especial nesta categoria profissional, porém sua interpretação é limitada. Com as evidências hoje disponíveis, a ausência de grupo controle de trabalhadores não bombeiros e, em especial, a quase inexistência de valores normativos para os índices da VFC por sexo, faixa etária e condição clínica, entre outras variáveis, limita interpretações de ordem mais qualitativa. Entretanto, observa-se que os valores medianos e o respectivo grau de dispersão foram semelhantes aos encontrados em estudo entre homens não atletas, porém de média de idade um pouco inferior (28 anos) 
e ACR consideravelmente superior (MOLINA et al., 2016). Nesse aspecto, reforça-se o entendimento de que boa parte da dispersão observada seja decorrente da própria natureza da VFC na faixa etária e na condição clínica estudada. Apesar da amostra não ser tecnicamente composta apenas por adultos jovens, a faixa etária estudada ainda representa um espectro de idade de elevada atividade autonômica na diminuição da VFC associada com a idade (VOSS et al., 2015).

Comparando-se os valores medianos dos índices da VFC observados com aqueles encontrados entre jovens atletas e/ou jovens ativos, os valores do grupo aqui estudado são consideravelmente menores (em alguns índices a diferença chega a ser de $50 \%$ ), tanto para índices temporais quanto espectrais, o que pode ser fruto das diferenças de idade e/ou de outras características das amostras, como da ACR (MOLINA et al., 2013). Por outro lado, comparando-se os valores aqui encontrados com aqueles sugeridos em proposta de valores normativos da VFC em registros de curto prazo, observou-se similaridade entre valores de RMSSD do repouso supino em AVA1, porém com valores praticamente 5 vezes menores para as áreas absolutas de baixa e alta frequência, o que indicaria menor modulação global nos voluntários bombeiros (NUNAN; SANDERCOCK; BRODIE, 2010). A natureza transversal do estudo, assim como a normalidade da condição clínica dos voluntários, não permite qualquer especulação no sentido de considerar que os valores aqui observados representam uma redução anormal da modulação autonômica. Por outro lado, há que se considerar esses achados na perspectiva de possível acompanhamento longitudinal desses voluntários, tendo em vista a relação entre depressão da VFC com aumento da mortalidade cardiovascular (VILLAREAL; LIU; MASSUMI, 2002).

Um outro achado importante foi a dominância simpática do equilíbrio vagosimpático de repouso, manifestada pelos valores da Razão BF/AF, que foram superiores a um em todas as três avaliações. Nesse sentido, rejeita-se a hipótese número um desta pesquisa. Apesar de valores medianos muito próximos a um, houve predominância relativa da modulação simpática. Entretanto, observou-se que havia 10 voluntários cujos valores de razão BF/AF no supino em AVA1 eram inferiores a um. Assim, não só se reforça a existência de grande dispersão nos padrões de modulação autonômica cardíaca nesses indivíduos, como se identificou ao menos dois padrões bem distintos da FAC no repouso supino entre esses bombeiros. Este foi, inclusive, o motivo pelo qual também se avaliou as respostas da FAC frente a um turno de trabalho em subgrupos secundo a dominância vago-simpática no repouso supino em AVA1. Tomando-se por base o fato 
da atividade simpática ser, em teoria, pró-arritmogênica, é lícito especular que dois terços desses voluntários, os simpaticotônicos, apresentaram, teoricamente, maior risco de ocorrência de arritmias, comparativamente ao terço que mostrou dominância vagal (SHEN et al., 2014; PUMPRLA et al., 2002; DEKKER et al., 2000). Vale ressaltar que esta especulação merece investigação futura.

Do ponto de vista dos efeitos da jornada de trabalho em comparação com a condição controle em laboratório, observaram-se diferenças nas médias dos iRR, tanto supino quanto ortostático, o que está em acordo com a taquicardia relativa observada nas avalições do quartel comparadas com aquelas do laboratório, conforme comentado anteriormente.

No contexto da avaliação da VFC e suas possíveis implicações com o risco cardiovascular, um achado de destaque foi a significativa redução do PNN50\%, bem aceito como marcador da atividade vagal (TASK FORCE, 1996; KLEIGER et al., 2005), em AVA3, comparativamente a AVA1. Significa dizer que após um turno de trabalho rotineiro em atividades operacionais, os bombeiros mostraram menor modulação vagal, que é considerada potencialmente cardioprotetora, especialmente em condições de fibrilação ventricular (FUKUDA et al., 2015; SHEN et al., 2014). Observe-se que nenhum dos índices espectrais mostrou modificação significativa na comparação entre as 3 avaliações. A maior dispersão dos índices espectrais pode justificar este fato, além de uma possível maior sensibilidade do PNN50\% visto ser um índice estatístico no domínio do tempo e não fruto de transformações matemáticas, como o são os índices espectrais.

Importante, ainda, comentar que a análise por subgrupo segundo o estado autonômico basal, também não revelou nenhum padrão específico de resposta entre as três avaliações, seja entre os vagotônicos, seja entre os simpaticotônicos. As poucas diferenças estatísticas apontadas no capítulo de resultados não apresentaram convergência que sustente padrão diferenciado de resposta entre os dois subgrupos.

Ainda quanto à menor modulação vagal em AVA3 SUP é fundamental estabelecer um elo imediato com os achados de correlação entre a ACR e os índices da VFC. Como se vê na Tabela 9, houve importante e consistente correlação positiva entre a ACR e todos os índices temporais em SUP e quase todos em ORT, além de correlação significativa em todos índices espectrais de áreas absolutas. Significa dizer portanto que quanto maior a ACR, maior a modulação vagal e autonômica global, o que coincide com achados anteriores (BUCHIHEIT; GINDRE, 2006). Essa associação entre ACR e 
índices da VFC, em especial da modulação vagal, tem sido alvo de discussão na literatura visto não haver convergência de resultados. Além de diferenças metodológicas entre os diferentes estudos, parece haver também influência da especificidade das modalidades esportivas envolvidas no aumento da ACR (MOLINA et al., 2013; AZEVEDO et al., 2014).

Interessante notar, entretanto, que essa correlação consistente em AVA1 praticamente desaparece na avaliação feita no início do expediente (AVA2). Entretanto, essas complexas interações voltam a se manifestar em AVA3, seja nos marcadores temporais da atividade vagal em SUP e em ORT, quanto na área espectral de alta frequência (Tabela 8). Este é um achado que se reveste de extrema importância, uma vez que se observou redução da modulação vagal em AVA3 ORT. Nesse sentido, abrese perspectiva no sentido em que o aumento da ACR possa representar aumento no nível de cardioproteção, especialmente em momentos críticos onde a atividade vagal se mostrou reduzida. Assim, um aumento da ACR poderia ser acompanhando de aumento da modulação vagal e global após um período de estresse vivenciado pelo aparelho cardiovascular, representado pelas altas cargas de trabalho a que bombeiros estão expostos em suas rotinas de trabalho. Importante mencionar que esta hipótese requer avaliação futura para sua confirmação.

\subsection{Limitações do Estudo}

A despeito de aspectos metodológicos de destaque que reforçam a importância dos achados, algumas limitações merecem ser discutidas. A natureza transversal limita a interpretação de alguns achados, em especial quanto ao julgamento de normalidade do padrão de regulação autonômica descrito, visto não haver seguimento para cruzamento dos dados de VFC com desfechos desfavoráveis em saúde. Há que se considerar ainda o relativo reduzido tamanho amostra. Nesse aspecto, entende-se que a limitação maior recaiu quando da análise de subgrupos, visto que o grupos dos vagotônicos ficou limitado a 10 voluntários. Entretanto, priorizou-se maior homogeneidade da amostra, aumentando-se assim a validade interna do estudo.

O número mediano de dias de intervalo entre AVA1 e AVA2/AVA3 (12 dias) se mostrou bastante adequado para as análises pretendidas (SILVA \& JUNQUEIRA, 1993; KLEIGER et al., 1991), mas há potencial limitação em alguns casos onde o intervalo se prolongou. Esta é uma limitação que foi consequente da dificuldade de obtenção de 
voluntários e de seguimento nas avaliações, visto haver necessidade de priorizar aspectos pessoais e de rotinas de trabalho. Entretanto, essa potencial influência fica mitigada visto ter ocorrido em poucos casos (apenas 10\% acima de 60 dias) e pelo fato de ter se adotado como padrão de conduta a conferência, junto aos voluntários, de que as condições gerais de vida, de trabalho, de treinamento físico e de composição corporal se mantiveram estáveis ao longo das três avaliações. Esse cuidado metodológico ocorreu para todos os voluntários e não somente para aqueles onde AVA2/AVA3 tiveram que ser realizadas com intervalo mais dilatado em relação a AVA1.

$\mathrm{Na}$ interpretação dos achados relativos aos efeitos do turno de trabalho sobre a FAC, há que se considerar a variação nas horas do dia em que as avaliações foram feitas, visto que AVA1 e AVA2 foram pela manhã e AVA3 no final da tarde. Apesar de evidências sobre a variação circadiana da VFC (MALPAS; PURDIE, 1990), o objetivo deste estudo foi verificar o estado autonômico momentâneo, ainda que resultantes de influências da jornada de trabalho e/ou de variações do ritmo circadiano. Ha que se considerar ainda que alguns dados indicam estabilidade da FAC em diferentes turnos na postura supina, o que minimiza o possível impacto da variação nos horários de avaliação (SILVA \& JUNQUEIRA, 1993).

Finalmente, há que se considerar possível limitação pelo fato da ACR ter sido estimada em condição de não-exercício, ou seja, por questionário. Novamente, entendese que o possível impacto desta limitação seja minimizado nesta pesquisa visto se tratar de método validado, com erro de estimativa menor que de alguns testes submáximos realizados em esteira (JACKSON et al., 1990). Destaca-se ainda que o questionário utilizado já foi empregado anteriormente em pesquisas com bombeiros, tendo boa aceitação na literatura especializada (POSTON et al., 2011).

Terminadas as interpretações dos principais fenômenos observados na presente pesquisa, passar-se-á às conclusões e considerações finais. 


\section{CONCLUSÕES}

Nesta pesquisa desenvolvida em um grupo de bombeiros do sexo masculino, clinicamente saudáveis e aptos para o serviço operacional, concluiu-se que:

1 - A função autonômica cardíaca de repouso se mostrou com padrão de grande dispersão inter-individual, de dominância simpática e com indícios de menor modulação global comparativamente a outros achados na literatura em grupos de não bombeiros.

2 - Não há um padrão único de modulação autonômica cardíaca entre esses bombeiros, sendo claramente identificados ao menos dois padrões típicos: um subgrupo de dominância vagal (minoritário) e outro de ampla dominância da modulação simpática no repouso supino.

As conclusões 1 e 2 implicam a rejeição parcial da hipótese número um desta pesquisa, no sentido em que apenas um terço do grupo mostrou dominância vagal no repouso supino.

3 - Não houve diferença significativa entre os índices de VFC avaliados em ambiente controlado no laboratório e aqueles avaliados nos quartéis, antes do início das atividades laborais, com exceção da média de iRR, que reflete taquicardia relativa observada no repouso supino no quartel, comparativamente à condição controle.

4 - Quanto aos efeitos de um turno diurno de trabalho operacional, houve diminuição da modulação vagal, expressa pela redução significativa do PNN50\%, ao final do turno comparativamente à condição referência de controle em laboratório.

As conclusões 3 e 4 implicam a confirmação da hipótese dois desta pesquisa, no sentido em que houve redução significativa de indicador da modulação vagal ao término de um turno de trabalho, e que, neste momento, o equilíbrio vago-simpático manifestava dominância simpática.

5 - A atividade operacional de rotina de bombeiros militares implica períodos curtos de sobrecarga cardiovascular intensa e/ou muito intensa, e predomínio de longos períodos de baixa demanda cardiovascular. Conclui-se, também, que a sobrecarga é variada e se mostrou dependente dos atendimentos prestados pelos bombeiros ao longo do turno de trabalho. Nesse sentido, confirmam-se as hipóteses três e cinco desta pesquisa.

6 - Os bombeiros avaliados se mostram fisicamente mais ativos do que a população em geral, assim como relataram ficar menos tempo sentado do que a média populacional. Entretanto, a maioria dos voluntários apresentou aptidão 
cardiorrespiratória menor do que o mínimo recomendado para o adequado desempenho profissional.

7 - Houve associação positiva entre a aptidão cardiorrespiratória e índices temporais e espectrais da VFC quando avaliada em ambiente controlado. Essa associação foi praticamente inexistente quando a VFC foi medida no início do expediente e voltou a ser significativa em alguns índices quando medida ao final do expediente. Esses achados confirmam parcialmente a hipótese número quatro e sugerem que a relação entre a aptidão cardiorrespiratória e regulação autonômica é diferente na condição de repouso em situação metodologicamente controlada em relação ao repouso do ambiente de trabalho.

Em resumo, conclui-se que a VFC de bombeiros militares, no repouso, se caracterizou por grande dispersão inter-individual e dominância simpática. Os bombeiros avaliados apresentaram reduzida modulação vagal na postura ortostática ao término do expediente de trabalho, comparativamente à situação controle. Conclui-se ainda que a atividade operacional desses bombeiros militares se desenvolveu majoritariamente em zona de intensidade cardiovascular leve, porém intercalada com curtos períodos de elevadíssima sobrecarga cardiovascular que, por si só, requerem adequado condicionamento físico. A concomitância de reduzida modulação vagal ao final do turno de trabalho com a correlação positiva entre a aptidão cardiorrespiratória e indicadores de modulação autonômica parassimpática e/ou global reforçam a importância da boa aptidão cardiorrespiratória entre esses profissionais devido a seu potencial efeito cardioprotetor.

Os achados desta pesquisa apresentam importante contribuição para o entendimento da modulação autonômica cardíaca entre bombeiros, no contexto da necessidade de se buscar métodos de fácil aplicação e de baixo custo na identificação de indivíduos mais suscetíveis para o desenvolvimento de eventos cardiovasculares agudos durante o desempenho das atividades laborais. Como desdobramentos importantes, destaca-se a necessidade de novas pesquisas que objetivem avaliar o possível efeito cardioprotetor associado ao aumento do treinamento físico, seus efeitos na modulação autonômica pré e pós-jornada de trabalho, bem como de procedimentos de avaliação no âmbito da saúde ocupacional, visando à detecção precoce de indivíduos mais suscetíveis. Desta forma, a pesquisa contribui para o desenvolvimento de estratégias de atuação preventiva dentro desta singular corporação, colaborando-se assim para que se 
possa atingir cada vez de forma mais abrangente seu lema maior: "VIDAS ALHEIAS E RIQUEZAS SALVAR". 


\section{REFERÊNCIAS}

ACSM. AMERICAN COLLEGE OF SPORTS MEDICINE. Diretrizes do ACSM para os testes de esforço e sua prescrição. 6. ed.. Rio de Janeiro: Guanabara Koogan, 2006.

ALBRIGHT, C.; THOMPSON, D. L. The Effectiveness of Walking in Preventing Cardiovascular Disease in Women: A Review of the Current Literature. Journal of Women's Health, v. 15, n. 3, p. 271-280, 2006.

AL-ZAITI, S. S.; CAREY, M. G. The Prevalence of Clinical and Electrocardiographic Risk Factors of Cardiovascular Death Among On-duty Professional Firefighters. J. Cardiovasc. Nurs., v. 30, n. 5, p. 440-446, 2015.

AMARAL, L. Manual Básico de Bombeiro Militar. Rio de Janeiro: CBMERJ, 2014.

ARAIZA, P. HEWESM H.; GASHETEW, C.; VELLA, C. A.; BURGE, M. R. Efficacy of a pedometer-based physical activity program on parameters of diabetes control in type 2 diabetes mellitus. Metabolism, v. 55, n. 10, p. 1382-1387, 2006.

ASTE, G. História do Corpo de Bombeiros. Rio de Janeiro: Imprensa Oficial do Estado do Rio de Janeiro, 1991.

AZEVEDO, L. F. PERLINGEIRO, P. S.; HACHUL, D. T.; GOMES-SANTOS, I. L.; BRUM, P. C.; ALLISON, T. G.; NEGRÃO, C. E.; DE MATOS, L. D. Sport modality affects bradycardia level and its mechanisms of control in professional athletes. International Journal of Sports Medicine, v. 35, n. 11, p. 954-959, 2014.

BASSETT, D. R. AINSWORTH, B. E.; SWARTZ, A. M.; STRATH. S. J.; O'BRIEN, W. L.; REI, G. A. Validity of four motion sensors in measuring moderate intensity physical activity. Medicine and Science in Sports and Exercise, v. 32, n. 9, p. 471480, 2000.

BASTOS, J. L. D.; DUQUIA, J. P. Um dos delineamentos mais empregados em epidemiologia: estudo transversal. Scientia Medica, v. 17, n. 4, p. 229-232, Porto Alegre, out./dez. 2007

BAUR, D. M. CHRISTOPHI, C. A.; TSISMENAKIS, A. J.; COZINHEIRO, E. F.; KALES, S. N. Cardiorespiratory fitness predicts cardiovascular risk profiles in career firefighters. J. Occup. Environ. Med., v. 53, n. 10, p. 1155-1160, 2011.

BAUR, D. M. et al. Low fitness is associated with exercise abnormalities among asymptomatic firefighters. Occup. Med., v. 62, n. 7, p. 566-569, 2012.

BAXTER, C. S.; LEIBA, A.; CHRISTOPHI, C. A.; KALES, S. N. Ultrafine particle exposure during fire suppression - is it an important contributory factor for coronary heart disease in firefighters? J. Occup. Environ. Med., v. 52, p. 791-796, 2010.

BJORGAAS, M.; VIK, J. T.; SAETERHAUG, A.; LANGLO, L.; SAKSHAUG, T.; MOHUS, R. M.; GRILL, V. Relationship between pedometer-registered activity, 
aerobic capacity and self-reported activity and fitness in patients with type 2 diabetes. Diabetes, Obesity and Metabolism, v. 7, n. 6, p. 737-744, 2005.

BRANDT-RAUF, P. W.; FALLON JR., L. F.; TARANTINI, T.; IDEMA, C.; ANDREWS, L. Health hazards of firefighters: exposure assessment. Br. J. Ind. Med., V. 45, P. 606-612, 1988.

BRASIL. Câmara Federal. Lei n. 8.255, de 20 de novembro de 1991, dispõe sobre a organização básica do Corpo de Bombeiros Militar do Distrito Federal, e dá outras providências. Brasília: Câmara Federal, 1991.

BROWN, T. E.; BEIGHTOL, L. A.; KOH, J.; ECKBERG, D. L. Important influence of respiration on human R-R interval power spectra is largely ignored. J. Appl. Physiol., v. 75, n. 5 , p. $2310-2317,1993$.

BUCHHEIT, M.; GINDRE, C. Cardiac parasympathetic regulation: respective associations with cardiorespiratory fitness and training load. Am. J. Physiol. Heart Circ. Physiol., v. 291, n. 1, p. 451-458, jul. 2006.

CARTER, J. M.; RAYSON, M. P.; WILKINSON, M. S.; RICHMOND, V.; BLACKER, S. Strategies to combat heat strain during and after firefighting. Bristol BS81BA, UK, 2007.

CARVALHO, J. L. A; ROCHA, A. F.; NASCIMENTO, F. A. O.; SOUZA NETO, J.; JUNQUEIRA JR., L. F. Development of a Matlab software for analysis of heart rate variability. ICSP'2002 Proceeding - 6th Internacional Conference on Signal Processing. Vol. 02: 1488-1491,2002.

CBMGO. Corpo de Bombeiros Militar do Estado de Goiás. História da Corporação. Goiânia: SSP/COMANDO GERAL DO CBMGO, 2016.

CHAN C. B.; SPANGLER, E. VALCOUR, J.; TUDOR-LOCKE, C. Cross-sectional relationship of pedometer-determined ambulatory activity to indicators of health. Obesity Research, v. 11, n. 12, p. 1563-1570, 2003.

CHOI, B.; SCHNALL, P. L.; DOBSON, M.; GARCIA-RIVAS, J.; KIM, H. R.; ZALDIVAR, F.; ISRAEL, L.; BAKER, D. Very Long (> 48 hours) Shifts and Cardiovascular Strain in Firefighters: a Theoretical Framework. Annals of Occupational and Environmental Medicine, v. 26, n.5, 2014.

CORNELISSEN, V. A.; VERHEYDEN, B.; AUBERT, A. E.; FAGARD, R. H. Effects of aerobic training intensity on resting, exercise and post-exercise blood pressure, heart rate and heart-rate variability. J. Hum. Hypertens., v. 24, n. 3, p. 175-182, 2010.

COSTA, C. S.; FREITAS, E. G.; MENDONÇA, L. C. S.; ALEM, M. E. R.; COURY, H. J. C. G. Work ability and quality of life of Brazilian industrial workers. Ciên. Saúde Colet., v. 17, n. 6, p. 1635-1642, jun. 2012.

CROUTER, S. E.; SCHNEIDER, P. L.; KARABULUT, M.; BASSETT JR., D. R.Validity of 10 electronic pedometers for measuring steps, distance, and energy cost. Medicine and Science in Sports and Exercise, v. 35, n. 8, p. 1455-1460, 2003. 
DEKKER, J.M.; CORVO, R.S.; FOLSOM, A.R.; HANNAN, P. J.; LIAO, D.; SWENNE, C. A.; SCHOUTEN, E. G. Low heart rate variability in a 2-minute rhythm strip predicts risk of coronary heart disease and mortality from several causes: the ARIC Study. Atherosclerosis Risk In Communities. Circulation, v. 102, n. 11, p. 1239-1244, 2000 .

DE LANGE, A. H.; KOMPIER, M. A.; TARIS, T. W.; GEURTS, S. A.; BECKERS, D. G.; HOUTMAN, I. L.; BONGERS, P.M. A hard day's night: a longitudinal study on the relationships among job demands and job control, sleep quality and fatigue. J. Sleep. Res., v. 18, p. 374-383, 2009.

DOCKERY, D. W. Epidemiologic evidence of cardiovascular effects of particulate air pollution. Environ. Health Perspect., v. 109, (Suppl. 4), p. 483-486, ago. 2001.

DONCHEVA, N. I.; NIKOLOVA, R. I.; DANEV, S. G. Overweight, dyslipoproteinemia, and heart rate variability measures. Folia Med., v. 45, n. 1, p. 8-12, 2003.

DURAND, G.; TSISMENAKIS, A. J.; JAHNKE, S. A.; BAUR, D. M.; CHRISTOPHI, C. A.; KALES, S.N. Firefighters' physical activity: relation to fitness and cardiovascular disease risk. Medicine and science in Sports and Exercise, v. 43, n. 9, p. 1752-1759, 2011.

DWYER, T.; PEZIC, A.; SUN, C.; COCHRANE, J.; VENN, A.; SRIKANTH, V.; JONES, G.; SHOOK, R.; SUI, X.; ORTAGLIA, A.; BLAIR, S.; PONSONBY, A. L. Objectively Measured Daily Steps and Subsequent Long Term All-Cause Mortality: The Tasped Prospective Cohort Study. PLOS One, v. 4, n. 10, p. 11, nov. 2015.

EKELUND, U.; STEENE-JOHANNSSEN, J.; BROWN, W. J.; FAGERLAND, M. W.; OWEN, N.; POWELL, K. E.; BAUMAN, A.; LEE, M. Does physical activity attenuate, or even eliminate, the detrimental association of sitting time with mortality? A harmonised meta-analysis of data from more than 1 million men and women. The Lancet, v. 388, n. 10051, p. 1302-1310, set. 2016.

ELSNER, K. L.; KOLKHORST, F. W. Metabolic demands of simulated firefighting tasks. Ergonomics, v. 51, p. 1418-1425, 2008.

FAHS, C. A.; ROSSOV, L. M.; SEO, D. I.; LOENNEKE, J. P.; SHERK, V.D.; KIM, E.; BEMBEN, D. A.; BEMBEN, M. G. Effect of different types of resistance exercise on arterial compliance and calf blood flow. Eur. J. Appl. Physiol., v. 111, n. 12, p. 2969-2975, 2011.

FERNHALL, B.; FAHS, C. A.; CORNO, G.; ROWLAND, T.; SMITH, D. Acute effects of firefighting on cardiac performance. Eur. J. Appl. Physiol., v. 112, p. 735$741,2012$.

FIREFIGHTERS BRASIL. História do Corpo de Bombeiros. Firefighters Brasil, 22 ago. 2011.

FLECK M. P. A.; LOUZADA, S.; XAVIER, M.; CHACHAMOVICH, E.; VIEIRA, G.; SANTOS, L.; PINZON, V. Aplicação da versão em português do instrumento abreviado 
de avaliação da qualidade de vida "WHOQOL-bref". Rev. Saúde Pública, v. 34, n. 2, p. 178-183, 2000.

FRANKE, W. D.; ANDERSON, D. F. Relationship between physical activity and risk factors for cardiovascular disease among law enforcement officers. Journal of Occupational Medicine, v. 36, n. 10, p. 1127-1132, 1994.

FRIEL, J. K.; STONES, M. Firefighters and heart disease. Am. J. Public Health, v. 82, n. 8, p. 1175-1176, ago. 1992.

FUKUDA, K.;KANAZAWAM, K.; AIZAWA, Y.; ARDELL, J. L.; SHIVKUMAR, K. Cardiac innervation and sudden cardiac death. Circ. Res., v. 116, n. 12, p. 2005-2019, 2015.

GOLDBERG, M. S.; BURNET, R. T.; BAILAR, J. C. III; TAMBLYN, R.; ERNEST, P.; FLEGEL, K.; BROOK, J.; BONVALOT, Y.; SING, R.; VALOIS, M. F.; VINCENT, R. Identification of persons with cardiorespiratory conditions who are at risk of dying from the acute effects of ambient air particles. Environ. Health Persp., v. 109, (Suppl 4), p. 487-494, 2001.

GUYTON, A.C.; HALl, J.E. Tratado de Fisiologia Médica. 12. ed. ed. Rio de Janeiro: Elsevier, 2011.

HASKELL, W.L.; LEE, I. M.; PATE, R. R.; POWELL, K. E.; BLAIR, S. N.; FRANKLIN, B. A.; MACERA, C. A.; HEATH, G. W.; THOMPSON, P. D.; BAUMAN, A. Physical activity and public health: Updated recommendation for adults from the American College of Sports Medicine and the American Heart Association. Med. Sci. Sports Exerc., n. 39, 1423-1434, 2007.

HAYNES, H.; MOLIS, J. U.S. Firefighter Injuries-2014. National Fire Protection Association, Quincy, MA., 2015.

HIRSCH, J. A.; BISHOP, B. Respiratory sinus arrhythmia in humans: how breathing pattern modulates heart rate. Am. J. Physiol., v. 241, n. 4, 620-629, out. 1981.

HOLDER, J. D., STALLINGS, L. A.; PEEPLES, L.; BURRESS, J. W.; KALES, S, N. Firefighter heart presumption retirements in Massachusetts 1997-2004. J. Occup. Environ. Med., n. 48, p. 1047-1053, 2006.

HORN, G. P.; BLEVINS, S.; FERNHALL, B.; SMITH, D. L. Core temperature and heart rate response to repeated bouts of firefighting activities. Ergonomics, v. 56, n. 9, p. 1465-73, 2013.

HURTADO, M. C. C. A ação do sistema neurovegetativo sobre o coração. Fisiologia Humana de Houssay. Porto Alegre: Artmed, 2004.

IVES, S. J.; WHARTON, M.; FEHLING, P. C.; SMITH, D. L. Exercise-induced heat stress disrupts the shear-dilatory relationship. Exp. Physiol., v. 101, n. 12, p. 15411551, dez. 2016.

IWANE, M.; ARITA, H.; TOMIMOTO, S.; SATANI, O.; MATSUMOTO, M.; MIYASHITA, K.; NISHIO, I. Walking 10,000 steps/day or more reduces blood 
pressure and sympathetic nerve activity in mild essential hypertension. Hypertension Research, v. 23, n. 6, p. 573-580, 2000.

JACKSON, A. S.; BLAIR, S. N.; MAHAR, M. T.; WIER, L. T.; ROSS, R. M.; STUTEVILLE, J. E. Prediction of functional aerobic capacity without exercise testing. Med. Sci. Sports Exerc., v. 22, n. 6, p. 863-870, dez. 1990.

JONSSON, A.; SEGESTEN, K.; MATTSSON, B. Post-traumatic stress among Swedish ambulance personnel. Emerg. Med. J., v. 20, p. 79-84, 2003.

JOUVEN, X. EMPANA, J-P.; SCHWARTZ, P. J.; DESNOS, M.; COURBON, D.; DUCIMETIÈRE, P. Heart-rate profile during exercise as a predictor of sudden death. New Engl. J. Med., v. 12, n. 352, Supp.19, p. 1951-1958, maio 2005.

JUNQUEIRA JÚNIOR, L. F. Regulação cardiovascular. Brasília: UnB, maio 2007.

Teaching cardiac autonomic function dynamics employing the Valsalva (Valsalva-Weber) maneuver. Adv. Physiol. Educ., v. 32, n. 1, p. 100-106, 2008.

Insights into the clinical and functional significance of cardiac autonomic dysfunction in Chagas disease. Rev. Soc. Bras. Med. Trop., v. 45, n. 2, p. 243-252, 2012.

KALES, S. N. SOTERIADES, E. S.; CHRISTOUDIAS, S. L.; CHRISTIANI, D. C. Firefighters and on-duty deaths from coronary heart disease: a case control study. Environ. Health, v. 2, n. 14, p. 1-13, nov. 2003.

KALES, S. N.; CHRISTIANI, D. C. Acute chemical emergencies. New Engl. J. Med., v. 19, n. 350, (Supp. 8), p. 800-808, fev. 2004.

KALES, S. N.; TSISMENAKIS, A. J.; ZHANG, C.; SOTERIADES, E. S. Blood pressure in firefighters, police officers, and other emergency responders. Am. J. Hypertens., v. 22, n. 1, p. 11-20, jan. 2009.

KALES, S. N.; SOTERIADES, E. S.; COSTAS, D.; CHRISTOPHI, A.; CHRISTIANI, D. C. Emergency duties and deaths from heart disease among firefighters in the United States. The New England Journal of Medicine, v. 356, n. 12, p. 1207-1215, 2007.

KANNEL, W. B.; KANNEL, C.; PAFFENBARGER JR., R. S.; CUPPLES, L. A. Heart rate and cardiovascular mortality: the Framingham Study. Am. Heart. J., v. 113, n. 6, p. 1489-1494, 1987.

KARASON, K.; MØLGAARD, H.; WIKSTRAND, J.; SJÖSTRÖM, G. Heart rate variability in obesity and the effect of weight loss. Am. Journal of Cardiol., v. 83, n. 8, p. 1242-1247, 1999.

KATZMARZYK, P. T.; CHURCH, T. S.; CRAIG, C. L.; BOUCHARD, C. Sitting time and mortality from all causes, cardiovascular disease, and cancer. Medicine and Science in Sports and Exercise, v. 41, n. 5, p. 998-1005, 2009.

KLEIGER, R. E.; BIGGER, J. T.; BOSNER, M. S.; CHUNG, M. K.; COOK, J. R.; ROLNITZKY, L. M.; STEINMAN, R.; FLEISS, J.R. Stability over time of variables 
measuring heart rate variability in normal subjects. The American Journal of Cardiology. 1991; 68:626-630.

KLEIGER, R. E.; STEIN, P. K.; BOSNER, M. S.; ROTTMAN, J. N. Time-domain measurements of heart rate variability. In: MALIK, M.; CAMM, A. J. (Eds.). Heart rate variability. Armonk, New York: Futura Publishing Company, 1995.

KORRE, M.; SAMPANI, K.; PORTO, L. G. G.; FARIOLI, A.; YANG, Y.; CHRISTIANI, D. C.; COSTAS, D.; CHRISTOPHI, A.; LOMBARDI, D. A.; KOVACS, R. J.; MASTOURI, R.; ABBASI, S.; STEIGNER, M.; MOFFATT, S.; SMITH, D. L.; KALES, S. N. Cardiac Enlargement in US Firefighters: Prevalence Estimates by Echocardiography, Cardiac Magnetic Resonance and Autopsies. J. Clin. Exp. Cardiolog., n. 7, p. 459-464, 2016 a.

KORRE, M.; PORTO, L. G. G.; FARIOLI, A.; YANG, Y.; CHRISTIANI, D. C.; CHRISTOPHI, A.; LOMBARDI, D. A.; KOVACS, R. J.; MASTOURI, R.; ABBASI, S.; STEIGNER, M.; MOFFATT, S.; SMITH, D. L.; KALES, S. N. Effect of Body Mass Index on Left Ventricular Mass in Career Male Firefighters. Am. J. Cardiol., n. 118, p. 1769-1773, 2016b.

KUEHL， K. S.; KISBU-SAKARYA， Y.; ELLIOT, D. L.;MOE， E. L.; DEFRANCESCO, C. A.; MACKINNON, D. P.; LOCKHART, G.; GOLDBERG, L.; KUEHL, H. E. Body mass index as a predictor of firefighter injury and workers' compensation claims. J. Occup. Environ. Med., n. 54, p. 579-582, 2012.

LEMON, P. W.; HERMISTON, R. T. The human energy cost of firefighting. J. Occup. Med., v. 19, p. 558-562, 1977.

MACIEL, B. C.; GALLO JR., L.; MARIN NETO, J. A.; LIMA FILHO, C. E.; TERRA FILHO, J.; MANÇO, J. C. Parasympathetic contribution to bradycardia induced by endurance training in man. Cardiovasc. Res., v. 19, n. 10, p. 642-648, 1985.

MALLIANI, A.; PAGANI, M.; LOMBARDI, F.; FURLAN, R.; GUZZETTI, S.; CERUTTI, S. Spectral analysis to assess increased sympathetic tone in arterial hypertension. Hypertension, n. 17, (suppl), p. 36-41, 1991.

MALPAS, S. C.; PURDIE, G. L. Circadian variation of heart rate variability. Cardiovasc. Res., v. 24, p. 210-213, 1990.

MBANU, I.; WELlENIUS, G. A.; MITTLEMAN, M. A.; PEEPLES, L.; STALLINGS, L. A.; KALES, S. N. Seasonality and Coronary Heart Disease Deaths in United States Firefighters. Chronobiology International, v. 24, n. 4, p. 715-726, jul. 2007.

McCORMACK, G.; GILES-CORTI, B.; MILLIGAN, R. Demographic and individual correlates of achieving 10,000 steps/day: use of pedometers in a population-based study. Health Promotion J. of Australia, v. 17, p. 43-47-2006.

MEERSMAN, R. E.; STEIN, P. K. Vagal modulation and aging. Biological Psychology, v. 74, n. 2, p. 165-173, 2007. 
MEHTA R. K. Impacts of obesity and stress on neuromuscular fatigue development and associated heart rate variability. Int. J. Obes., v. 39, n. 2, p. 208-2013, fev. 2015.

MELIUS, J. Occupational health for firefighters. Occupational Medicine, n. 16, p. 101-108, jan./mar. 2001.

MELO, S. A. O. História do Corpo de Bombeiros Militar de Minas Gerais. Belo Horizonte: Centro de Ensino de Bombeiros, 2015.

MENEZES, J.P. O Corpo de Bombeiros no Pará. Belém: Ed. do Autor, 2007.

MILESKI, K. S.; LEITÃO, J. L.; LOFRANO-PORTO, A.; PORTO, L. G. Healthrelated physical fitness in middle-aged men with and without metabolic syndrome. J. Sports Med. Phys. Fitness, v. 55, n. 3, p. 223-230, mar. 2015.

MOLINA, G. E.; PORTO, L. G.; FONTANA, K. E.; JUNQUEIRA JR., L. F. Unaltered R-R interval variability and bradycardia in cyclists as compared with non-athletes. Clin. Auton. Res., v. 23, n. 3, p. 141-148, jun. 2013.

MOLINA, G. E. PORTO, L. G.; FONTANA, K. E.; JUNQUEIRA JR., L. F. Postexercise heart-rate recovery correlates to resting heart-rate variability in healthy men. Clin. Auton. Res., v. 26, n. 6, p. 415-421, dez. 2016.

NFPA. National Fire Protection Association. NFPA 1582: Standard on Comprehensive Occupational Medical Program for Fire Departments. Quincy, MA: National Fire Protection Association, 2007.

NOGUEIRA, E.C. A prevalência de sobrepeso, obesidade e seus riscos à saúde em bombeiros militares do Distrito Federal. Dissertação (Educação Física). 99f. Brasília: UnB, 2014.

NUNAN, D.; SANDERCOCK, G. R.; BRODIE, D. A. A quantitative systematic review of normal values for short-term heart rate variability in healthy adults. Pacing Clin. Electrophysiol., v. 33, n. 11, p. 1407-1417, nov. 2010.

PILLAY, J. D.; VAN DER PLOEG, H. P.; KOLBE-ALEXANDER, T. L.; PROPER, K. I.; VAN STRALEN, M.; TOMAZ, S. A.; VAN MECHELEN, W.; LAMBERT, E. $\mathrm{V}$. The association between daily steps and health, and the mediating role of body composition: a pedometer-based, cross-sectional study in an employed South African population. BMC Public Health, v. 22, n. 15, p. 174, fev. 2015.

PORTO, L. G.; JUNQUEIRA JR., L. F. Comparison of time-domain short-term heart interval variability analysis using a wrist-worn heart rate monitor and the conventional electrocardiogram. Pacing Clin Electrophysiol, v. 32, n. 1, p. 43-51, jan. 2009.

POSTON, W. S.; HADDOCK, C. K.; JAHNKE, S. A.; JITNARIN, N.; TULEY, B. C.; KALES, S. N. Prevalence of overweight, obesity, and substandard fitness in a population-based firefighter cohort. J. Occup. Environ. Med., n. 53, p. 266-273, 2011.

PUMPRLA, J.; HOWORKA, K.; GROVES, D.; CHESTER, M.; NOLAN, J. Functional assessment of heart rate variability: physiological basis and practical applications. International Journal of Cardiology, v. 84, n. 1, p. 1-14, 2002. 
ROBINSON, B. F.; EPSTEIN, S. E.; BEISER, G. D.; BRAUNWALD, E. Control of heart rate by the autonomic nervous system. Studies in man on the interrelation between baroreceptor mechanisms and exercise. Circ. Res., v. 19, n. 2, p. 400-411, 1966.

ROUTLEDGE, F. S.; CAMPBELL, T. S.; MCFETRIDGE-DURDLE, J. A.; BACON, S. L. Improvements in heart rate variability with exercise therapy. Can. J. Cardiol., v. 26, n. 6, p. 303-312, 2010.

SANTOS, L.P. A expectativa de sobrevida do bombeiro militar do DF e a reforma dos regimes de Previdência Pública Brasileira. Brasília: CBMDF, 2011.

SAWADA, Y. Hemodynamic effects of short-term noise exposure- comparison of steady state and intermittent noise at several sound pressure levels. Jpn Circ. J., v. 57, p. 862-872, 1993.

SILVA, P.R. \& JUNQUEIRA JR, L.F. Caracterização postural e cronobiológica da função autonômica baseada nas análises temporal e espectral da variabilidade dos intervalos R-R do eletrocardiograma em indivíduos normais. Tese de Mestrado Faculdade de Ciencias das Saúde - Departamento de Clínica Médica - Univesidade de Brasília, 1993.

SHEN, M. J.; ZIPES, D. P. Role of the autonomic nervous system in modulating cardiac arrhythmias. Circ. Res., v. 14, n. 114, p. 1004-1021, mar. 2014.

SIMKHOVICH, B. Z.; KLEINMAN, M. T.; KLONER, R. A. Particulate air pollution and coronary heart disease. Curr. Opin. Cardiol., v. 24, p. 604-609, 2009.

SINGH, J.P.; LARSON, M. G.; TSUJI, H.; EVANS, J. C.; O’DONELL, C. J.; LEVY, C. Reduced heart rate variability and new-onset hypertension: insights into pathogenesis of hypertension: the Framingham Heart Study. Hypertension, v. 32, n. 2, p. 293-297, 1998.

SYTKOWSKI, P. A.; D’AGOSTINO, R. B.; BELANGER, A. J.; KANNEL, W. B. Secular trends in long-term sustained hypertension, long-term treatment, and cardiovascular mortality. The Framingham Heart Study 1950 to 1990. Circulation., v. 93, p. 697-703, 1996.

SMITH, D. L. PETRUZZELLO, S. J.; KRAMER, J. M.; MISNER, J. E. Physiological, psychophysical and psychological responses of firefighters to firefighting training drills. Aviat. Space Environ. Med., v. 67, n. 11, p. 1063-1068, 1996.

SMITH, D. L., PETRUZZELlO, S. J.; GOLDSTEIN, E.; AHMAD, UZMA, A.; TANGELLA, K.; FREUND, G. G.; HORN, G. P. Effect of live-fire training drills on firefighters' platelet number and function. Prehosp Emerg Care, n. 15, p. 233-239, 2011.

SMITH D. L.; BARR, D. A.; KALES, S. N. Extreme sacrifice: sudden cardiac death in the US Fire Service. Extrem. Physiol. Med., v. 2, n. 1, p. 2-6, 2013.

SMITH, D. L.; DEBLOIS, J. P.; KALES, S. N.; HORN, G. P. Cardiovascular Strain of Firefighting and the Risk of Sudden Cardiac Events. Exerc Sport Sci Rev. v. 44, n. 3, p. 90-7, 2016a. 
SMITH, D.L.; HALLER, J. M.; BENTO, R.; MOORE-MERREL, L. Firefighter Incident Rehabilitation: Interpreting Heart Rate Responses. Prehosp Emerg Care, v. 20, n. 1, p. 28-36, $2016 b$.

SNOW, V. BARRY, P.; FITTERMAN, N.; QASEEM, A.; WEISS, K. Pharmacologic and surgical management of obesity in primary care: a clinical practice guideline from the American College of Physicians. Ann. Intern. Med., n. 142, p. 525-531, 2005.

SONE, H.; KATAGIRI, A.; ISHIBASHI, S.; ABE, R.; SAITO, Y.; MURASE, T.; YAMASHITA, H.; YAJIMA, Y.; ITO, H.; OHASHI, Y.; AKANUMA, Y.; YAMADA, N.; JD STUDY GROUP. Effects of Lifestyle Modifications on Patients with Type 2 Diabetes: The Japan Diabetes Complications Study (JDCS) Study Design, Baseline Analysis and Three Year-Interim Report. Hormone and Metabolic Research, n. 9, p. 509-515, 2002.

SOTERIADES, E. S.; EVANS, J. C.; VASAN, R. S.; MURABITO, J. M.; KELLYHAYES, M.; BENJAMIN, E. J. Depressive symptoms, coronary heart disease and mortality in the Framingham heart study. Circulation, v. 104, n. 17), p. 531-532, 2001.

SOTERIADES, E. S.; SMITH, D. L.; TSISMENAKIS, A. J.; BAUR, D. M.; KALES, S. N. Cardiovascular disease in US Firefighters: a systematic review. Cardiol. Rev., v. 19, n. 4, p. 202-215, 2011.

SOTHMANN, M. S.; SAUPE, K.; JASENOF, D.; BLANEY, J. Heart rate response of firefighters to actual emergencies. Implications for cardiorespiratory fitness. J. Occup. Med., v. 34, p. 797-800, 1992.

SOUZA, F. Como funciona o Corpo de Bombeiros. How Stuff Works, 2014.

TASK FORCE OF THE EUROPEAN SOCIETY OF CARDIOLOGY AND THE NORTH AMERICAN SOCIETY OF PACING AND ELECTROPHYSIOLOGY. Heart rate variability - standards measurement physiological interpretation, and clinical use. Circulation, v. 93, n. 5, p. 1043-1065, 1996.

TZIOMALOS, K.; DIMITROULA, H. V.; KATSIKI, N.; SAVOPOULOS, C.; HATZITOLIUS, A. I. Effects of lifestyle measures, antiobesity agents, and bariatric surgery on serological markers of inflammation in obese patients. Mediators Inflamm., n. 2010, 2010.

WIJKMAN, M.; LANNE, T.; ÖSTGREN, C. J.; NYSTROM, F. H. Diastolic orthostatic hypertension and cardiovascular prognosis in type 2 diabetes: a prospective cohort study. Cardiovasc Diabetol., v. 2, n. 15, p. 83, jun. 2016.

VILLAREAL, R. P.; LIU, B. C.; MASSUMI, A. Heart rate variability and cardiovascular mortality. Curr. Atheroscler. Rep., v. 4, n. 2, p. 120-127, mar. 2002.

VON HEIMBURG, E. D.; RASMUSSEN, A. K.; MEDBO, J. I. Physiological responses of firefighters and performance predictors during a simulated rescue of hospital patients. Ergonomics, v. 49, n. 2, p. 111-126, 2006. 
VOSS, A.; SCHROEDER, R.; HEITMANN, A.; PETERS, A.; PERZ, S. Short-term heart rate variability-influence of gender and age in healthy subjects. PLoS One, v. 30, n. 10, Supp. 3, mar. 2015.

WELK, G. J.; DIFFERDING, J. A.; THOMPSON, R. W.; BLAIR, S. N.; DZIURA, J.; HART, P. The utility of the digi-walker step counter to assess daily physical activity patterns. Medicine and Science in Sports and Exercise, v. 32n. 9, Suppl., 481-488, 2000. 